\title{
Retour aux traditions - signe de réussite sociale : les rondels de la Collection Hosmer (Université McGill, Montréal)
}

\section{Ariane Isler-de Jongh}

Volume 16, numéro 1, 1989

\section{URI : https://id.erudit.org/iderudit/1073326ar}

DOI : https://doi.org/10.7202/1073326ar

\section{Aller au sommaire du numéro}

\section{Éditeur(s)}

UAAC-AAUC (University Art Association of Canada | Association d'art des universités du Canada)

\section{ISSN}

0315-9906 (imprimé)

1918-4778 (numérique)

\section{Découvrir la revue}

\section{Citer cet article}

Isler-de Jongh, A. (1989). Retour aux traditions — signe de réussite sociale : les rondels de la Collection Hosmer (Université McGill, Montréal). RACAR : Revue d'art canadienne / Canadian Art Review, 16(1), 29-42.

https://doi.org/10.7202/1073326ar

\section{Résumé de l'article}

The collection of domestic stained glass and glass paintings recently set up in the new building of the McGill School of Architecture used to decorate the main staircase and the dining-room windows of Charles Hosmer's house, built by Montreal architect Edward Maxwell around the turn of the century.

Charles R. Hosmer was then a prominent businessman, the head of Ogilvie Flour Mills, and his house on Drummond Street was a sign of his position in the flourishing city of 1900. It was to be the house of an art collector, who was interested in paintings as well as in "objets d'art," which he would buy himself or through agents. Indeed we know from Maxwell's ledgers that these glass paintings were acquired as a group from a London dealer of Flemish or Dutch origin, Martin van Straaten.

This collection of 39 small domestic glass panels, of varied quality and origins, comprises Flemish and Dutch roundels, piecess from the Rhineland and Switzerland, and some heraldic panels. This type of glass used to adorn windows of wealthy houses, private chapels or cloisters. The roundel itself is a single piece of colourless glass, circular, oval or rectangular, painted with grisaille and silver-satin and occasionally, after the sixteenth century, with coloured enamels. The Swiss panels, on the other hand, consist of a main piece in the centre, richly framed with decorative and allegorical subjects. McGill's Hosmer Collection is, as far as we know, unique in Canada. In acquiring it, Charles Hosmer followed the lead of British collectors, who had been keenly interested in northern European domestic glass, at least since the eighteenth century. These small panels are of average quality, although some of them are outstanding. As a group, they present a remarkable anthology of styles and techniques in the sixteenth and seventeenth centuries, as well as examples of nineteenth-century repairs or even pastiches. The catalogue consists of a check-list according to the Corpus vitrearum norms (thus representing the first contribution to the Canadian C.V.), accompanied by detailed notices describing the current state of research.
Tous droits réservés (C) UAAC-AAUC (University Art Association of Canada | Association d'art des universités du Canada), 1989
Ce document est protégé par la loi sur le droit d'auteur. L’utilisation des services d'Érudit (y compris la reproduction) est assujettie à sa politique d'utilisation que vous pouvez consulter en ligne.

https://apropos.erudit.org/fr/usagers/politique-dutilisation/ 


\title{
Retour aux traditions - signe de réussite sociale: les rondels de la Collection Hosmer (Université McGill, Montréal)*
}

\author{
ARIANE ISLIER-I)L JONGH \\ Université de Vicloria
}

Ihe collection of domestic stained glass and glass paintings recente set up in the new building of the lle (jill school of Architecture used en deconate the main staticase and the dining-room windows of Chanles Hosmer's house, buile br Mommeal anchited lidward Maxwedl aromed the turn of the centure.

(harles R. llosmer was then a promincm businessman, the head of Ogilvie likour Mills, and his house (m) Drummond Suced was a sign of his position in the flomishing (ity of $190(0)$. I was 10 be the house of an ant collector, who was interested in paintings as well as in "objets d'ant," which he would bur himsell or through agents. Indeed we know from Maxwell's ledgers that lhese glass paintings were acquired as a group fiom a london dealer of Flemish or Duth origin, Martin van Stratalen.

This collection of 39 small domestic glass pancls, of varied quality and origins, comprises flemish and Duteh roundels, piecess from the Rhincland and Switzerland, and some heraldic pancls. This rype of glass used to adom windows of wealuhy houses, priate chappels or eloisters. The romelel itself is a single piece of colomless glass, circular, oral or rectamgulat, painted with grisatle and silver-satin and orcasionalls. aller the sixteconth centur. with colomedenamels. Ihe Swiss pancels, on the ofher hand, consist of a main piece in the centre, richle framed with decolative and allegorical subjects

Me Cill's Hosmer Collection is, as far als we know. unique in Camada. In acepuiring ir. Charles I Iosmer followed the lead of British collectors, who had becon keenly interested in morthem limepean domestic glass, at least since he eighteculh century. These small pancls are of arerage quality, although some of them are outstanding. As a group), they present a remathable anthology of styles and techniques in the sixtecmth and serenteconth centuries, as well as (examples of ninctecmthcentury repairs or even pastiches. The calalogue consists of a check-list according to the Corpus vitrearum norms (thus representing the first comtribution to the Camadian (..L.), accompanied by detailed notices describing the cument state of research.

\section{INIRODLC TION}

I.es questions soulevées par la présence d'une collection de rondels à Montréal sont nombreuses et

* Je tiens à remercicr le Visual Arts Committee de l'université Mc(rill, à Montréal, et surtout les professeurs John Bland et Bruce Anderson qui se sont intéressćs à mon travail ct l'ont encouragé dès le jour ou j’ai découvert cette collection intéressante. line recherche de ce genre nécessite de nombreuses consultations et il serait difficile d'énumérer les nombreux chercheurs qui ont bien voulu molfrir leurs commentaires. Je voudrais pourtant remercier très particulièrement le professcur Philippe Verdier. ainsi que Yecte Vanden Bemden, à Bruxelles, Sybill Kummer, à Zurich, et William Cole et llilary Wayment, en Angleterre, pour la générosité avec laquelle ils mont lait bénéficicr de lcurs vastes comnaissances. touchent à des domaines très différents. Cette introduction en donnera un bref aperçu.

I.e rondel, parfois appelé aussi griset, est une pièce de verre incolore (ou à peine coloré, suivanı son origine), de forme circulaire, ovale ou rectangulaire, peinte de grisaille et de jaune d'argent et parlois, dès le milieu du xvir siècle, de couleurs émaillées. Techniquement, les rondels apparaissent donc en mêrne temps que les développements du vitrail monumental, où l'emploi du verre de couleur, peint de noir en trois tons, cède de plus en plus le pas, dès la Renaissance, aux procédés de peinture sur verre incolore. En effet, bien qu'il existe quelques rares exemples de rondels datant de la lin du xive siècle, ils apparaissent de 
plus en plus nombreux vers la fin $d u x^{e}$ et, dès le début $d u x{ }^{e}$ siècle, sont produits quasiindustriellement dans certains centres des Flandres et des anciens Pays-Bas, dans les pays limitrophes du Rhin jusqu'au sud de l'Allemagne et en Suisse alémanique.

Ces petits vitraux étaient destinés principalement à un usage domestique, ornant les fenêtres de maisons aisées, de chapelles privées ou de cloîtres. Leur production se développe parallèlement à une période d'expansion de la société urbaine et bourgeoise; c'est ainsi qu'on en voit ornant les fenêtres de la chambre qui forme le décor du diptyque de la Vierge de Martin van Nieuwenhove par Memling (1487) ou encore, au siècle suivant, celles de certaines scènes d'intérieur de Vermeer.

Les sujets de ces "vitraux civils" étaient le plus souvent religieux, mais pouvaient aussi être allégoriques ou illustrer des proverbes ou même des sujets de la vie quotidienne. Lorsque les fenêtres où ils étaient insérés étaient assez grandes, dans un cloître par exemple, ils étaient souvent groupés en série, selon un programme thématique (histoires de Joseph, de Daniel, saints patrons, etc.), et parfois reliés entre eux par un décor à cuirs et à grotesques occupant l'espace libre de la fenêtre.

Les rondels étaient peints dans des ateliers, souvent importants, où des peintres-verriers se groupaient autour d'un maître qui assurait aussi la formation d'apprentis. Cette organisation permettait une production abondante basée sur la copie de gravures ou de dessins. Ceux-ci étaient fournis par un peintre ou par le maître-verrier lui-même et il existe encore des cahiers de modèles qui ont été transmis de génération en génération (voir l'analyse des $\mathrm{n}^{0 \mathrm{~s}} 7,14$ et 15 , et 16). Mais la pratique usuelle de production était la copie de gravures qui circulaient de plus en plus en Europe dès la fin $d u x^{e}$ siècle et transmettaient les derniers modèles, les idées courantes, les styles nouveaux. La copic n'en est pas toujours littérale, il peut y avoir des omissions, des adaptations (voir n ${ }^{\text {os }} 27$ ou 36), ou même des glissements de sens ou de style (par exemple dans les $\mathrm{n}^{\text {os }} 3$ et 21 ). Ce rôle de la gravure par rapport aux arts décoratifs est très généralisć et on peut le documenter, par exemple, dans les poteries "istoriate" de Majolique, dans les carreaux de céramique des pays rhénans, sans oublicr la source inépuisable des modè. les d'ornements. Elle assure aussi une sorte de "pollinisation croisée ", transmettant les cartons de tapisseries, comme c'est peut-être le cas pour le rondel $n^{\circ} 9$.

Certaines pièces, d'une qualité supérieure, étaient exécutées avec grand soin par un maîtreverrier (voir $n^{0} 1$ ), alors que d'autres peuvent être de qualité variable et signalent ainsi le travail en série d'un atelier. En rassemblant des dossiers comparatifs, comme on a pu le faire pour les $n^{\text {os }} 9$, 14 et 15 , et 27 , on peut espérer arriver peu à peu à une meilleure connaissance des ateliers et de leur mode de production.

On peut s'étonner que des objets d'art aussi répandus que les rondels entre le $\mathrm{XvI}^{\mathrm{e}}$ et $\mathrm{xvIII}{ }^{\mathrm{e}}$ siècles - on en vendait même à la foire de Lyon en $1588^{1}$ — n'aient pas eu plus d'intérêt pour les historiens d'art jusqu'à ces dernières années; même si la plupart d'entre eux en ont vu des exemples en étudiant la peinture de la Renaissance dans le nord de l'Europe, il en est bien peu qui y aient porté quelque attention. Il est évident que, du fait de sa production de masse, ou tout au moins de grande série, le rondel se compare mal au grand art du vitrail monumental. Il se trouve dans la même situation que la gravure par rapport à la peinture. Sa destination essentiellement domestique - même s'il orne des bâtiments religieux, ce sera le cloître, l'hôpital ou une chapelle privée-le situe au niveau des arts décoratifs. Ce n'est qu'en reconnaissant l'importance "séminale " de ceuxci, leur valeur d'instruments de communication culturelle et artistique, dans un contexte social que l'histoire de l'art traditionnelle tendait à oublier, que des objets aussi modestes que les rondels deviennent intéressants à étudier.

A cela il faut ajouter un autre argument qui remonte à la remise en question des critères esthétiques à la fin du xvirr ${ }^{\mathrm{e}}$ siécle: on sait qu'avec l'avènement du néo-classicisme, une grande quantité de vitraux furent abandonnés ou mis en vente. Les amateurs anglais, qui n'étaient pas encore mordus par la nouvelle mode, en profitèrent pour acquérir d'importantes collections et ce trafic de vitraux a pu être bien documenté par Jean Lafond $^{2}$. Il faut rappeler d'ailleurs que les rondels étaient déjà fort bien connus en Angleterre où les "lainiers" et les tisserands flamands qui s'étaient établis $\mathrm{au} \mathrm{XVI}^{\mathrm{e}}$ et au XVII $\mathrm{XI}^{\mathrm{e}}$ siècles avaient souvent amené avec eux des séries de rondels qu'on retrouve dans des églises de petites villes de province. Au Xvirr ${ }^{e}$ siècle par contre, on assiste à la création de collections privées par des amateurs, comme Horace Walpole, qui décore les fenêtres de Strawberry Hill de séries de rondels, dont un bo nombre sont encore en place ${ }^{3}$.

1 Voir Jean Lafond, "Lc vitrail civil français à l'église et au muséc ", Médecine de France, l.xxviI (1956), 17-32; cité par Yvettc Vanden Bemden, "Le fichier international de documentation du rondel ", Revue des archéologues et historiens d'art de Louvain, XII (1979), 151.

2 Jean Lafond, "Le commerce des vitraux étrangers anciens en Angleterre au XviII" et au xix siècles ". Bulletin des Sociétés savantes de Haute-Normandie-Histoire de l'Art, $\mathbf{x x}$ (1960), 5-15.

3 A Catalogue of the Classic Contents of Strawberry Hill, collected 
Dès la période victorienne, les conditions sociales et économiques qui influencent l'établissement de collections d'objets d'art ont complètement changé: les amateurs fortunés sont plus nombreux, particulièrement en Amérique du Nord, et une collection d'art devient signe de réussite socialc en même temps-ou peutêtre davantage - que plaisir esthétique. Les marchands répondent à cette augmentation de la demande en favorisant la circulation de pastiches ou en bricolant des réparations de verres anciens. En fait, ils ne font que poursuivre une pratique normale des ateliers de peintres-verriers qui, au cours des siècles, ont toujours réparé les dégâts causés aux verrières par les intempéries ou les événements humains, remplaçant les morceaux manquants par du verre ancien ou par des nouvelles pièces peintes dans la tradition ancicnne. C'est encore pratique normale (voir la plupart des vitraux héraldiques, en particulier les $n^{\text {os }} 23,37$ et surtout 17), qui peut se justifier si elle est ouvertement reconnue. Malheureusement, ce n'était pas toujours le cas à la fin du $\mathrm{xIx}^{\mathrm{e}}$ et au début du $\mathrm{xx}^{\mathrm{e}}$ siècles, notamment lorsque l'acquéreur était un nouveau riche plus facile à duper!

Pour ce qui est de la collection Hosmer, sa présence à Montréal est intéressante à plus d'un chef. Tout d'abord elle peut éclairer sous un jour nouveau l'étude des collections d'art à Montréal dès la fin de l'époque victorienne, étude qui s'inscrit dans un contexte où les conditions économiques du Nouveau Monde se combinent de façon complexe avec des traditions britanniques encore très vivantes ${ }^{4}$. Cette collection, installée maintenant dans le nouveau bâtiment de l'Ecole d'architecture de l'université McGill, décorait, jusqu'à il y a quelques années, les fenêtres du grand escalier ct de la salle à manger de la maison que Charles Hosmer fit construire, au tournant de notre siècle, par l'architecte montréalais Edward Maxwell.

Charles R. Hosmer était un homme d'affaires important de Montréal, à la tête des minoteries Ogilvie, et sa maison de la rue Drummond est à l'image de sa position dans une ville en pleine expansion. C'est la maison d'un amateur d'art, collectionneur de peinture mais aussi d'objets

by Horace Walpole (Londres, 1842). On trouve aussi par exemple, dans la petite ville tisserande de Bradfordon-Avon (Holy Trinity Church), une fenêtre décorée de 25 rondels flamands, donnés vers 1760 , d'après la tradition locale.

4 Janet M. Brooke, conservateur de l'art européen au Musée des Beaux-Arts de Montréal, prépare une exposition sur les collectionncurs de peinture européenne du Xıx ${ }^{\mathfrak{c}}$ siècle actifs à Montréal jusqu'à la Première Guerre mondiale. Cette exposition, dont les dates prévues sont du 14 décembre 1989 au 25 février 1990, sera accompagnée d'un catalogue et d'essais traitant des différents aspects de cc problème. d'art qu'il fait acheter ou achète lui-même en Europe. Nous savons en effet, par les registres de Maxwell, que ces vitraux furent achetés "en bloc ", en 1901, à un marchand londonien, Martin van Straaten ${ }^{5}$. Cet antiquaire était spécialisé, semble-t-il, dans les objets d'origine flamande ou néerlandaise, car il a fait par deux fois des dons au Victoria and Albert Museum, entre autres de carreaux de faiencc hollandais. Il serait intéressant de trouver quelles étaicnt ses sources sur le continent.

Cependant un autre élément s'ajoute à l'étude de cette collection. En effet, à la mort de son père, en 1927, Miss (Olive Hosmer trouva dans la cave de la maison, encore emballés dans leur caisse d'origine, un autre groupe de vitraux: il s'agissait de vitraux anglais typiques de la fin du $\mathrm{XIX}^{\mathrm{c}}$ siècle représentant les cinq beaux-arts sous la forme d'élégants troubadours, dans un décor évoquant les oeuvres de Selwyn Image ${ }^{6}$. Ces vitraux furent données par Miss Hosmer à St Alban's, une école privée de garçons à Brockville, Ontario, où ils furent installés dans la chapelle. Les plans d'Edward Maxwell n'apportent au problème qu'un complément négatif: en effet, alors que les élévations présentent dans tous ses détails le programme de décoration de la maison (le salon $\mathrm{XVII}^{\mathrm{e}}$ blanc et or, les panneaux de bois sculptés de la salle à manger, les curieux piliers du grand hall, les fers forgés, et même les fresques du plafond du boudoir XVIII indiquées par quelques jambes de nymphes se balançant dans les écoinçons), les fenêtres sont laissées en blanc, laissant supposer qu'aucune décision n'avait encore été prise à leur sujet ${ }^{7}$.

Il est fort probable que Hosmer commanda tout d'abord des fenêtres au goût du jour, comme on peut encore en voir à Montréal au Mount Stephen's Club, l'ancienne demeure de George Stephen, Lord Mount Stephen. Cependant, ayant vu ou appris l'existence de cette collection de rondels chez van Straaten, à qui il avait déjà commandé d'autres objets d'art, il se rendit compte qu'il pourrait les faire installer chez lui et, en particulier, faire insérer les pièces les plus remarquables dans une très belle grande fenêtre " art nouveau »dont il confia l'exécution aux verriers montréalais Castle and Son. Ce faisant, il se rattachait à la tradition des collectionneurs anglais qui avaient, dès le $\mathrm{xvirI}^{\mathrm{e}}$ siècle, ainsi que nous l'avons déjà mentionné, porté un grand intérêt aux vitraux civils du nord de l'Europe.

5 Canadian Architecture Cóllection, Université McGill, Montréal, Edward and W.S. Maxwell Archives, Office Ledgers (L 1900-1903).

6 Voir entre autres Martin Harrison, Victorian Stained Glass (Londres, 1980), 67-68, fig. 73 et pl. 28.

7 Maxwell Archives, Project $n^{0} 142.0$ (House for C. K. Hosmer). 
La collection comporte 39 pièces, d'origines ct de qualités diverses. On y troure des rondels flamands ou hollandais, des pièces provenant de la Rhénanie ou de Suisse, ou encore des vitraux héraldiques, probablement d'origine hollandaise ou germanique. (On y troure des pièces d'art populaire, dont certaines sont cncore très proches des xylographies (qui leur ont vraisemblablement servi de modèles ( $n^{\prime \prime} 4,10,28,32$ ), alors (que d'autres éroquent la vie quotidienne dans une époque parfois très troublée $\left(n^{\circ 1} 6,26,30\right)$. Les grarures qui ont serri de sources ont pu être identifiées avec: précision dans deux cas (n ${ }^{\prime \prime s} 27$ et 36); d'autres rondcls peurent être étudićs d'après des dessins connus dont ils se rapprochent (n"l, 7, 14 et 15$)$. Certaines pièces, comme le saint Jacques ( $\left.n^{\prime \prime} 11\right)$, se rapportent évidemment à des séries de gravures de saints du genre de celles de Schöngauer, alors que d'autres (en particulier les n"s 12 et 20 ) posent le problème d'une pastiche éventuel: que penser de leur excellent étal de conservation, d'un dessin qui manque de linesse pour un sujet qui touche a des sources littéraires ou théâtrales? Li pourtant plusicurs des connaisseurs consultés optent pour une datation du Xvir" siècle.

Au chapitre des techniques, la rarićté est tout aussi grande, domnant des exemples très différents de l'emploi de la grisaille et du jaune d'argent, ainsi que des procédés de peinture émailléc. Le style va du dessin le plus ralfiné (n"1) au traitement le plus populaire (n" 28), ch passant par des exemples de travail d’atelier en série dont nous avons déjà mentionné l'intérêt. Les deux vitraux suisses (n"s 16 et 34 ) fournissent un complément à celte anthologie des techniques: leur "statur " est un peu particulier au sein du Corpus Vitrearum, mais on pourrait proposer qu'ils se rattachent tout à fait bien au genre des rondels insérés clans une fenêtre décorcéc de cuirs en de grotesques, comme cétait souvent le cas en pays tlamand. En effer, la miniature centrale du vitrail suissc est faite d'unc seule pièce peinte comme le rondel, ct le cadre décoratif, serti de plombs, peut être comparé aux cncadrements flamands, même s'il est plus compact.

Quant aux vitraux héraldiques, ils n'ont puêtre encorc étudiés comme ils le mériteraient et nous nous sommes contcntées de les blasonner.

Le catalogue qui suit présente l’état actuel de la recherche: chaque pièce a été identifićc selon les normes du Corpus Vitrearum, représentant ainsi la première contribution à la branche canad lenne du Corpus Vitrearum, ainsi qu'au Fichier international de documentation du rondel (créé en 1976 par le comitć belge du (orpus Vitrearum). Des remarques détaillées accompagnent les rondels qui ont fait l'objet d'une étude plus approfondie.
Ajoutons enfin qu'ils ont récemment été ncttovés el restaurés arec grand soin par Théo Lubbers, à Montréal, ct ont pu être conscrvés dans leurs fenêtres d'origine.

\section{(CATALOC:L}

\section{N'1. Scène de décapitation (saint Maurice ou saint. Victor d'Aganine?), Anvers, anciens \\ Pays-Bas, aturibué à I Dirk Vellert, vers 1523 (Fig. 33)}

lerre blane peint de grisatle et jatune dargent

Diamiole: $22 \mathrm{~cm}$.

Inventaire n" 8.5.0(0). 1

(onstratow: complet, fentes recollées lors du nettoyage en 1986 ; la partic en haut, à gauche, est passableméni clfacéc.

I iconographie proposée du martyre de samt Maurice d. Aganne se basc surtout sur la représentation du même sujet sur un des volets du triptspue de la Comcitixion de Pierre des Marres alu Musée de Cologne, date de 1517. ou l'organisation des persomnages principanx est asse\% semblablex. Cependant les scenes de camage. au fond a

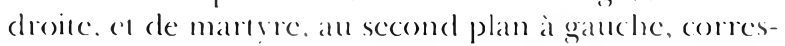
pondraient mieus at l'histoire de same Mantrice d'Apaméc. un saint gree". Il ne faul donc pas exclure nom plus

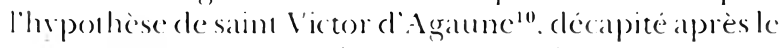
massance évoqué en arrièré-plan, el qui étant vénéré en Rhenanic

Ca rondel, malgré le maurais état de la partic supérieurc à galuche, csi certainement la plus belle pièce de la collection Hosmer. L intensite dramaticpuc du profil du mallor. le chiffommage du manteau jeté à terre. le dessin des cheraux et sumtout le persommage dubourreau et la puissance de som gesse résuméc par quelques lignes de forec autour du pirot de la jambe droite sont d'une: qualité exceptiomnclle. Bien des éléments suggèrent le dessin tres expressif de Dirk Vellert. à commenecr pall des déails comme le rendu des chereux du bourreau, semblable a celui diun clessin au British Museum", ce le style sténographique des petits persomnages du fond (bien que ceux-cipuissent se trourer aussiche\% P. Coeke ian Aclst-ou d'Alost - aree qui V'ellert a sourentéc confondu12). L'empereur Maximien, assistant au sup)plice, montc sur un cheval richement harmaché, a droite, est a rapprocher du dessin de l'empereur Domitien assistant au supplice de l'apotre Jean ${ }^{13}$ (Fig. 34): la

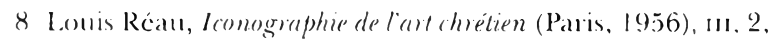
(9)35-39): Grete Ring. "Picrre des Marres", Jahbuch fiir Kunstaissenschafi, 11 (1924). 110-15.

c) Mantice et Willed Dratice. Snints and their Eimblems (1916; Xiw York, 1971), 86.

10) Réalı, Iconographie, 111, 3, 1321.

11 A. E. Popham, Calalogue of Draunings br Duldh and Flemash Artists in the British .Museum (Londices, 1932), $v, 11^{\circ}$ 5 B3.

12 Voil Alloert Durer alux Pay-Bas, son ioyage (1520-1521), som influence, cataloguce exposition palais des Beaux-Arts (Bruxclles, 1977), 207: ainsi (pu'un dessin de la collection lugt. Institut nécrlandais. Paris (inv. n" 5928$)$.

13 Custat Giluck, "Beitrage zur (ieschichte der Antwerpenes Malerei im xis. Jahrhundere". Jahrbuch der Kumsthistori-

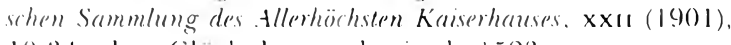
10-3.1. pl. 1: (Blick datte ce dessin de 1523. 
tête du personnage féminin, de dos au promier plan, cst traitée comme celle de la femme assise au centre du groupe écoutant Moïsc qui montre les tables de la loi ${ }^{14}$ (Fig. 35); il faut aussi remarquer le dessin de la main gauche de ce même personnage du premier plan, une main nerveuse, au petit doigt crispé comme celui du Christ avec le centurion de Capernaum ${ }^{15}$ (Fig. 36). Pour autant qu'on puisse juger par les quelques traces qui cn subsistent. l'architecture de la ville d'Agaune, au fond à gauche, pcut se rapprocher de celle de Capernaum. Quant au profil du martyr et au dessin de l'oreille bicn ourlée, il faut les comparer avec ceux de deux autres vitraux: cclui du personnage faisant facc à Antiochus condlamnant les sept frères, provenant de la Chartreuse de I.ouvain (Metropolitan Museum of Art, New York, inv. $\left.n^{\prime \prime} 17.120 .12\right)$ et celui de Gédéon dans le rondel dit de la Toison d'(Or (Paris, Institut néerlandais, coll. F. Lugt, Inv. n" I 8579; Fig. 37).

La date proposée de 1523 correspond bien à celle des dessins datés et justific aussi l'influence durable du contact arec Dürer au cours de l'hiver 1520-21 : comparer la pose et l'apparence du bourreau avec celui de la Décapitation de saint Jean-Baptiste de Dürer, datée de 1510 (B. 125), alors que la composition générale présente quelque analogie avec celle du Martyre des dix-mille chrétiens, peint par Dürer en $1508^{16}$.

\section{No 2. Crucifixion avec un religieux, présenté par saint Pierre, et une religieuse, anciens Pays-Bas (Louvain?), $\mathrm{xvI}^{\mathrm{e}}$ s. (Fig. 38)}

BLASON : (sur le côté du prie-Dieu) écartelé, au l et 4 à 3 coupes posées 2 et l, au 2 et 3 à 3 bustes, 2 et I, à l'écu d'or en abîme.

Verre blanc peint en grisaille et jaune d'argent; quelque travail au petit bois.

Diamètre: $23 \mathrm{~cm}$.

Inventaire $\mathrm{n}^{\circ} 85.005 .2$

CONSERVATION: la grisaille est très pâle: plombs de casse et réparation par collage (un petit morceau manquant en haut à gauche a été remplacé en 1986 et la main droitc du (Christ repeinte).

A rapprocher de la Religieuse agenouillée devant sainte Marguerite (Louvain, Musée communal Van der KelenMertens, Inv. n"B/III/41).

\section{No3. La Charité, Pays-Bas, début xvires.} (Fig. 39)

INSCRIPTION: charitas

Verre blanc peint de grisaille et jaune d'argent, sanguine et émaux (bleu, violet, brun) travail au petit bois. Ovale: $20 \times 25 \mathrm{~cm}$.

Inventairc $\mathrm{n}^{\circ} 85.005 .3$

CONSERVATION: complet; avant 1986, fendu et recollé entrc deux verres; en 1986, nettoyé et recollé.

14 Glück, "Beitrage", fig. 7 (signé et daté de 1523)

15 Glück, "Beitrage ", fig. 10 (signé el daté de 1523).

16 Willi Kurth, ed., The Complete Woodcuts of Albrecht Dïrer (1927; New York, 1963), pl. 212: Fedja Anzelewsky, A/brecht Dürer, das malerische Werk (Berlin, 1971), 212-18.
La ('harité, vêtue d'une robc violette sous un manteau de pourpre, est assise, tenant une poire dans sa main droite, et cntourée de quatre putti, dont un lui apporte unc corbeille de fruits et de feuillages. Ellc est placée sur l'avant-scène d'un décor architectural dont deux bâtiments, dans l'arrière-plan à droite, sont surmontés de feuillage.

Il s'agit là d'un travail d'atelier de second ordrc, si l'on en juge par la maladresse de la perspective et la grossièreté des putti. Pourtant il sc pourrait que ce soit une mauvaise copie d'une gravure que l'on peut rapprocher de la série des Saisons d'après Martin de Vos, gravée par Adriaen (ollaert ${ }^{17}$, ou encore de la série des Vertus princières gravées par les frères Johann et Raphael Sadcler d'après J. Stradenus ${ }^{18}$.

\section{No 4. Saint Antoine de Padoue, ancien Pays-Bas, vers 1550 (Fig. 40)}

Verre blanc peint de grisaillc (sépia) et jaune d'argent (ocre asse\% foncé)

Ovale: $30 \times 21.5 \mathrm{~cm}$.

Inventaire $\mathrm{n}^{0} 85.005 .4$

CONSERVATION: avant 1986, plombs de casse, partie supérieure gauche doublée, couverte rouge au dos; en 1986 trois plombs de casse ont pu être supprimés, remplacés par du collage; la partie supćrieure a été nettoyée et réparée, deux pièces manquantes ont été remplacées.

\section{$N^{0}$ 5. La justice d'Herkinbald, Pays-Bas ou Rhénanie, $x_{\mathrm{VI}}{ }^{\mathrm{e}}$ s. (Fig. 41)}

Verrc blanc peint de grisaille (sépia) et de jaune d'argent; travail au petit bois.

Diamètre : $23.5 \mathrm{~cm}$

Inventaire $\mathrm{n}^{0} 85.005 .5$

CONSERVATION: complet, plombs de casse.

Les sources littéraires et artistiques de la légende d'Herkinbald sont bien documentées ${ }^{19}$. Elles se rapporteraient à la légende d'un comte Archambaud de Brabant qui égorgca son neveu pour le punir d'avoir violé une servante de sa maison. A la mort du comte, comme l'Eglise lui refusait l'extrême onction, une hostie miraculeusc apparut sur la languc du mourant. Cc thème prend ainsi une grandc importance à l'époque des discussions religieuses au sujet de l'Eucharistie, suscitées par la Réformation.

Lcs premières illustrations connues de ce sujet sont les peintures qu'exćcuta Roger van der Weyden pour ['Hotel de ville de Bruxelles entre 1432 et 1445 . Celles-ci disparurent lors de l'incendic de 1695, mais elles sont connues par les tapisseries de Tournai, commandées par l'évêque de Lausanne, Georges de Saluces (1440)1461), et conservées à Berne (Musće historique, Trésor de la Cathédrale (le Lausanne). Tous les exemples ultérieurs se rattachent à ce premier modèle, très populaire

17 Un rondel d'après le Printemps se trouve au Victoria and Albert Museum, Londres ( $\left.{ }^{\circ} \mathrm{C} 396-1923\right)$; voir aussi Burlington Magazine, xLIX (1926), 233-34.

18 Voir Konnedy (Gallery (New: York), Master Prints 7 (1979$8(0)$, n.p.

19 Voir notamment Anna Maria Cetto, Der Berner Trajan- und Herkinbald-Teppich (Berne, 1966). 
dans les provinces flamandes du sud; on peut citer en particulier une tapisserie bruxelloise d'après un carton de Jan van Roome 20 . On connaît pourtant aussi un dessin de l'entourage de Holbein l'aîné, projet pour un rondel décrivant la même scènc d'égorgement, ainsi qu'une letrine gravée par Holbcin le jeune, qui témoignent de la diffusion du modèle dans les pays germaniçues ${ }^{21}$.

\section{N"6. Cabotage de vin ou Dragage de la Meuse,} Pays-Bas, 1584 (Fig. 42)

INSCRIPTIONS: (sur la voile) houldrreyggen plë̈tman

(au bas du rondcl) $[\mathrm{H}]$ tonemans oud man [int] iater, 1584

Verre blanc, peint de grisaille (sépia) légèrement rehaussé de jaune d'argent

Orale: $26.5 \times 17.5 \mathrm{~cm}$.

Inventaire $n^{\prime \prime} 85.006 .1$

conservation: complet, mais probablement recoupé puisque le dessin et l'inscription sont tronqués; l'emblème sur la voile était entouré de deux éléments qui ont été grattés, probablement à unc datc ancienne.

l.c titre que nous avons donné à ce rondcl dérive de l'inscription sur la voilc $:$ pleytman = l'homme de proue, "pleÿt " étant une forme du mot " plecht", prouc, en moyen néerlandais, expression spécialement utilisée pour la navigation sur la Meusc; dreÿgen=draguer, saisir au grapin 22 .

L'emblème dessinć sur la voile éroque les hiéroglyphes ou les signes astrologiques en faveur au xvi" siècle $e^{2: 3}$. ou peut-être encore lés signes de guilde, mais nous n'arons pas concore pu lidentifier et le problème se uoure compliqué par le grattage des deux éléments qui accompagnaicnt ce symbole.

\section{N"7. Joseph explique les songes de Pharaon, anciens Pays-Bas (Liège?), fin $\mathrm{XVI}^{\mathrm{c}}$ ou début XvII"s. (Fig. 43)}

Verre peint de grisaille et de jaunc d'argent (deux tons); bord des plis au petit bois.

()vale : $26.5 \times 19 \mathrm{~cm}$.

Imentaire $n^{\prime \prime} 85.006 .2$

(:ONSERVATION : intact.

11.l.lstratons: McGill Reponter, x. 19)(25 jamier 1978); Hebdo Canada/Canada Weekly, vi, 19 (10 mai 1978), 7; Communiqué (Ogilvie Mills), 3 (juin 1978), 8; Québec at a Glance, x, 1 (juillet 1979), page de couverture.

I.a scène représente Joseph debout à gauche devant le Pharaon assis sur son trônc, ayant à ses côtés le chef des

20) M. Crick-Kunziger, Catalogue des Tapisseries (XN" au $11 \prime^{\prime}$ s.). Musées Rovaux d'Art et d'Histoire (Bruxelles, 19:56), 27-28 et pl. 16.

21 Reproduits dans (ctto, Berner Teppich, figs 80 et 82 .

22 Renseignements aimablement communiqués par le professeur Paul Zumthor, à Montréal.

2.3 Comme la Monade de John Dee, par exemple. Voir John Dee, Monas hieroglyphica (Anvers, 1j64). échansons et un autre serviteur; dans le fond à gauche, la scènc du rêve du Pharaon (Gen. 41:1-36). L'histoire de Joseph a été fort souvent illustrée au Moycn Agc et à la Renaissance, et très spécialement par les peintres verriers flamands. Il existe en particulier des séries de rondels, qui, bien qu'incomplètes, copient très fidèlement un groupe de dessins attribués à Lambert Lombard; ceux-ci forment un carnet de modèles utilisés à plusieurs reprises par un atelier de Liège ${ }^{24}$. Notre rondel ne correspond à aucun de ces dessins, mais comme, d'après leur numérotation, il en manque quelques-uns, con particulier celui qui aurait pu servir de modèle ici, on ne peut exclure la possibilité qu'il aurait pu être fait d'après un des dessins perdus.

De toutes façons plusieurs détails stylistiques nous permettent de rapprocher notre rondel des exemples liégeois : les drapés rattachés par un noeud sur l'épaule et les chausses de Joseph; la tunique boutonnée. le turban et le sceptre de Pharaon; le traitement des cheveux et des barbes; la scònc du rêve, à rapprocher de celle du rève de Joseph; les détails architecturaux, entr'autres l'oculus du fond ${ }^{25}$. I'autre part les colonnes marbrées se retrouvent dans un autre rondel de Lic̀ge, celui du Fils Prodiguc, à l'Hôpital cle Bavière. On observe aussi d'ailleurs dans ce dernier rondel une maladresse dans le dessin des mains et des pieds semblable à celle de notre rondel

\section{$\mathrm{N}^{\prime}$ 8. Vitrail héraldique, Pays-Bas?, xvir $\mathrm{s}$.} (Fig. 44)

BIASON: parti, au I écartclé : 1 et 4 coticé d'or et de gucules, un paon hissant au naturel brochant sur le tout; au 2 d'argent à 3 pals de gueules, à dextre un canton d'azur; au 3 d'or à 3 fasces de gucules. Au 2 parti, 1 d'or à l'arbre de sinople liité au naturel sur une terrasse de sinople; 2 d'or au singe (:) de sable. Le heaume porte en cimier un paon rouant.

Verre blanc peint d'ćmaux de couleurs (rouge, jaune, bleu et vert) et de noir.

()ale: $25 \times 19 \mathrm{~cm}$.

Inventaire n" 85.006.3

(ONSERVATION: alant 1986, cassé et recomposé entre deux verres, le $1 / 4$ inféricur droit et le bord supérieur clroit tròs abîmés et remplacés par des morcéaux de verre d'ćpoque, non sans perdre la structure. Après restauration en 1986, plombs de casse et collages, certains morceaux refaits pour compléter les parties mentionnées plus haut.

Comparer le parti de dextre avec celui de sénestrc du n" 23.

24 Annc-Marie Didier-Lamboray, "Les vitraux de l'histoire de Joseph à l'église Saint-Antoine de Liège et leurs modèles ", Bulletin de l'Institut Royal du Patrimoine Artistique, vin (1965). 201-21. Didier-Lamborav propose une date du troisième quart du Xvi" s. pour ce carnet.

25 Didicr-Lamboray, "Vitraux ", fig. 6 c pour la tunique, le turban et le sceptre, fig. 6 a pour le rêve de Joseph et fig. $6 \mathrm{f}$ pour les détails archirecturaux. 
$\mathrm{N}^{\prime \prime}$ 9. Réconciliation de Jacob et d'lisaü, anciens Pays-Bas (Louvain?), début $\mathrm{xvI}^{\mathrm{e}} \mathrm{s}$. (Cover)

Vcrre blanc pcint de grisaillc (sépia) et jaune d'argent (deux tons); travail au putois et au petit bois.

Diamètre : $21 \mathrm{~cm}$.

Inventaire n" 85.00)(3.4

Conservation: plombs de casse ct une fente à gauche.

biblogoraphile: Cancala Collects Middle Ages/Le Moyen Age au trazers des collections canadiennes, The Norman Mackensie Art Galler! L'niversity of Regina (Regina, 1986). Catalogue de l'cxposition, 35-36, 166-(i7, n"30 (illustration)

It.lestratoxs: Me Gill Reporter. x. 19 (25 janvicr 1978): The Leadline. 1II, 2 (avril 1978), 12: Linizersity Affaim Affarres unizersitaires (mai 1978), 3; (Sueber at a Cilance, $x$. I (juilled 1979), parge de courerture.

I.iconographic de ce rondel pose un probleme: une aure version du môme sujet qui se mourc à Bogbroke, (Oxfordshire, a éci publice sous le titre de "Joscph Mecting his Father Jacol)" (cen. 16:28-30); Fig. 16) $)^{266}$. Nous proposons pluton d'r roir la réconciliation de

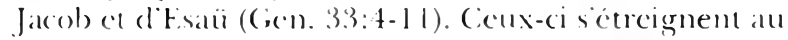
premier plan, en presence de Rachel, tenant Joscph par la main. suivic de lia el de ses enfants, ansi que diune servante: à droite, deux des serviteurs enroyés a la rencontre d'Fatii: dans l'arriore-plan. derriore des rochers. des chameaux el diatures serviteurs. (iclle interporiattionse troure dailleurs confirméc par la septiome lappisscric de l'Histoire de Jacob). Lisséc a Bruxelles dans le deuxiome quart du xit" siocke d'apres des cartoms de Bernardran ()rev quion date demsiron 1525: on y roit.

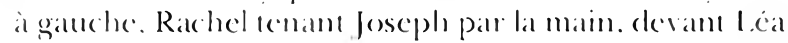
cl les atutres confants. el i droile Jacob) e Fsaü dans une position semblable a celle de notre rondele ${ }^{2 i}$. L a diflérence principale reside dans les costumes, ceux du ron-

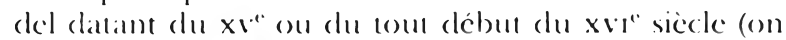
trourc des coiffes semblab)es à celle de léal che\% L ucas de Levicon) (. on pen supposer un modiele antéricur. (op)ié par le pointre du rondel el (pui auratil aussi inspiré vall ()iler.

Les différonces strlistiques entre le rondel de Bogbroke cl celui de la collection Hosmor illustrent bien une caractéristique frépuente de la production des rondels: deux compositions scmblables, donc d'après le même modèle. exécutés par deux mains absolument différentes (les deux pieces copient la môme maladresse anatomicuc de l'avant-bras gatuche d'Fsati qui est beaucoup trop long). Alors que le rondel de Beghbroke présente un dessintourmenté soulignant l’intensité d'expression des deux persommages principaux, celui de Montréal est traté dins un strle d'unc grande claté linéaire, arce des volumes au modelé tres simplifié. Lees physionomies sont intéressantes ct variées.

Pour mieux illustrer cette comparaison, il se trouve (quil existe an moins trois rondels exécutés d'après la grarure de Jacob (ormclisz. van ()ostsanen représentant la Sainte (ène dans la Grande Passion (1511-1514) : l'un. au King's College de Cambridge (précédemment

26 Peter Ncwton. The County of Oxford. Corpus Vitrearum Medii Acvi, Greal Britain, 1 (londes, 1979). 35 ct pl. I7e. 27 Crick-Kun\%iger, Tapisseries, n"s 30,46 et pl. 39. dans la collection du Dr. W. Cole), est rraité dans le mềne style "ébourilfé " que celui de Bcgbroke (Fig. 47), alors que lc second (Louvain, Musée van der Kelen-Mertcns, n" B $/ 111 / 25$, attribué à un atelier de Louvain; Fig. 48) présente unc linćaritć semblablc à celle de notre rondel. quoiqu'encore plus accentuée; le sule du troisiome rondel (à Watford, Herts., St Matthew's (hurch), dont nous n'arons malheureusement guine mauraise photographic, semble intermédiaire contre les deux antres: les chercux et les barbes y sont très proches de ceux du rondel de Montréal.

Pour revenir à colui-ci, deux détails méritent encore d'ôtre notés: less doigts très eflilés de Rachel et des deux ficres, (pui. d'apres A. F. Popham ${ }^{2 *}$, seraicnt unc caractéristipuc de Jacol) (Cornclisz.; cnfin la curieuse robe à gros pois d'un des servitcurs, à droite, se retrouve sur trois des apotres de la Sainte Cène de King's College circe plus haut. Tous ces éléments nous semblent justifier une attribution à un atelier de lourain.

\section{N"10. Crucifixion, Pays-Bas, 1550-1600 (Fig. 49)}

l'orre blanc peint de grisaille er jaune d'argent: travail all petil bois.

Diamedre: $21.5 \mathrm{~cm}$.

Intentaire $11 " 85.0(0)(5)$

(a) NFRIATON: (omplet et intact.

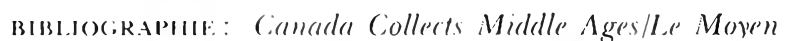
Age all draiens des collectioms canadienmes. The Norman Mackembie Art Gallery, Liniversity of Regina (Regina. 1986). (atalogue de lexposition. 34-35. 165-66. n"29) (illustration)

\section{N"11. Sainl Jacques, Pays-Bas ou Rhénanie, fin $\mathrm{XVI}^{\mathrm{C}} \mathrm{s}$ s. (Fig. 50)}

Lin écu (coupre par le plomb de bordure) porte la moitié diun $\mathrm{H}$

Vorre blanc point de grisaille (sépia) avec écu en jaune d'angent: tratail an pelit bois.

()vale: $23 \times 17.5 \mathrm{~cm}$.

Inemtaire n"

(anstraten: recoupe, le rondel initial devait ôtre passablement plus grand. Avant 1986, un gros plomb de cassc transversal, nombreuses (assures, contre ćclaté, un gros morceall en l 2 lunce en bas à droitc remplacé par du verre blanc. Restautation en 1986: remisc en plombs, certanos calssures fincment recollées, d'aures reparées par des plombs de casse, le triangle central, colui de gauche co la $1 / 2$ lune remplacés et repeints.

X'12. L'apothicaire ou Le chirurgien-barbier, Allemagne ou Pays-Bas?, xvir"s. (?) ou pastiche du $\mathrm{xix}^{\mathrm{e}} \mathrm{s}$. (fait la paire avec le $\left.n^{0} 20\right)$ (Fig. 51 )

Verre blanc peint de grisaille (sépia) rehaussé de jaune d'argent.

$16.5 \times 10.5 \mathrm{~cm}$.

Inventaire $n " 85 .(0) 7.2$

28 Lettre à B. Rackham du 17 mars 1931, citée dans les notes d'archives du rondel (:352-1930 au Victoria and Albert Museum, Londres. 
CONSERVATION: intact.

II.LCSTRATIONs: Montreal Scene (25 février-3 mars 1978), 5 (couleurs); University Affairs/Affaires universilaires (mai 1978), 3; Communiqué (Ogilvie Mills). 3 (juin $1978), 8$.

\section{$\mathrm{N}^{\circ}$ 13. Vitrail héraldique ou Symbolique,} Rhénanie(?), fin $\mathrm{xvII}^{\mathrm{e}}$ s. (Fig. 52)

BLASON: d'argent au cherron de sable portant un crâne d’argent, chargé de trois feuilles de trèfle d'or, dcux cn chef, une en pointc. Surmonté d'une crosse. Devise: Moriatur ne moriatur.

Verre blanc peint de grisaille et jaunc d'argent.

Ovalc: $20.5 \times 16 \mathrm{~cm}$.

Inventaire n" 85.007.3

(oNSERVATION: avant 1986, plombs de casse et fentes; 111 morceau manquant à droite remplacé par un motif végétal peint cn grisaille. Remis en plombs en 1986, lc triangle de droite et une petite pièce au centre de la crosse remplacés et repeints.

\section{X"14. Daniel dans la fosse aux lions, anciens Pays-Bas (Fcole de Malines?), vers 1530 (même séric que le $\mathrm{n}^{\prime 1}$ 15) (Fig. 53)}

INSCRIPTIONS: graffiti sur le fond noir; on distinguc la datc 1565

V'erre blanc peint de grisaille (sépia) ct de jaune d'argent assce foncé.

() cogone: $22.5 \times 21 \mathrm{~cm}$.

Inventaire n" 85.008.1

(:ONSLRVATION: complet (probablement recoupé d'un rondel circulaire de $22.5 \mathrm{~cm}$. de diamètre environ), un plomb de casse.

in.cistration: Suébec at a Glance, x, I (juillet 1979), 2. RIMARQUE: voir commentaires sous le n" 15 .

\section{N'15. Suzanne délivrée par l'intervention de} Daniel, anciens Pays-Bas (Ecole de Malines?), vers 1530 (même série que le $\mathrm{n}^{0}$ 14) (Fig. 54)

Vcrre blanc peint de grisaille (sépia) et de jaune d'argent assez foncé

()ctogone: $22.5 \times 21 \mathrm{~cm}$.

Inventaire n" 8.5.008.2

cONSERVATION: complet (probablement recoupé d'un rondel circulaire de $22.5 \mathrm{~cm}$. de diamètre environ).

Ces deux rondels font partie d'une série illustrant dcux des chapitres apocryphes du livre de Daniel (Dan. 14:36 ct 13:45). Le premier représente Daniel en prière dans la fosse aux lions. Du ciel surgit un ange portant le prophète Habacuc (en le tenant par les cheveux!) qui apporte à Daniel sa pitance. Le second représente Suranne, suivie de deux soldats; à gauche, les deux vieillards, dont l'un fait des mains un geste d'argumentation. Suzanne, mains jointes, a un mouvement d'écart. A l'arrière-plan Daniel prie, debout, les yeux au ciel.

Il existe une autre version du rondel de Daniel, d'une autre main, mais suivant dans tous ses détails le même modèle (Shrewsbury, Shropshire, St Mary's Church; Fig. 5j). I)'autre part, le Victoria and Albert Museum à Londres conserve un rondcl de Suzanne et les vieillards (j636-1859) qui, sans être de la même main non plus, offre de grandes similitudes dans les costumes, le traitement des plis et surtout les riches détails du décor architectural italianisant (Fig. j6). Enfin un quatric̀me rondel, Suzanne devant le juge (collection privéc USA) a été publié par $\mathrm{H}$. Schmitz $z^{29}$ et fait apparemment partie de la même séric. Or le modèle du rondel du V and A est connu : c'est un très beau dessin à la plume et à la mine de plomb, qui était encorce, en 1979, attribué à Aert Ortkens (Paris, Institut néerlandais, coll. F. I.ugt, Inv. n" 6612; Fig. 57). Sans vouloir entrer dans le débat très compliqui au sujet du "pseudo-Aert Ortkens" $"$, on peut proposer que les doux rondels de la collection Hosmor mu été peints daprès des dessins d'une série atri' se à Adrian van den Houte ou à son atelier de Malı:('s. ()n sait que celui-ci comportait de nombreux collaboratcurs et le modèle de notre "Suzannc" pourrait bicn avoir été d'un autre dessinateur que celui de Daniel, contribuant à la même série; ceci expliquerait une composition beaucoup plus dynamique, tout en utilisant les mêmes éléments de costumes et d'architecture. En tous cas, nos deux rondels sont apparemment du même peintre, qui scrait, si l'on en juge par les caractèrestechniques, un collaborateur secondaire d'un atelier commu par sa considirable production.

\section{$N^{\circ} 16$. Les prophéties de Jacob sur son lit de mort, vitrail commémoratif, Franz-Joseph Müller, Zoug (Suisse), 1694 (Fig. 58)}

INSCRIPTIONS: (dans le cartouche supérieur):

Die Zwölfl (s)ün Jacob für in kame

von I(m) Den L(e)tsten sägen namen

Er sa(g)t als (e)r stärben wolt

wa(s) zu künftig geschächcn solt $G(E)$ NE.XI.IX

(dans le cartouche inférieur, des deux côtés des armes du donateur) :

Diser Schilt // Verehr[t] HansJacob Rellstab // Der Zei[t] Leibschu[tz] zuo Rüeschlik// hen meincm hoch-

geehrten Herren // vetter|e]n Heinrich

Schwarzenbach zu // L.ude Redicken

Anno // I[6]94

(signé) I M Zug

BLASON: coupé, au l parti d'or à l'aigle bicéphale de sable, et d'azur à la marque d'or formée de deux bâtons passés en sautoir, l'un en bande terminé par deux anneaux, l'autre en barre tcrminé par un anneau; au 2 losangé d'or et d'azur.

Verre blanc peint de noir et de jaune d'argent, ainsi que d'émaux (bleu, vert, rougc-brun et violet); diapures à l'aiguille et au petit bois dans les rideaux du lit et dans la robe de l'ange.

29 Hermann Schmitz, Deutsche (Slasmalerei der Gotik und Renaissance Rund- und Kabinettscheiben (Munich, 1923), nº6.

30 Voir bibliographie du sujet chez. Hilary $G$. Wayment, "A Rediscovered Master: Adrian van den Houtc (c. 14591521) and the Malines-Brussels School ", Oud Holland, LXxxII (1967), 172-202; 1.XXXIII (1968), 71-94; LXXXIV (1969), 257-69. 
$28.5 \times 20 \mathrm{~cm}$.

Inventaire $\mathrm{n}^{\circ} 85.008 .3$

CONSERVATION: complet, nombreux plombs de casse (certains ont pu être remplacés par collage en 1986).

Bibliographie: A. Isler-de Jongh, "Deux vitraux commémoratifs suisses à Montréal ", Archives héraldiques suisses, Annuairc 1978, 5̃-60 (illustr. noir/blanc).

ILlustrarion: Montreal Scene (25 févricr-3 mars 1978), 5 (couleurs).

La composition générale des deux vitraux suisses (voir aussi n" 34) de la collection Hosmer dérive d'un schéma très courant où le thème principal est encadré dans une construction architectonique en arc de triomphe dont le style a évolué au cours des siècles, la Renaissance y introduisant des motifs italianisants d'abord, puis de plus en plus fantaisistes. L'encadrement du vitrail Rellstab-Schwar\%cnbach est formé de deux colonnes aux socles et aux chapitaux ornés de masques, soutenant un arc surbaissé interrompu par un cartouche entouré de cuirs découpés portant le textc biblique versifić qu'illustre le motif central: dans un grand lit à baldaquin, vu de $3 / 4$ cn perspective et monté sur unc estrade de deux ou trois marches. Jacob, appuyé contre des coussins, élève les deux mains en signe de bénédiction et évoque les temps à venir; ses douze fils sont groupés autour de lui dans des attitudes diverses. Les écoinçons paraphrasent en quelque sorte tout le vitrail: celui dc gauche, le baptême du (hrist, rappelle que, si Jacob) peut préfigurer le Christ $^{31}$, les prophéties de l'Ancien Testament avaicnt pris pour l'Eglise réformée une valcur renouvelée, la promesse d'une vie nouvelle; l'écoinçon de droite représente un arquebusicr en costume de bourgeois de l'époque passant par la rue d'un village à flanc de coteau. C'est v'raisemblablemcnt notre donatcur. En effet le textc du cartouche inféricur nous apprend que nous avons ici un exemple de vitrail dédicatoire par lequel un personnage veut en honorer un autrc, et, ce faisant, s'honore lui-même, puisque son nom va aussi ctre mentionné : "Par ce vitrail, Hans Jacob Rellstab, arquebusicr à Rüschlikon, veut rendre hommage à son très honorable cousin, le sieur Heinrich Schwarzenbach, de Lude Redicken ". Il n'est pas nécessaire de reprendre ici le détail des recherches généalogiques et héraldiques déjà publiées qui ont permis de documenter le vitrail avec précision ${ }^{32}$. Elles ont aussi contribué à résoudre le problème posé par la date du vitrail, dont le centésime est oblitéré par un plomb dc casse. A première vue, le décor de grotesques indiquerait une date tardive $\mathrm{du} \mathrm{xvI}^{\mathrm{e}}$ siècle, rappelant les décorations de céramique à l'italiemne, citées au xvir ${ }^{\circ}$ siècle par l'historien anglais Evelyn à propos du château de Madrid ${ }^{33}$. On sait l'importance des influences culturelles et artistiques rapportés par les régiments suisses à l'étranger, mais les effects de ces influences se font sentir souvent avec un retard notoire.

31 Emile Mâle. L'art religieux du xm" siècle en France, II (Paris, 1958), 29.

32 Ariane Isler-de Jongh, "Deux vitraux commémoratifs suisses à Montréal ", Archives héraldiques suisses (Annuaire 1978), 57.

33 Anthony Blunt, Art and Architecture in France, 1500 to 1700 (Harmondsworth, Angleterre, 1973), 51-52.
D'autre part, l'analyse stylistique permet de reconnaître des traits caractéristiques d'un artiste de Zoug. Franz-Joseph Müller. Notons en particulier le procédé qui consiste à détacher les motif's de l'encadrement sur des panneaux de petits points noirs, de même que le damas de la robe de l'ange et celui de la tenture qui s'écarte pour révéler le sujet central. De plus l'emploi d'un ćmail bleu vif et éclatant (grell) n'apparaît qu'après $1670^{34}$.

Franz-Joseph Müller (16.58-1713) ćtait membre d'une célèbre famille de peintre-verriers de \%oug où les traditions d'atelier se transmctlaicnt de gćnération en génération arec les cahiers de commandes et d'esquisses ${ }^{35}$. Nous avons pu montrer que le monogramme qui signe ce rondel dans le coin inférieur droit du cartouche de dédication s’inscrit bien dans la sćric dés monogrammes connus de F.J. Müller et confirme ainsi la clate de $1694^{36}$.

Ajoutons encore qu'il est possible que l’écoinçon de gauche soit rapporté d'un autre vitrail; le dessin en est plus raffiné, le style moins populaire, et l'émail bleu utilisé semble moins vif.

\section{N" 17. Vitrail héraldique, Allemagne? (Fig. 59)}

Original: pastiche du XIX" s.? (l'original a été cassé lors de la restauration en 1986 el recopic par M. Lubbers).

BLASON : d'hermine à la clouble bande d'argent chargéc d'unc ćtoile d'or à 6 branches.

Verre blanc peint de grisaille, noir et jaune d'argent.

Diametre: $20 \mathrm{~cm}$.

Inventaire n" 85.(008.4

CONSERVATION: intact (voir plus halul).

$\mathrm{N}^{\prime \prime}$ 18. Vitrail héraldique, Pays-Bas ou Allemagne?, xvir s.? (Fig. 60)

BLASON: d’argent à la porte de barrière d'or. Heaume surmonté d'un lćvrier issant entre deux ailes.

Verre blanc peint de grisaille et jaunc d'argent; diaprures au petit bois sur le champ.

Diamètre : $20 \mathrm{~cm}$.

Inventaire n" 8.5.008.j

CONSERvation: complet, deux plombs de casse.

$\mathrm{N}^{0}$ 19. Saint Pierre, Pays-Bas (Brabant ou Limbourg), 1653 (recomposé au XIX ${ }^{2}$ s.; Fig. 61)

INSCRIPTIONS: en haut, banderole sur le cadre:

S. Pceter.

en bas: Peerken Coninckx wedūc van Giesbert Michils $\mathrm{A}^{\circ} 1653$

dans le fond, à droite, ćcu portant les initiales PR.

Verre blanc, pcint de grisaille et jaune d'argent, de sanguine et d'émail bleu.

Ovale: $23.5 \times 18.5 \mathrm{~cm}$.

Inventaire n" 8.5.009.1

34 Jenny Schneider, Glasgemälde, catalogue des collections du Musée national suisse, 11 (\%urich, 1970), 16.

$3 j$ Voir Schneider, Glasgemälde, 467 et 488.

36 Isler-de Jongh,, "Deux vitraux suisses ", 59. 
CONSERVAIION: avant 1986, nombreuses brisures mal réparées, probablement recomposé de deux ovales différents (lc bas du vêtement, qui cst sur la même piècc que l'inscription du bas, n'est pas de la même coulcur que celui de la partie supéricurc). $\Lambda$ la restauration de 1986, Théo Lubbers a soigncuscment recollé ce qui pouvait l'ĉtrc, ajouté 3 plombs de casse ct remplacé un matuais morceau à gauche par un morceau peint qui rétablit quelque peu l'équilibre de la pièce.

\section{$N^{0} 20$. Le docteur (médecin ou juriste),} Allemagne ou Pays-Bas?, xvil ${ }^{\mathrm{e}}$ s. (?) ou pastiche du xix"s. (fait la paire avec le n"12) (Fig. 62)

verre blanc peint de grisaille et jaune d'argent; tratail all petit bois.

$16.5 \times 10.5 \mathrm{~cm}$.

Inventaire n" 8.5.009.2

(oNStrvaton: complet, un plomb transversal de soutien ajoutć en 1986: "givrage "alu dos (vernis mastic du

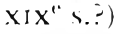

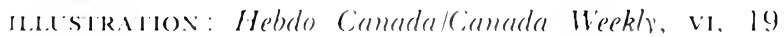
(10) mai l978). 7.

\section{IT" 21. Le Printemps-Flore. Pays-Bas, milieu XVII"s. (Fig. 63)}

INSCRIPIION: (cn bas) De I.icffolicke Lentens lit macchl mons en vee verblÿt

V'erre blanc peint d'émaux (blew, violet), noir, jaunc d'argent a sanguine.

()ale: $18 \times 12 \mathrm{~cm}$

Inscrlatire $12^{\prime \prime} 8.5 .009 .93$

CONSERTAION: intaCt

H.testratows: Magill Reporter, x, 19 (25 janvicr 1978). 19: ('mizersity Affairs/Affaires unizersitaires (mai 1978). 3: (2uibec at a Glance. x, I (juillet 1979). 3.

Le sujel des quatre saisons. ou des mois de l'annće. cst frégucmmont représenté au Xvil" siècle ct sc prête bicn allillustration de proverbes ou d'adages. I.c Victoria and Albort Muscum a. par exemp)le. deux rondels (Printemps. et Hiver. (..71 et 82-1934) tratités dans un style et unc technipuc rós semblables à celui de la collection Hosmer, mais illustrant le sujet par une description érocatrice plutôt que par l'allégoric.

Ce qui c'st intéressant ici, c’est que ce rondel présconte deux excmples de "glissements" d'iconographie, en même tcmps (quil illustre très précisćment des phénomenc's comomicpues importants de la Hollande du xvi" siècle : la mode ct la spéculation sur lestulipes ${ }^{3 i}$. En elfet notre lilore, couronnée de fleurs et tcnant dans sa main droitc unc tulipe qui pcut ĉtre la fameuse "Icyclen Yellow and Red " ${ }^{38}$, retient sur sa hanche, de sa main gatuche, unc corbeille pleine de flcurs : elle illustre ainsi très précisćment l’iconographic de sainte Dorothćc, vénćrćc dans les pays germaniques surtout, et représentće dès le xur" siècle sur des vitraux ct, en particulier, sur

37 Simon Schama, The Embarrassment of Riches: An Interpretation of Dutch Culture in the (rolden Age (New York. 1987), $350-71$.

38 Schama, Riches, 356. un rondel de Souabe datant des environs de $1470^{39}$. Au $\mathrm{XVII}^{\mathrm{e}}$ siècle, cette iconographie est donc reprise sans modification dans un contexte profane pour illustrer un mythe classique et un proverbe (voir aussi la Saskia en Flore peinte par Rembrandt en 1634 [Leningrad, Musée (lc l'Hermitage] ct comparer d'autre part avec la Flore " classique " de Martin de Vos citée au no 3).

Nous avons évoqué plus haut les sérics illustrant les quatre saisons. L'unc d'clles est la séric gravéc par Wenceslaus Hollar cn 1643-1644". "Le Printcmps"y est représenté par unc joune femme richement vêtue de soic et de dentelles, tenant cles tulipes à la main, et sc détachant sur un londs de paysage représcntant une grande maison cle campagne entourée d'un parc fort élaboré. Ccttc gravurc parut l'année avant que Hollar némigre à Anvers pour fuir les troubles religieux et politiques en Angletcre. Le rapport arec notre rondel est nettement celui de l'adaptation d'un modicle aristocratique à une utilisation bourgeoise et même populairc. si l'on en juge par la légende qui peut se tracluire ainsi : "L'aimable tcmps du printemps rend hommes et bêtes heureux"!

\section{$\mathrm{X}^{\prime \prime}$ 22. Vitrail héraldique, Pays-Bas?, $\mathrm{xvII}^{\mathrm{e}} \mathrm{s}$. (recomposé au xix ${ }^{e}$ s.) (Fig. 64)}

B1.ASON: (la pièce a élé recomposée en cleux partics): la partic inféricure porte un écu presfuc complet: d’argent au lion hissant de sable, armé et lampassć de gucules: la partic supéricure porte couromne comtale ct le haut d'un écu d’argent, parti, dont la moitic dexuc montre le haur de la tête d'un lion hissant de sable. lampassé de gucules, tournć vers séncstre.

lerre blanc peint dimaux (jaune, bleu, rouge) et de noir.

() vale: $23.5 \times 17.5 \mathrm{~cm}$.

Incentaire n" 85.(0) 10

(ONSERVATION: arant 1986 , vitrail recomposci de deux partics distinctes mais du môme style; nombreuses brisures mal réparces: (n 1986, réparation soigncuse par collage et 3 plombs de casse; 2 morceaux à galuche, l'un continuant le dessin du haut, l'autre étranger au vitrail, ont ćté remplacés par un nouvcau morceau peint rétablissant unc certaine stmcirie.

\section{N" 23. Vitrail héraldique, Pays-Bas, xviI" s. (mal recomposé all xix s.) (Fig. 6.5)}

BLASON: parti, au I compé d'hermine et d'azur: au 2 ćartelé : 1 et 4 coticé d'or cl de gueules, un paron hissant at naturel brochant sur le tout; 2 et 3 d'or a 3 fasces de gueulcs. Lc heaunc est surmonté de deux ailes coupées d'hermine et diaur.

V'erre blanc peint d'ómalux (bleu, jaune et rouge) et de sépia.

()vale: $25 \times 19 \mathrm{~cm}$.

Inventaire $n^{\circ} 85.011 .1$

39 Schmitz, Deutsche Glasmalerei, pl. 4

10 Richard Pennington, A Descriptive Catalogue of the Etched Work of Wenceslaus Iollar-1607-1677 (Cambridge, 1982). $n^{\prime \prime s}$ 606-609; illustration in Maria van Berge, Wenzel Hollar. 1606-1677 (Paris, Institut néerlandais, 1979), pl. 10, et J. L. Verinson et Ann Saunders, The Four Seasons by Wenceslas Hollar (Norfolk, 1979), s.p. 
CONSERVATION : avant 1986 , nombreuses brisures réparées entre deux verres, deux morceaux remplacés et anciens placés sans tenir compte de la structure; réparé en 1986 avec plombs de casse, les 3 morceaux étrangers remplacés par des morceaux nouveaux, peints de façon à compléter le vitrail.

\section{$\mathrm{N}^{0} 24$. Vitrail héraldique, Pays-Bas, $\mathrm{xvII}^{\mathrm{e}} \mathrm{s}$.} (Fig. 66)

BLASON : parti, au l d'azur à 3 chapeaux au naturel; au 2 de gueules à la bande d'argent accompagnée de 2 lions hissant d'or, l'un en chef, l'autre en pointe. Le heaume est surmonté d'un panache "végétal"(?).

Verre blanc peint de grisaille (sépia), de jaune d'argent et d'émaux (bleu, rouge).

Ovale : $25 \times 19 \mathrm{~cm}$.

Inventaire $\mathrm{n}^{0} 85.011 .2$

CONSERVATION : avant 1986, nombreuses brisures réparées entre deux verres, deux morceaux remplacés et mal repeints; après 1986, plombs de casse, les morceaux étrangers ont été remplacés par des morceaux nouveaux, repeints.

\section{$\mathrm{N}^{0}$ 25. Vitrail héraldique, Allemagne (Westphalie?), $\mathrm{xVI}^{\mathrm{e}}$ ou $\mathrm{xVII}^{\mathrm{e}}$ s. (Fig. 67)}

BLASON : d'argent à l'aigle aux ailes repliées de sable. L'écu découpé est surmonté d'un heaume portant un masque de grotesque au-dessous de la visière et surmonté de deux ailes déployées.

Verre blanc peint de grisaille et jaune d'argent avec quelques touches d'émail bleu. Le champ de l'écu est couvert de diaprures au petit bois et à l'aiguille; travail de petit bois dans les lambrequins.

Ovale : $22 \times 18.5 \mathrm{~cm}$.

Inventaire $\mathrm{n}^{\circ} 85.012$

CONSERVATION : complet, plombs de casse.

\section{No 26. Le forgeron, vitrail commémoratif, emblème parlant, Pays-Bas (Brabant ou Limbourg), 1653 (Fig. 68)}

INSCRIPTION : (au bas du vitrail)

Meus Smits ende Geritten

Iochaims syn Huysuroūw

$\mathrm{A}^{\circ} 1653$

Au mur, un écu d'or chargé d'un A noir.

Verre blanc peint de grisaille (sépia), de jaune d'argent, de sanguine et d'émail bleu.

Ovale : $23 \times 17.5 \mathrm{~cm}$.

Inventaire $\mathrm{n}^{\circ} 85.013 .1$

CONSERVATION : avant 1986, très mauvais état de conservation, de grandes fissures longitudinale et transversale recollées entre deux verres; vers le centre, un morceau manquant remplacé par du verre étranger; réparation soigneuse en 1986 par collage et des plombs de casse (l'un d'eux oblitère une partie de l'inscription). Le morceau étranger a été remplacé et repeint.
No 27. Le Bon Samaritain, d'après une gravure de Martin Heemskerck datée de 1549 (Br. Mus. 1872-10-12-442), fin $x^{2} \mathbf{r}^{\mathrm{e}} \mathrm{s}$. (Fig. 69)

Verre blanc peint en grisaille (sépia), jaune d'argent et sanguine(?)

Ovale : $22.5 \times 19 \mathrm{~cm}$. (probablement recoupé)

Inventaire $\mathrm{n}^{\circ} 85.013 .2$

CONSERVATION: deux plombs de casse; un morceau manquait à droite et a été remplacé et repeint en 1986. Tous les contours avaient été redessinés (probablement au $X_{I} X^{e} s$.); après nettoyage, l'équilibre entre modelé et trait est meilleur.

illustration: The Gazette, Montréal, 21 janvier 1980.

Malgré une qualité de peinture sur verre assez médiocre, la composition à la fois dense et dynamique pouvait laisser soupçonner un modèle intéressant. En effet il existe une gravure de, ou d'après, Martin Heemskerck (1498-1574) datée de 1549, donc de la période de maturité de l'artiste, après son séjour en Italie entre 1532 et 1537 (Fig. 70). Il n'y a rien dans le style de Heemskerck qui suggère l'importance donnée au trait dans le rondel de Montréal, et le modelé excessif de la musculature, si caractéristique du maniérisme nordique de Heemskerck, se trouve à peine suggéré dans le rondel. D'autre part, le décor de la gravure a été presque entièrement supprimé : seules demeurent les silhouettes du prêtre et du lévite, s'éloignant sur un chemin bordé de trois arbres. Mais dans ses lignes générales, dans la plupart des détails et dans ses proportions, le sujet principal suit le modèle avec soin.

Ce qui augmente grandement la valeur exemplaire de ce rondel, c'est la comparaison avec deux autres pièces exécutées d'après le même modèle. Celle du Victoria and Albert Museum ( $n^{\circ}$ 1256-1855), que nous ne connaissons malheureusement que par une bonne reproduction en noir et blanc et par les deux lignes que lui consacre Rackham dans le chapitre sur les vitraux peints à l'émail (sous une attribution erronée d'ailleurs) ${ }^{41}$, est d'une toute autre qualité de dessin et de modelé (Fig. 71). Elle semble même utiliser les ressources de la peinture sur verre (souplesse du trait au pinceau, enlevage des lumières au petit bois ou à l'aiguille) pour enrichir le modèle gravé : la ville qu'on aperçoit esquissée à l'arrière-plan de la gravure prend corps et volume; on y voit un puissant bâtiment moyenâgeux à tour fortifiée, dans lequel ont été percées de grandes fenêtres arquées, des toits en pente et des cheminées, mais aussi des ruines auxquelles s'accrochent des arbres vigoureux. Les proportions du sujet principal sont légèrement modifiées et le tout prend plus d'ampleur.

Le rondel de Wisbech St Mary présente quelques différences notoires (Fig. 72) : en inscrivant la composition dans un cercle, le peintre verrier a ajouté des arbres des deux côtés et modifié considérablement l'arrièreplan; la ville est devenue un groupe de ruines devant lesquelles se détache un petit bâtiment classique à portique. Dans ces transformations, le prêtre et le lévite ont disparus! La peinture à l'émail vert, bleu et rouge s'ajoute au jaune d'argent pour créer un ensemble très

41 Bernard Rackham, A Guide to the Collections of Stained Glass (Londres. Victoria and Albert Museum, 1936), pl. 62. 
plaisant. Ces deux rondels doivent être datés de la fin du $\mathrm{xVI}^{\mathrm{e}}$ siècle; le rondel de Montréal, oeuvre d'un peintre de second ordre ou même d'un apprenti, est plus difficile à dater, probablement postérieur aux deux autres.

\section{$\mathrm{N}^{0}$ 28. Pieta, Allemagne ou Pays-Bas, $\mathrm{xvI}^{\mathrm{e}}$ s.?} (Fig. 73)

Verre blanc peint de grisaille (sépia) et jaune d'argent; beaucoup dc travail au petit bois.

Ovale : $23.5 \times 20 \mathrm{~cm}$

Inventaire $n^{\circ} 85.013 .3$

CONSERVATION : intact.

No 29. Adoration du Crucifix, vitrail commémoratif, Pays-Bas, 1665 (Fig. 74)

INSCRIPTION: Aert van Meeselaer

Catelÿn versluÿsen

sÿn huÿsvroūw

(la date est inscrite sur le côté de l'autcl)

Verre blanc peint de grisaille (sépia), d'émail bleu et dc jaune d'argent.

Ovale : $25 \times 19 \mathrm{~cm}$.

Inventaire $\mathrm{n}^{\circ} 85.013 .4$

CONSERVATION: complet, verre en très mauvais état, une fente réparée en 1986 par un plomb de casse.

\section{$\mathrm{N}^{0}$ 30. Promenade sous les tilleuls, vitrail} commémoratif, Pays-Bas, $\mathrm{xvII}^{\mathrm{e}}$ s. (Fig. 75)

INSCRIPTIONS: Willem Adriaensen Seeúw Maritgen Fansde syn : h : vw

(en bas) $W \bar{y}$ rÿden alhier l[]gs de linden die ons hier soecket / sullen o[n]s vind[c]n en dat niet anders dan in deu [...] / eer d[a]er v[oo]r wÿ te dancken hebben den heer / [d]acr []eni[]h soudmen soecken onder de linden / emen [] dacr soo niet en souden vinden / dan w[]l met groots onner en schanden sülex / []ageg[]kx geschiet in allen landen daer om ecr / de[]oll moet rÿden engaen $\mid \ldots]$

Verre blanc peint de sépia, jaune d'argent et émail bleuvert; enlevage au petit bois.

Ovale : $26 \times 20 \mathrm{~cm}$.

Inventaire $\mathrm{n}^{\circ} 85.014 .1$

CONSERVATION: complet, mais multiples fractures et nombreux plombs de cassc, dont beaucoup ont pu être ćliminés à la restauration de 1986 (l'inscription a, de ce fait, été quelque peu restaurée).

\section{$\mathrm{N}^{0} 31$. Le Bon Samaritain, Pays-Bas, fin $\mathrm{xvi}^{\mathrm{e}} \mathrm{s}$.} (Fig. 76)

INSCRIPTION : (peut-être postérieure, XVII ${ }^{e}$ s.?) Den prÿster.noch./ Levÿt.gheen.barmbar./ ticheÿt.en.doet// En.verbÿ.gaende. cn./ heeft.het.haer.niet./ verdrooten// Macr. cen.samaritaen/ Den.gewonden.syn./ Drück. boet// Die.heelt.olÿ.en wÿn/In.sÿn.wondc gegooten.
Verre blanc peint de grisaille (sépia), de jaune d'argent et de sanguine; enlevage au petit bois.

Ovale: $14 \times 9.5 \mathrm{~cm}$.

Inventaire $\mathrm{n}^{\circ} 85.014 .2$

CONSERVATION : incomplet, plombs de casse, dont un a pu être supprimé à la restauration; un large triangle manquant en haut à gauche a étć aussi remplacé et peint en 1986

Cet autre rondel du Bon Samaritain présente bien des similitudes avec le $n^{\circ} 27$. Il pourrait provenir du même atelicr, à en juger par la technique de peinture, le pommelage du cheval, l'importance du trait cernant un dessin assez mal modelé. Il faudrait aussi chercher un modc̀le chez Heemskerck, puisque le tableau du Bon Samaritain par ce peintre, au Musée Frans Hals de Haarlem (catal. n" 156), utilisc le même schéma du Samaritain se penchant pour relever le malheureux, schéma dont on peut suggérer un modèle chez Dürer dans la Descente de (Croix de 1507 (B.14). Il cxiste une autre version du même rondel à Shrewsbury, Shropshire, G.B.

No 32. Tobie rentre chez son père, accompagné de Sarah et de l'archange Gabriel, Pays-Bas, $\mathrm{XVII}^{\mathrm{e}}$ s. (Fig. 77)

INSCRIPIION: TOBIA(S), SARA (au-dessus des personnages)

PAL'PERTAS (au-dessous de Raphaël).

Verre blanc peint de grisaille et de jaune d'argent; travail au petit bois.

Ovale : $24 \times 18 \mathrm{~cm}$

Inventaire $\mathrm{n}^{\circ} 85.014 .3$

CONSFRVATION: une grande fente remplacée en 1986 par un plomb de casse; un morccau manquant cn haut à droite (remplacé auparavant par du verre blanc) a été repeint en 1986.

illustrations: Communiqué (Ogilvie Mills), 3 (juin 1978), 1; Québec at a Glance, x, 1 (juillet 1979), page de couvcrture.

No 33. Annonciation, Pays-Bas (Haarlem?), début XVII ${ }^{\mathrm{e}}$ s. (Fig. 78)

INSCRIPTION: AVE MARIA / GRACIA PLENA

Verre blanc peint de grisaille et jaune d'argent. Ovale: $23 \times 17.8 \mathrm{~cm}$.

Inventaire $\mathrm{n}^{\circ} 85.011 .4$

CONSERVATION: très mauvais ćlat de conservation, nombreux plombs de casse; deux morceaux au moins ont ćté remplacés antérieurement par du verre étranger (au xıx $x^{\mathrm{e}}$ s.?) d'un style tout-à-fait différent.

$\mathrm{N}^{0}$ 34. Jacob et les troupeaux de Laban, vitrail commémoratif, Suisse (Berne ou Bienne), 1678 (Fig. 79)

INSCRIPTIONS : (dans le cartouche supérieur): Laban g[a]b Jacob für die Müeh / die bundt[e]n Schaff auss seine Vieh/Er schelt di[e] Stäblogts vor die Herd / auf das si[e] sich darüber Mehrt/ Gott 
me[h]rt und mehrt den der in ehrt. Hoffn[u]ng Last nicht Zuschan / den [w]erden. Rom.j.V.

(dans le cartouche inférieur):

Hr. Jacob / Risold diser / Zeit Predican[t] / Zu Mühliberg / und fr. Salome / [W]yss sein Ehgmah[l] /

1678

(des deux côtés de ce dernier, armes des donateurs).

BLASONS: à gauche, Risold: d'azur, à l'arbalète d'or posée sur un mont de trois coupeaux de sinople, accompagnée de trois fleurs de lys d'or; à droite, W'yss : parti de gueules ct d'argent à la fleur de lys de l'un dans l'autre.

Verre blanc peint de noir et de brun, de jaune d'argent et d'émaux (bleu, vert, rouge, violet et mauve); lumières enlevées au petit bois et travail à l'aiguille dans le champ des écus.

$27 \times 18 \mathrm{~cm}$.

Inventaire $n^{\circ} 85.015$

CONSERVATION: complet, plombs de casse.

bibliographie: A. Isler-de Jongh, "Deux vitraux commémoratifs suisses à Montréal ", Archives héraldiques suisses. Annuaire 1978, 55-60 (illustr. noir/blanc).

Comme pour l'autre vitrail suisse, il nous a été possible de retrouver les documents généalogiques et héraldiques qui s'y rapportent ${ }^{42}$. Par contre le vitrail n'est pas signé et, en se basant sur la composition générale et les détails décoratifs, il n'est possible pour le moment que de suggérer une origine de Berne ou de Bienne, peutêtre d'après une gravure du Zurichois Jost Amman, datée de $1564^{43}$. La miniature centrale (environ $12 \times 9 \mathrm{~cm}$.) nous montre une cour de ferme avec ses bâtiments, un puits, quclques arbres; au premier plan. Jacob présente les baguettes rayées aux brebis choisies qui viennent à l'abreuvoir. On sait qu'à cette vue elles entraient en chaleur et, arrivées à termc, mettaient bas des agneaux tachetés. En choisissant pour cette " expérience "les bêtes les mieux constituécs, Jacob se vit rapidement à la tête d'un important troupeau, tout en laissant à Laban des modèles de race pure, mais plus chétive.

Ainsi, pour citer le texte du premier cartouche, "Dieu fait prospérer celui qui l'honore ", car "l'espérance ne trompe point ". (On retrouve donc ici l'importance donnéc par les luthériens à la doctrine paulinienne de la justification par la foi, doctrine symbolisée par les deux figures de l'encadrement, appuyées sur l'ancre de la foi et portant la colombe de l'espérance. On est bien loin de la Glose ordinaire de Strabo (référence iconologique courante avant la Réformation) qui voit, dans le troupeau de Jacob, une image de l'universalité de la chrétienneté.

\section{$\mathrm{N}^{0}$ 35. La Résurrection, Pays-Bas ou Allemagne (Francfort s.M.?), vers 1600 (Fig. 80)}

Verre blanc peint de grisaille, d'émail bleu, de jaune d'argent et de sanguine.

42 Isler-de Jongh, "Deux vitraux suisses ", 55.

43 S. Beeh-Lustenberger, Glasgemälde aus Frankfurter Sammlungen (Francfort s.M., 1965), $\mathrm{n}^{\circ} 67,166$.
Ovale monté dans un rectangle $38.5 \times 18.5 \mathrm{~cm}$. Inventaire $\mathrm{n}^{0} 85.016$

CONSERvation: l'ovale est structuré par un cadre de plomb, double dans les parties supérieure et inférieure, simple sur les côtés; l'espace entre ces plombs ct le reste du rectangle a été rempli (au $\mathrm{xIx}^{\mathrm{e}} \mathrm{s}$.?) de inorceaux disparates, anciens pour la plupart. La tête du soldat de droitc semble aussi être un remplacement. Trois morceaux récents dans l'ovale, dont dcux jaunes, tcints dans la masse, et un troisième peint de grisaille brunc, ont été remplacés en 1986. Plombs de casse.

L'iconographie de la Résurrection où Jésus s'éléve au dessus du tombeau dans une nuée lumineuse remonterait au tout début du xvI" siècle (A. Dürer, B.15, Grande Passion, gravure sur bois, 1510; Altdorfer, B.47, gravure sur bois, 1512). Le Musée de Francfortsur-le-Main conserve un vitrail provenant du cloître des Dominicains, daté de 1594 et copié d'une gravure de Jacob de Isaacsz ${ }^{44}$. Le groupe des soldats surpris dans leur sommeil est tout-à-fait semblable à celui de notre rondel, mais le Christ n'a pas le même élan dynamique.

L.cs morceaux qui subsistent du cadre original, ainsi que la qualité des émnaux, suggèrent une originc hollandaisc de la fin du xvre siècle, copiant une gravure peutêtre antérieure à celle de Jacob do Isaacsz.

$\mathrm{N}^{\circ} 36$. Hérode et les Rois Mages, d'après une gravure d'après Martin de Vos (série de l'Enfance du Christ n ${ }^{0} 5-\mathrm{Br}$. Mus. 1937-9-15-334), Pays-Bas, début xviI ${ }^{\mathrm{e}}$ s. (Fig. 81)

INSCRIPTION: ajoutće ultérieurement, étrangère au sujet et incomplète

Verre blanc peint de grisaille (sépia), de jaune d'argent, de sanguine et d'émaux de couleur (bleu, violet et rouge).

$20 \times 18.5 \mathrm{~cm}$.

Inventaire $\mathrm{n}^{\circ} 85.017$

CONSLRVATION : complet, une fente réparée par un fin plomb de casse.

illustration: Montreal Scene (25 févricr-3 mars 1978), 4 (couleurs).

Hérode est assis à gauche sur un trône abrité d'un dais en forme de tente. Gaspard et Melchior sont debout directcment au pied du trônc, alors que Balthazar monte encore les deux marches qui y accèdent. L'n personnage enturbanné se tient un peu en recul, à la gauche d'Hérode, portant un grand livre fermé. Les Mages ont de bcaux gestes dialectiques des mains. On trouve au second plan, un palais de maçonnerie avec un portique surelevé, orné d'une draperie; dans un paysage de dunes et de collines, un chameau et un âne, le premier monté par un chamelier; à l'arrière-plan, une maisonnette modeste (chapelle? étable de Béthléhem?) et une grande construction circulaire à trois étages (temple de Jérusalem?), le troisième étage étant une tour centrale carrée surmontée d'une coupole.

Ce panneau est la copie très fidèle d'une gravure exécutée d'après Martin de Vos (1531-1603), la cin-

44 Beeh-Lustenberger, Glasgemälde, n" 80, 198-205. 
quième de la série de l'Enfance du Christ, probablement par le graveur G. de Jode, qui a signé les nos 3 et 8 de la série (Fig. 82). Pour faire rentrer la composition rectangulaire de la gravure dans un panncau presque carré, le peintre verrier a supprimé, à gauche, deux personnages secondaires à l'action (vraisemblablement lecteur ct commentateur de l'écriturc sainte, puisque celui qui tient le livre ourert sur ses genoux portc une robe dont lc bas est décoré d'une bande portant lc mot TORA). De même, il a supprimé, à clroite, directement au deuxième plan, au picd de l'escalier, un groupe d'hommes armés de hallchardes $\mathrm{ct}$, en troisième plan, unc grande construction à deux étages de strle classique, sorte de basilique animée par une foule de petits personnages accoudés aux fenêtres ou sortant sur la place pour admirer le chameau et l'âne. Ceux-ci font évidcmmont partie de la suite des Rois et n'ont donc pas été clfacés. En outre le portique de la gravure abrite la scène précédant la discussion animce à laquclle nous assistons, c'est-à-clire l'arrivée des Rois devant Hérode. L'élage inférieur qui forme la base de l'édifice circulaire du fond sur le rondel a remplace un simple terre-plein courommé d'un mur de soutionement. La place laisséc libre par la basilique est en partic occupec par des collines. Pour tout le restc. l'essentiel du sujet, la copic est très mimuticusc et traduit dans des coloris riches et variés les inclications graphiques de textures et de décorations des tissus.

La peinture émaillée sur verre se développe en Hollande dans la deuxiome moitié du xvi" siècle. Ftant donné les dates dactivite du graveur (jusque vers 1591). on peut cstimer que ce panncau est un travail hollandais des conviroms de $16(0)$.

\section{N"37. Vitrail héraldique, Pays-Bas, xvir"s.} (Fig. 8.3)

BL.ASON : d'argent au cherron de sable accompagné de 3 douloirs d'or.

Verre blane peint de grisaille, de jaune d'argent et d'émail noir.

Diamètre: $24.3 \mathrm{~cm}$.

Inventaire 10 " 85.018
CONSFRVATION: avant 1986, plusicurs morceaux manquaient dans la partie supérieurc et à gauche, ainsi que dans le bas, à droitc; nombreux plombs de casse. Theo Lubbcrs a restauré les pièces d'origine en les collant et a remplacé les morceaux manquants en complétant le dessin (ajoutant même un cimicr sur le heaume!).

\section{$\mathrm{N}^{0}$ 38. Vitrail héraldique, Pays-Bas?, XvII ${ }^{\mathrm{C}}$ s.?} (Fig. 84)

BLASON: parti, au I de sable aux 3 aiglettes bicéphales d'or, au vol abaissé, couronnécs du même; au 2 coupé, le 1 d'argent à 2 fasces de gueules. le 2 d'argent à une fasce de gucules, au chof de sable chargé d'une hûre d'or cncadrée de 2 ramures du même. Le heaume est surmonté d'une couronne de marquis portant en cimier unc aiglette bicéphale.

Verre blanc peint de grisaille, de jaune d'argent et d'émaux noir ct rouge.

Ovalc: $24 \times 18 \mathrm{~cm}$.

Inventaire $n^{\prime \prime} 85 .() 19$

(oNSERVATION: avant 1986, nombreuses fractures mal recollćcs, entre deux verres; depuis 1986, quelques plombs de casse, d'autres picces soigneusement recollécs.

\section{N'39. Vitrail héraldique, Allcmagne?, xvII ${ }^{\mathrm{e}}$ s.?} (Fig. 8j)

BI.ASON: de sable au lion d'or, armé et lampassé d'argent, à la triple (?) bande d'argent brochant sur le tout: le heaumc est surmonté d'un bourrelet de chevalier portant en cimier un lion issant d'or bandé d'argent.

Vere blanc peint de noir et jaune d'argent.

Diamctre: $26.2 \mathrm{~cm}$.

Inventaire n" 85.020

consfrvation: quelques plombs de casse; une grande pièce a été remplacée (antéricurement à 1986) par du verre pcint moderne, suivant soigneusement le dessin (différence de ton des jaunes ct différence de qualité du verre visible au revers).

1000 Craigdarroch Road Victoria, Colombie-Britannique V8S 2 A4 


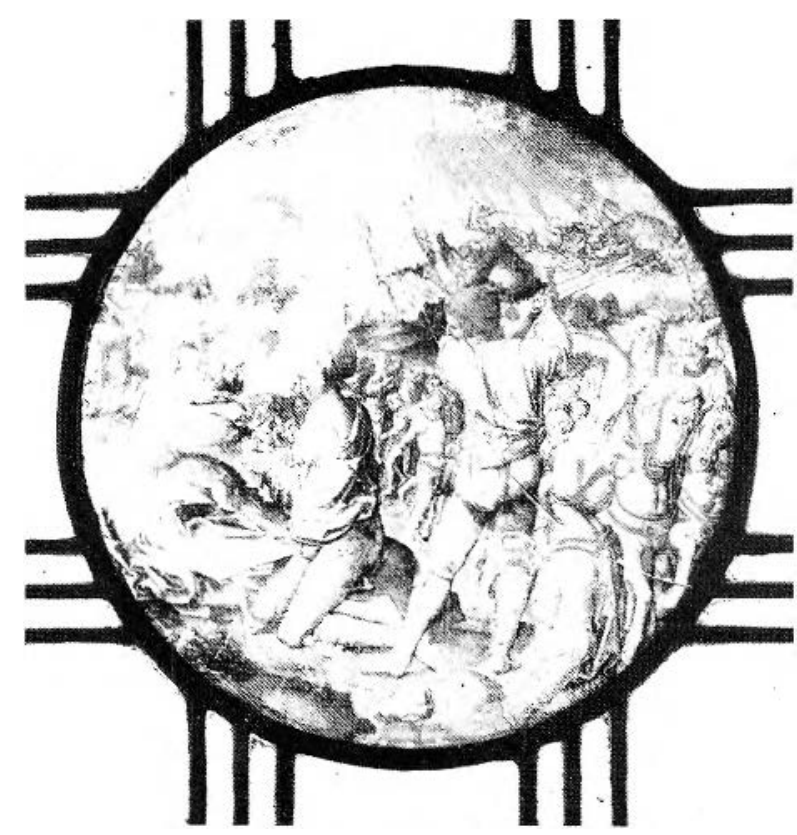

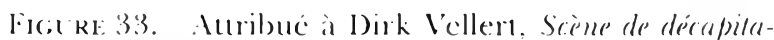

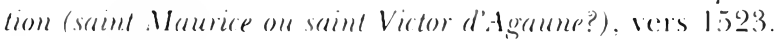
Montrial, Universite Mc(ill, Collection Hosmer, n" d'incentatire 85.005.l (Photo: Dan Corsillo, licole d'architecture, Lniversité Mc(jill, Montréal).

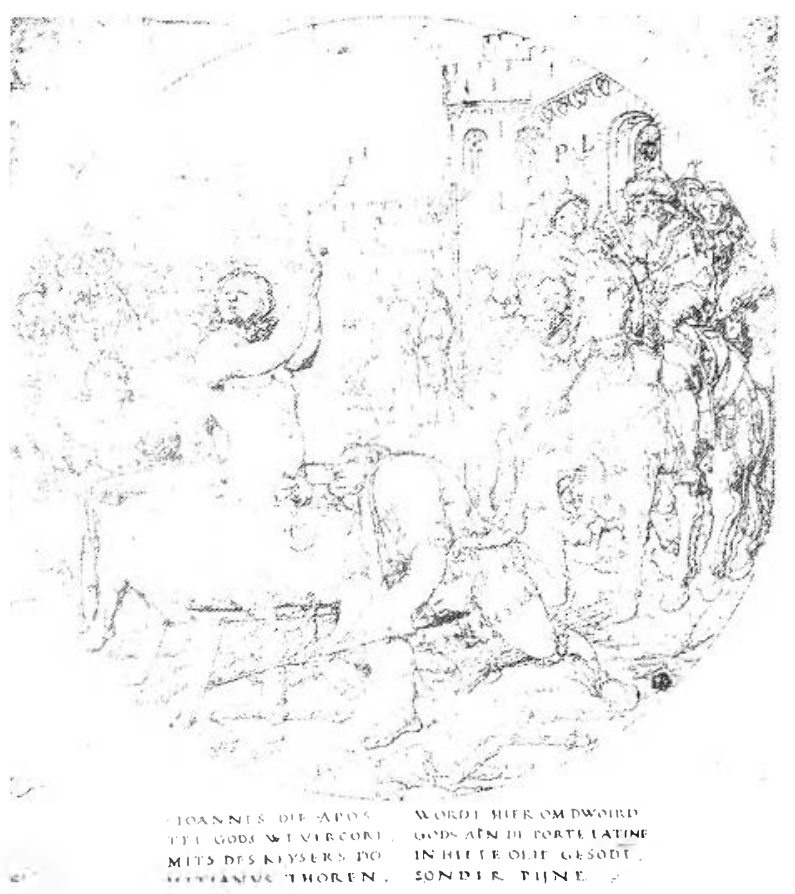

Figuks: 34. Dirk Vellert, Le martyre de saint Jean l'évangéliste, vers 1523. Anciennement at Berlin, cabinet roval des costampes (Photo: reproduit du Jahrbuch der K'uresthastorischen Sammlungen des Allerhörhsten Kaiserhanes, XXII $[19(0)]$, p). v). 


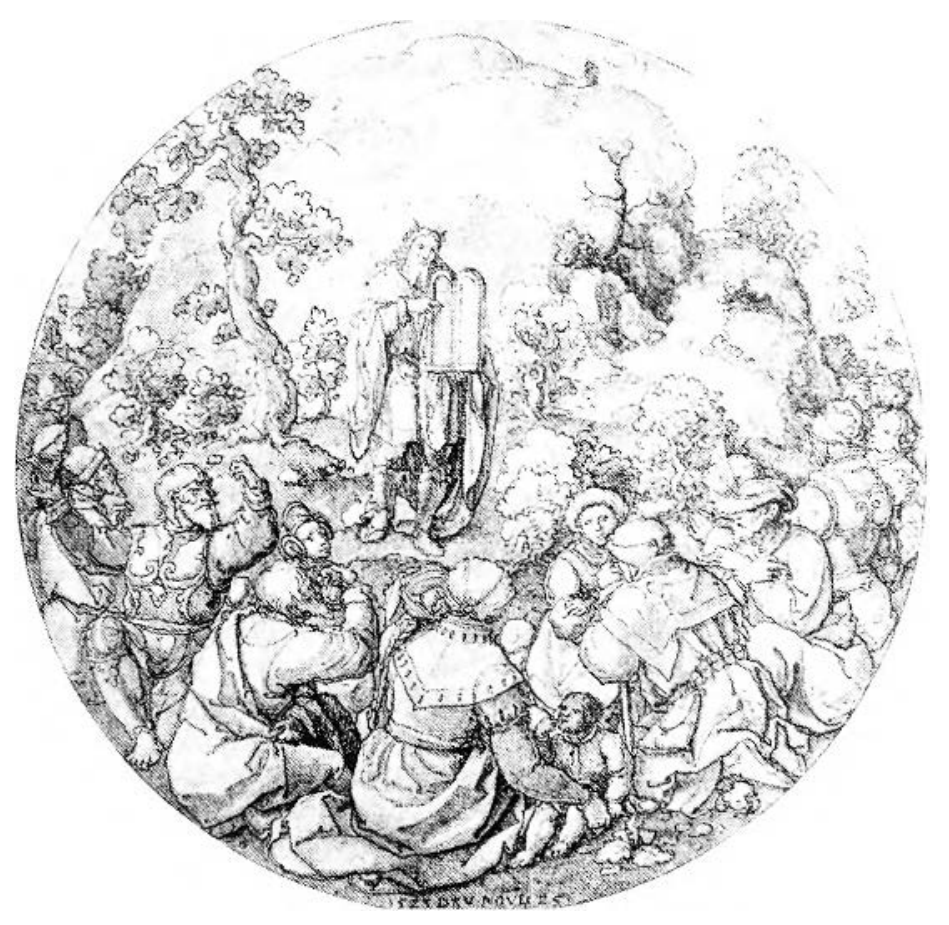

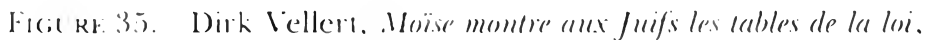
1.123. Anciconement a lleimar. Musce du (irand-eluché (Photo):

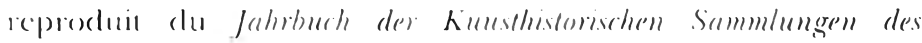

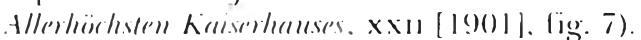

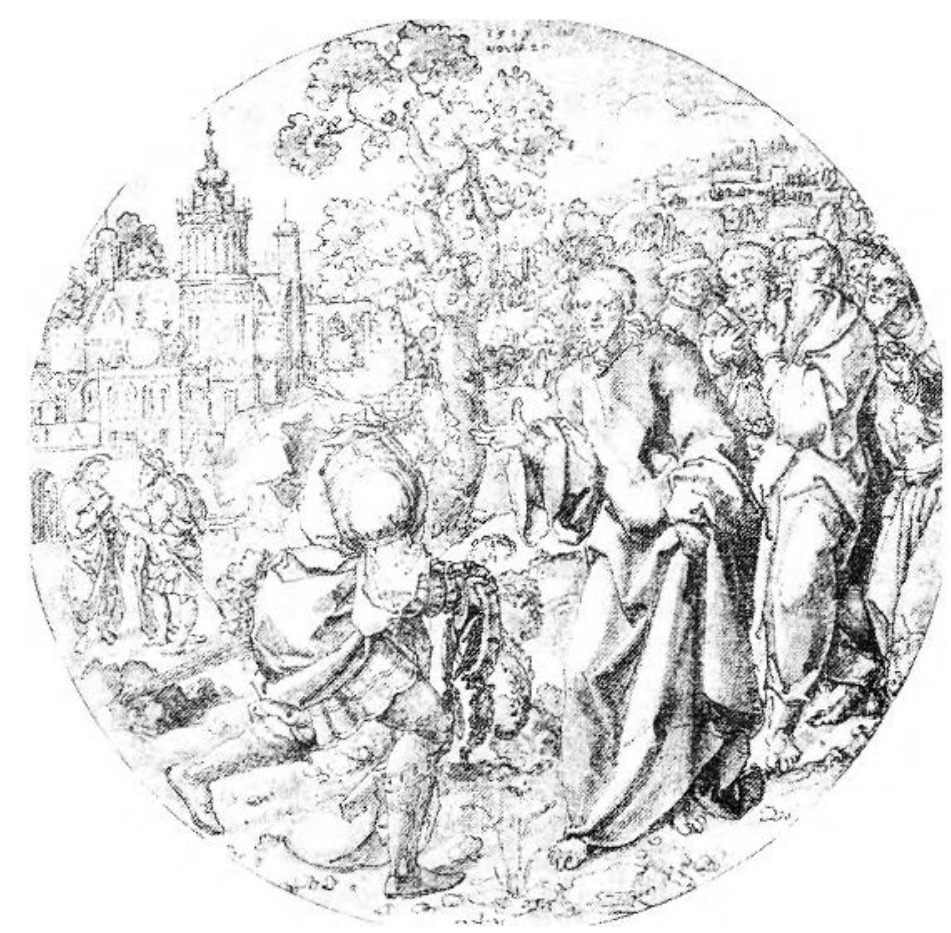

Figere: 36. Dirk Vellert, Christ el le centurion de Capernaum. 1523. Ancicnnement a llimar, Musée du (Band-duché (Photo): reproduit du Jahrbuch der Kunsthistorischen Sammlungen. des Allerhöchsten keniserhanises. xxu11901]. fïg. 10). 


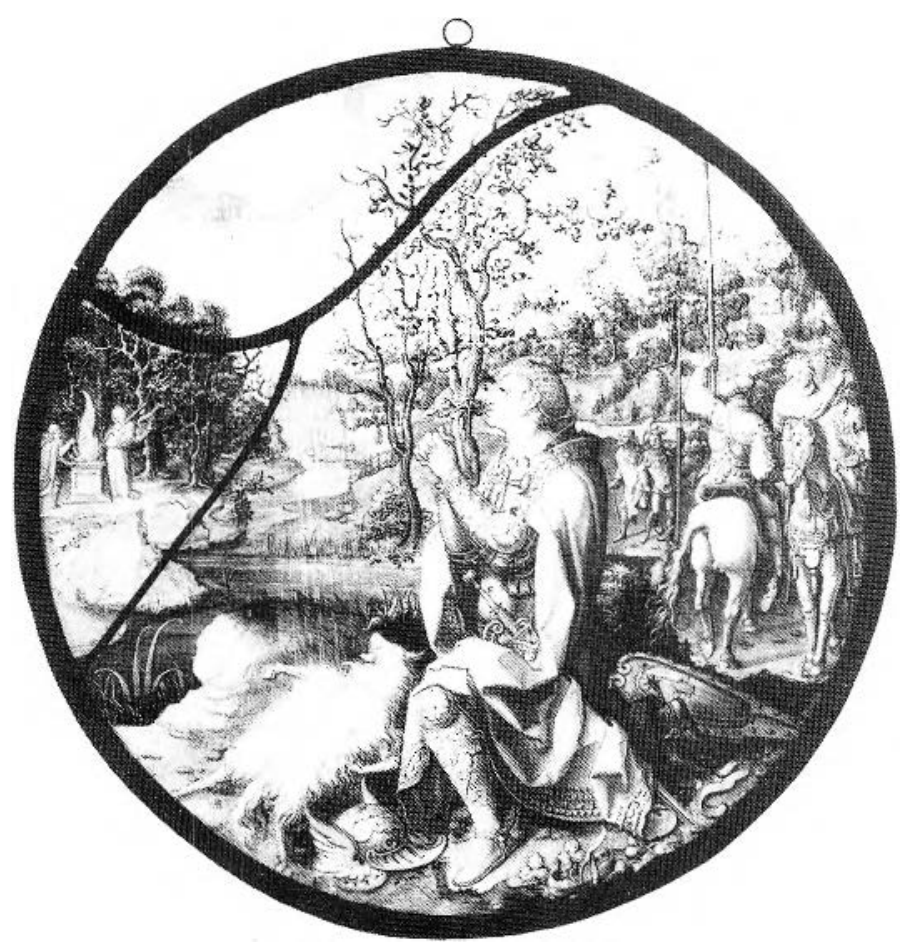

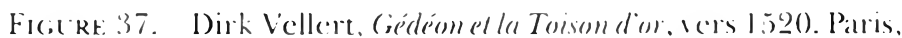
Institut ncerlandis. (ollection F. I.ugt. n" d'imentative I 857 ? (Photo): Fondation Cinstodia, Institut necrlandais, Partis, (c) Coll. IF. I.ugt).

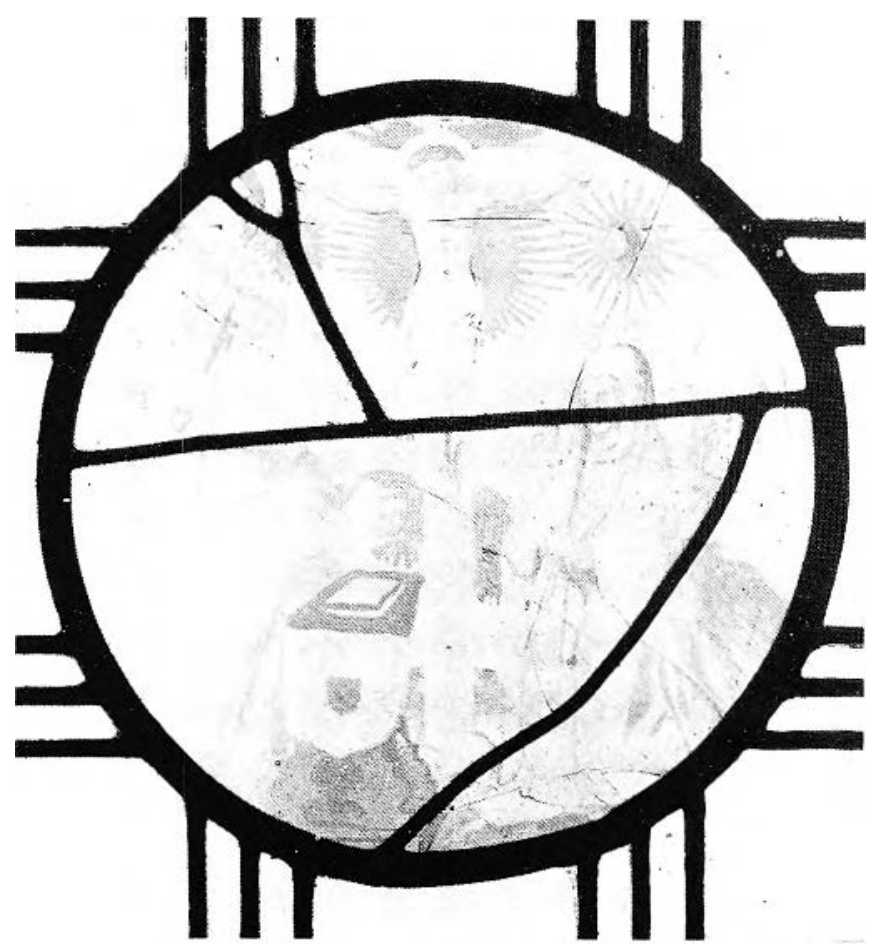

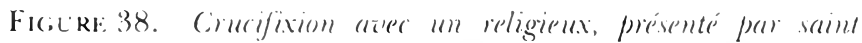
Pierre, "t une religieuse, Xvi"s. Montréal. L'niversitc Magill, Collection Hosmer, n" d'imentate 85.005.2 (Photo: Philippe Isler, Montréal). 


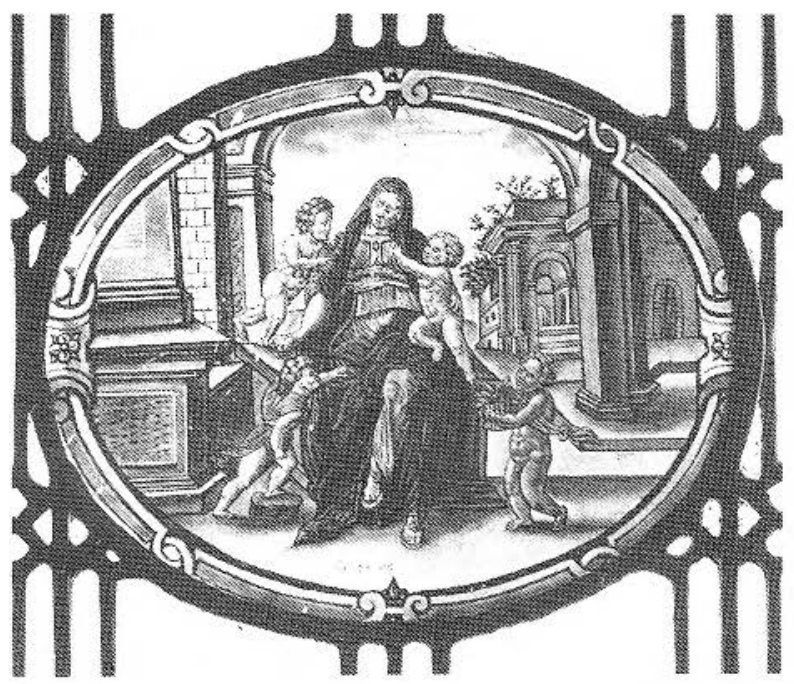

Ficive 39. Ia Charité, début xvu"s, Montréal, Lniversité McGill, Collection Hosmer, $\mathrm{n}^{\circ}$ d'inventaire 85.005.3 (Photo: Philippe Isler, Montréal).

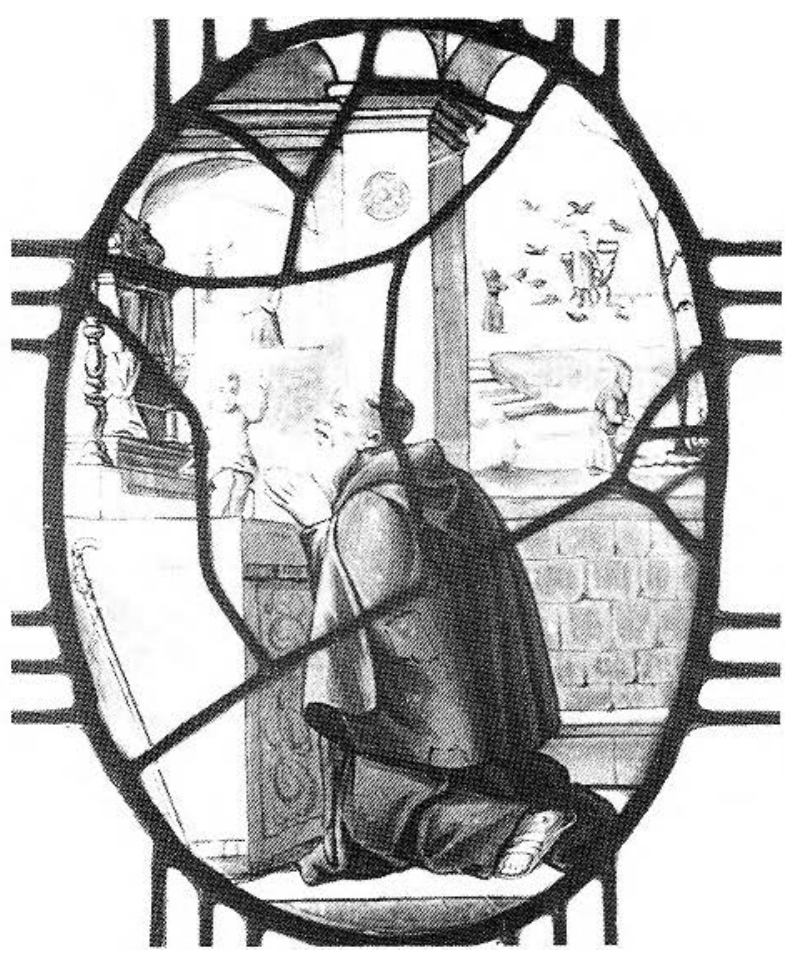

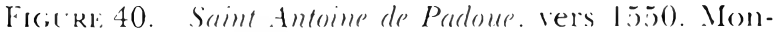
tréal Lniversité McGill Collection Hosmer, n" d'inventaire 85.005.4 (Photo: Philippe Isler, Montreal).

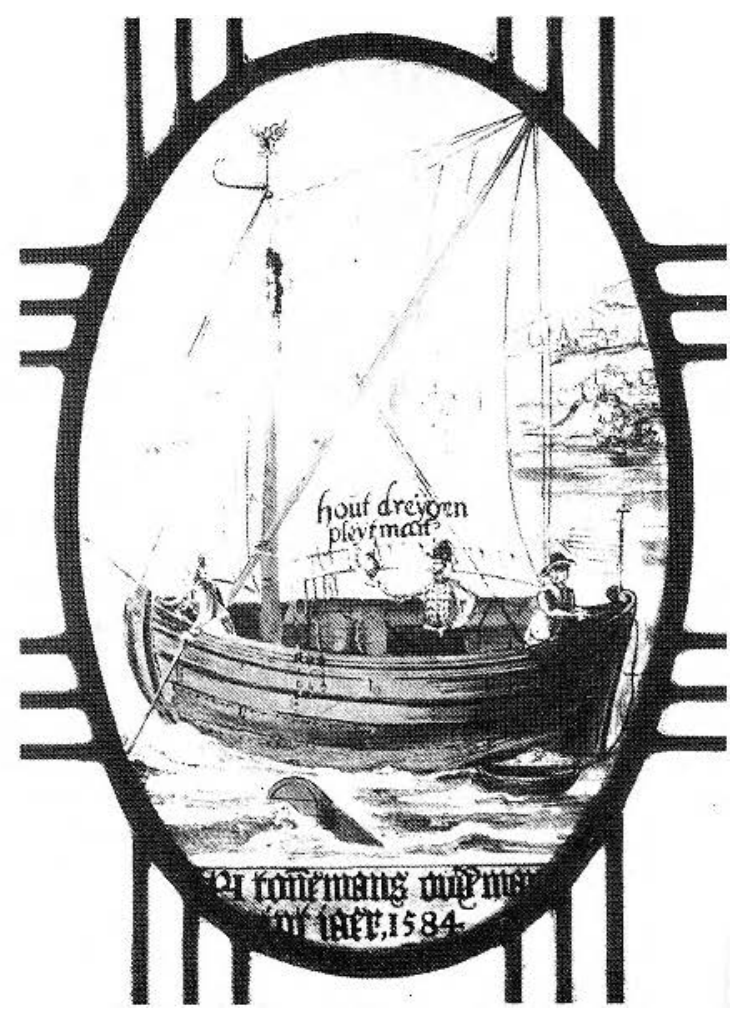

Iisgure 42. Cabotage de vin ou Dragage de la Meuse, 1584. Montréal, L'niversité McGill, (onllection Hosmer, n" d'inventaire 85.006.1 (Photo: Philippe Ister, Montréal). 


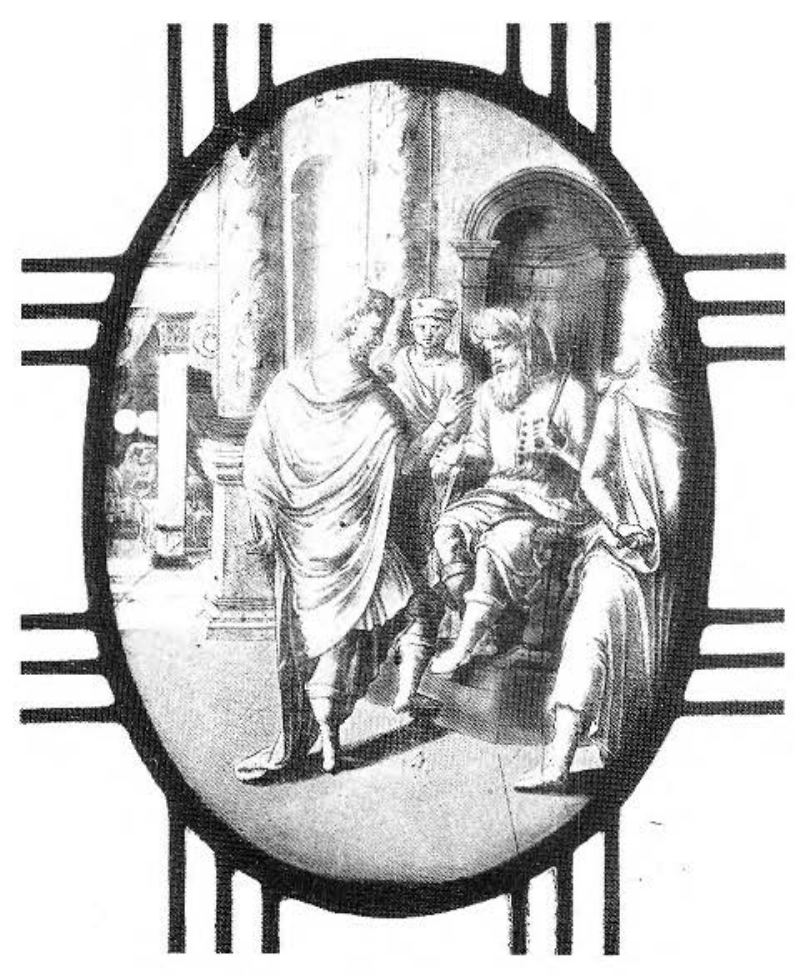

FigLre 43. Joseph explique les songes de Pharaon, fin $\mathrm{xvI}^{\text {" }}$ ou début xvin"s. Montréal, Université Mc Gill, Collec-

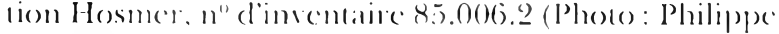
lster. Montrial).

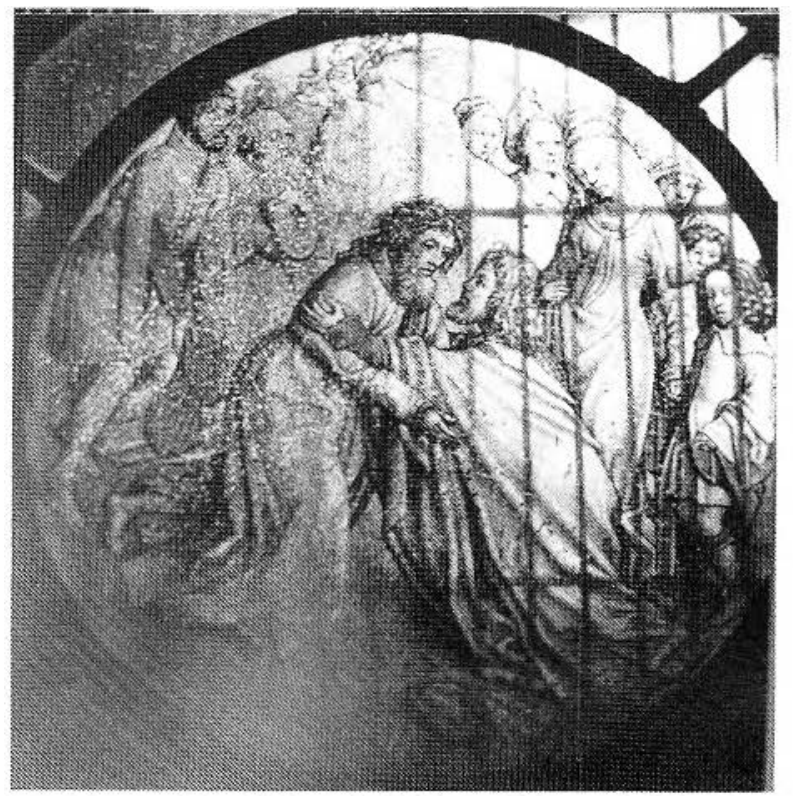

Ficiure 46. "Rencontre de Joseph el de Jacolo", fin $x v^{\prime}$ s. Begbroke, ()xfordshire, (;.B. (Photo): Y'vette V'anden Bemden).

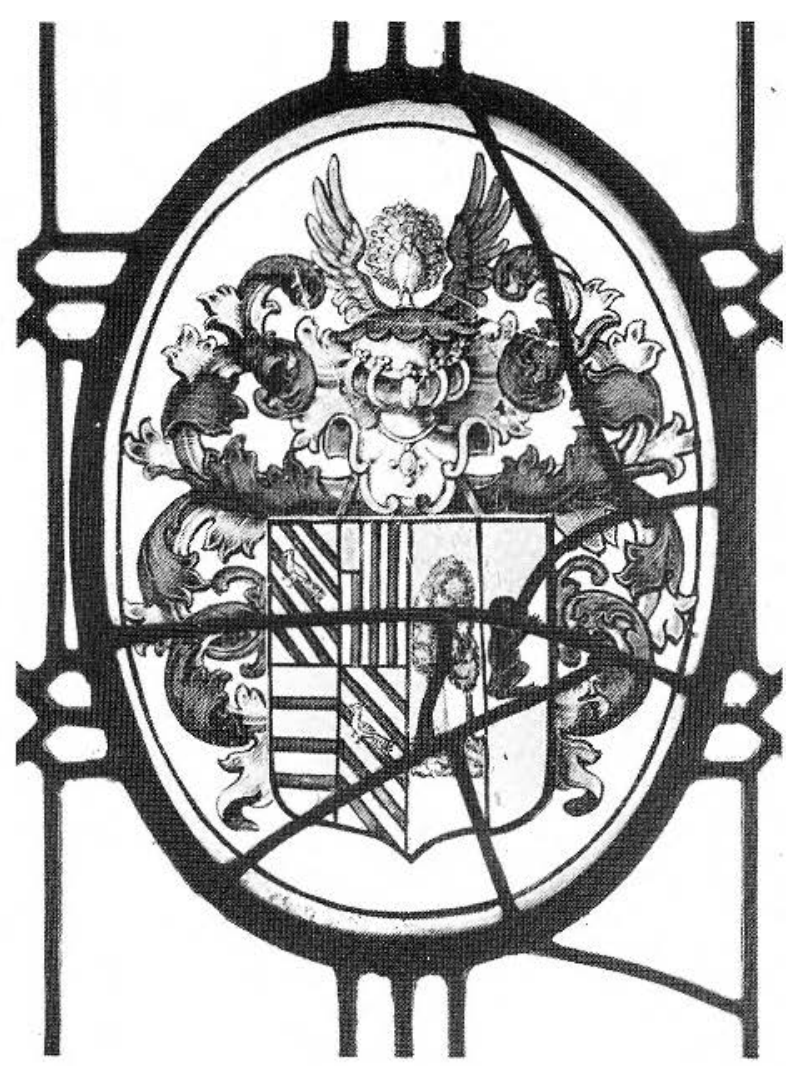

Finere 14. Vitrail heraldique, xvers. Montreal, Unirersite McGill. Collection Hosmer, n" d'imsentaire 8.5.0()(i.3 (Photo: Philippe Isler. Montréal).

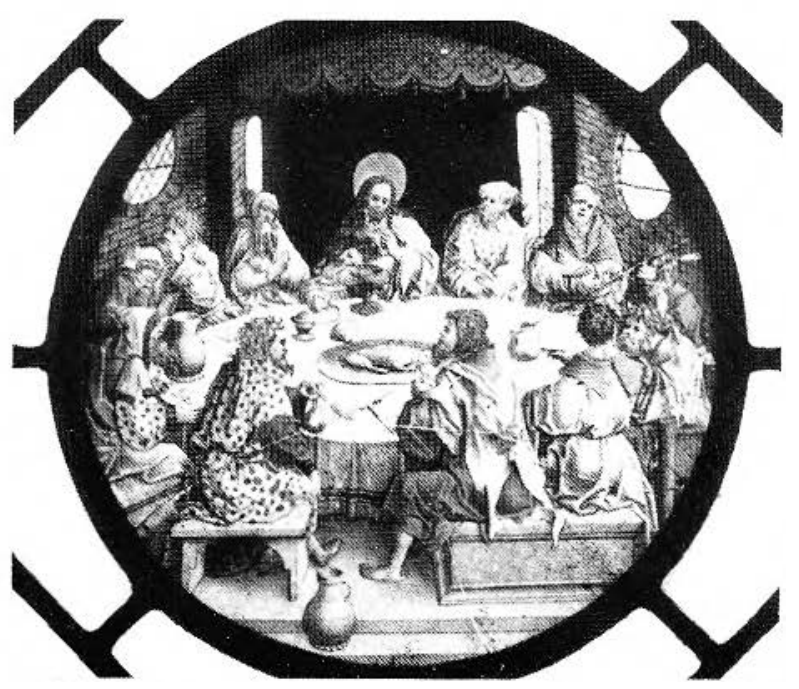

Figurr: 47. La Samle Cène, débul xvi ${ }^{\mathrm{e}} \mathrm{s}$. Cambridge, King's (ollege (Phoro: aimablement fournic par le Dr. II. (i)lc). 


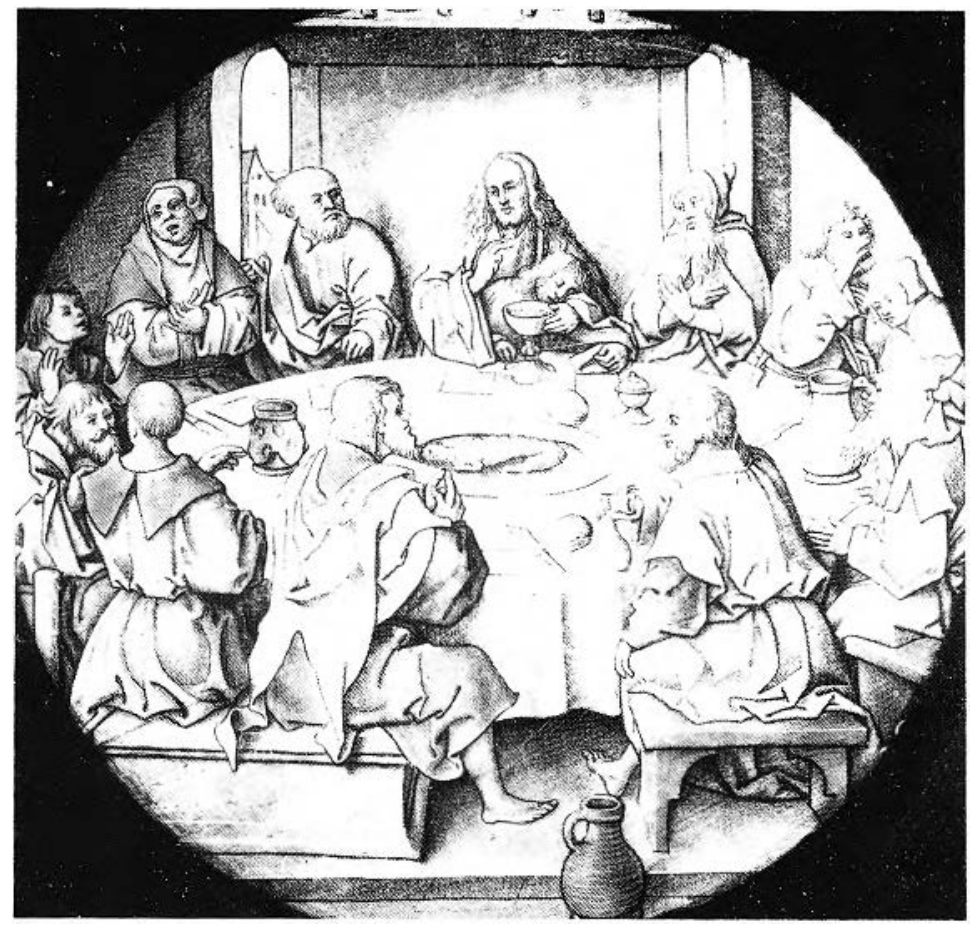

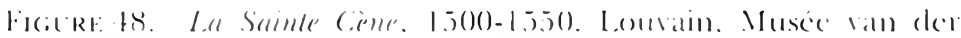

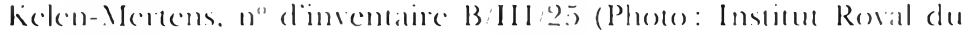
Piltimone antistique, (c) A.(.... Bruxelles).

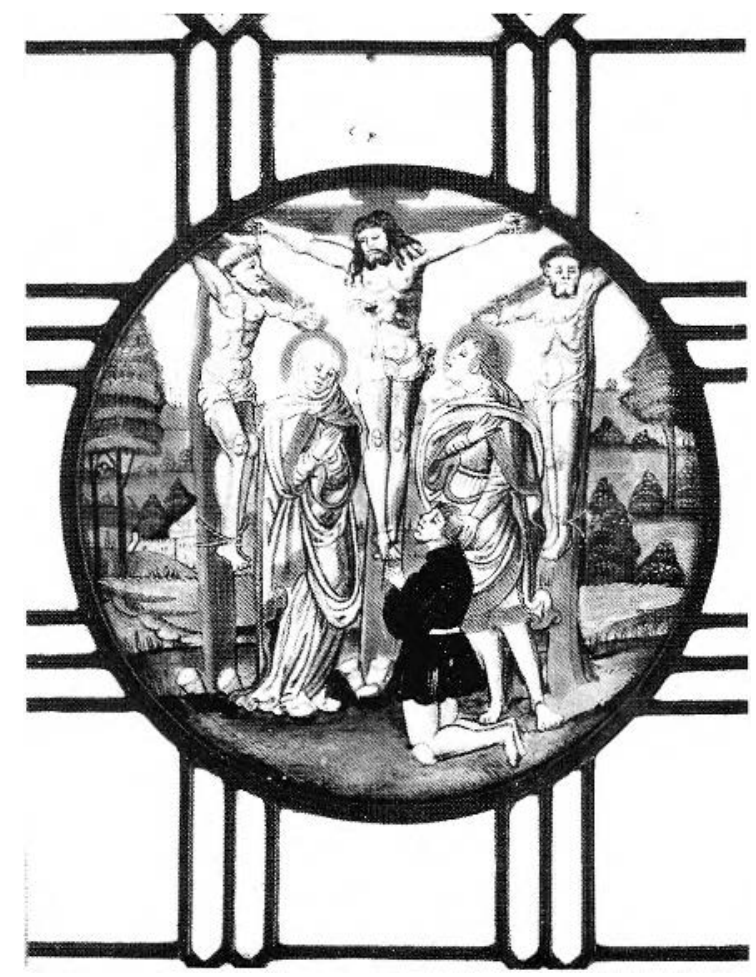

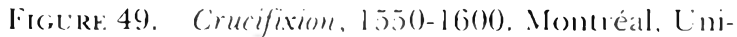
versité McGill, Collection Hosmer. n" d'imentaire 85.006 .5 (Photo : Dan (orsillo, Ecole d'architecture, Lniversité Mc(¡ill, Montréal). 


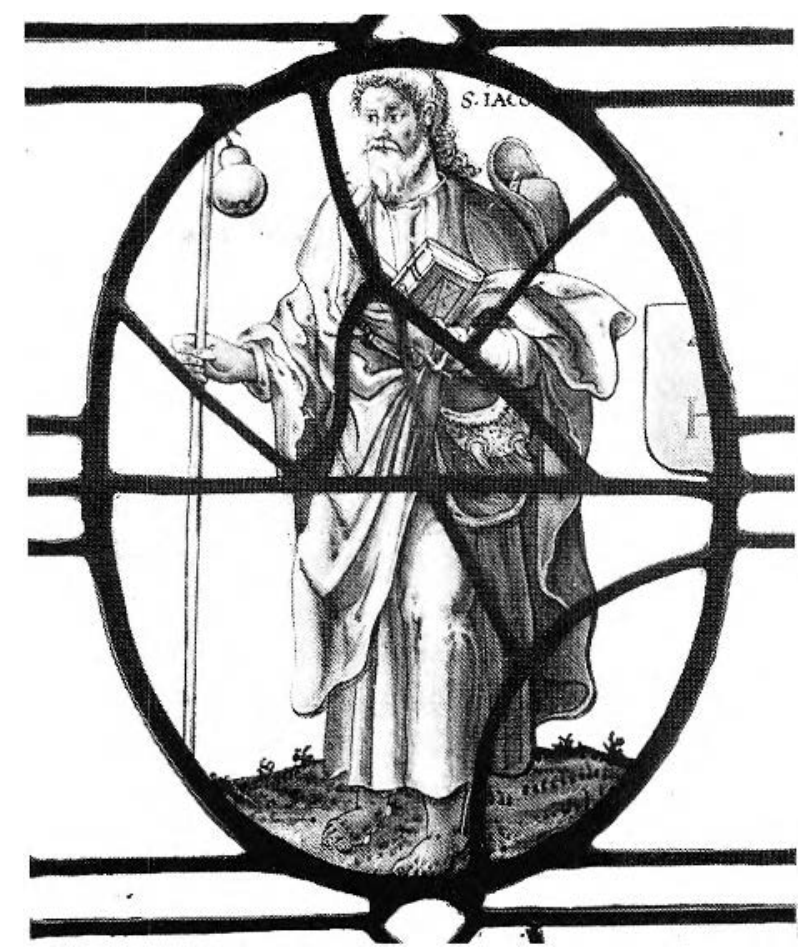

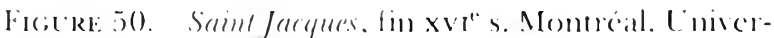

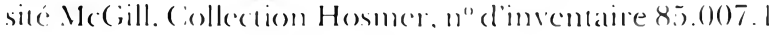
(Phono: Philippe Isler. Montreal).

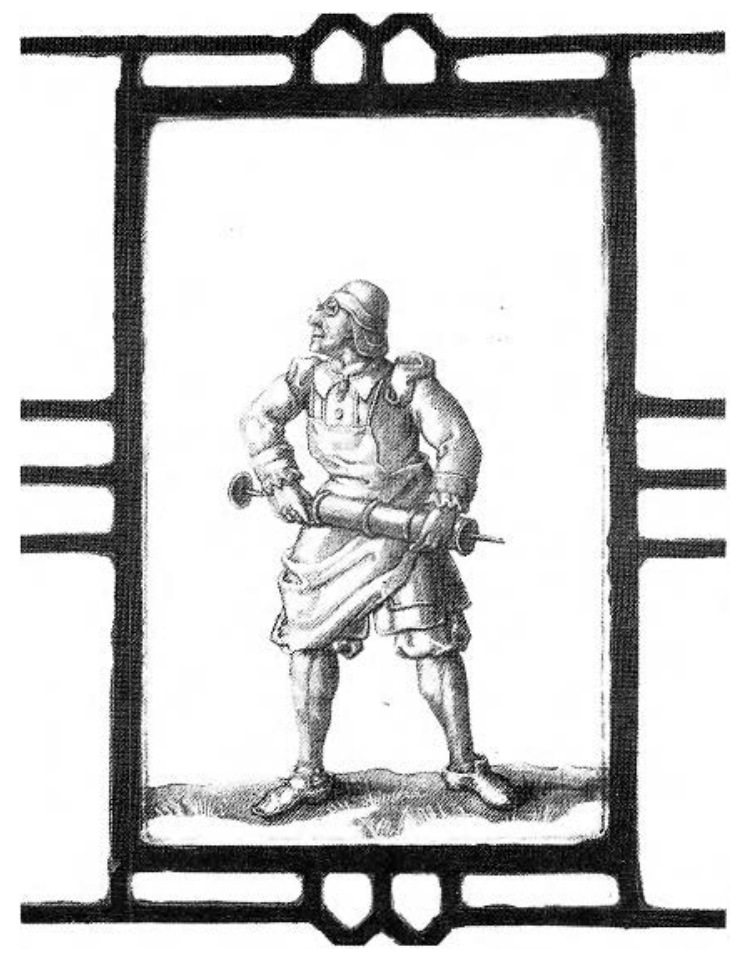

Ficitre 51. liapothicaire on Le chirurgian-barbirer.

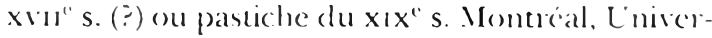
sité Mc(Gill. Collection Hosmer. n" dimentaire 8.5.007.2 (Photo: Philippe: Ister, Montréal). 


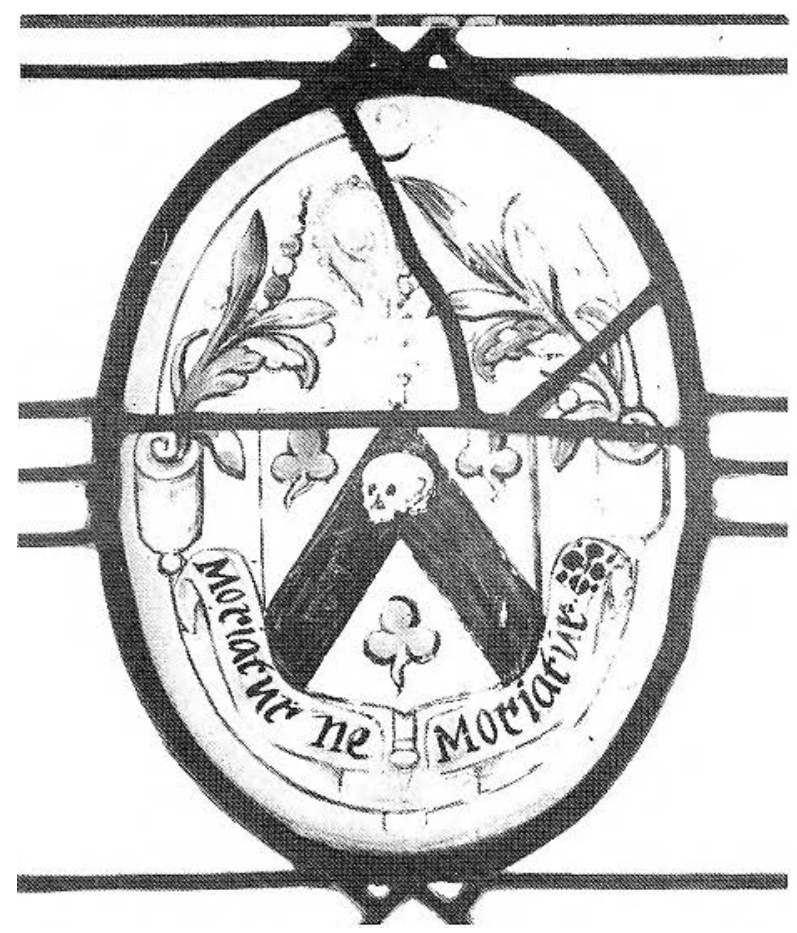

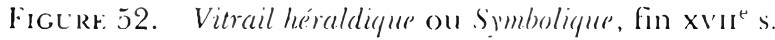
Montréal, Lniversitc Mc(;ill, Collection Hosmer, n" d'inventaire 8.5.007.3 (Photo): Philippe Isler, .Montréal).

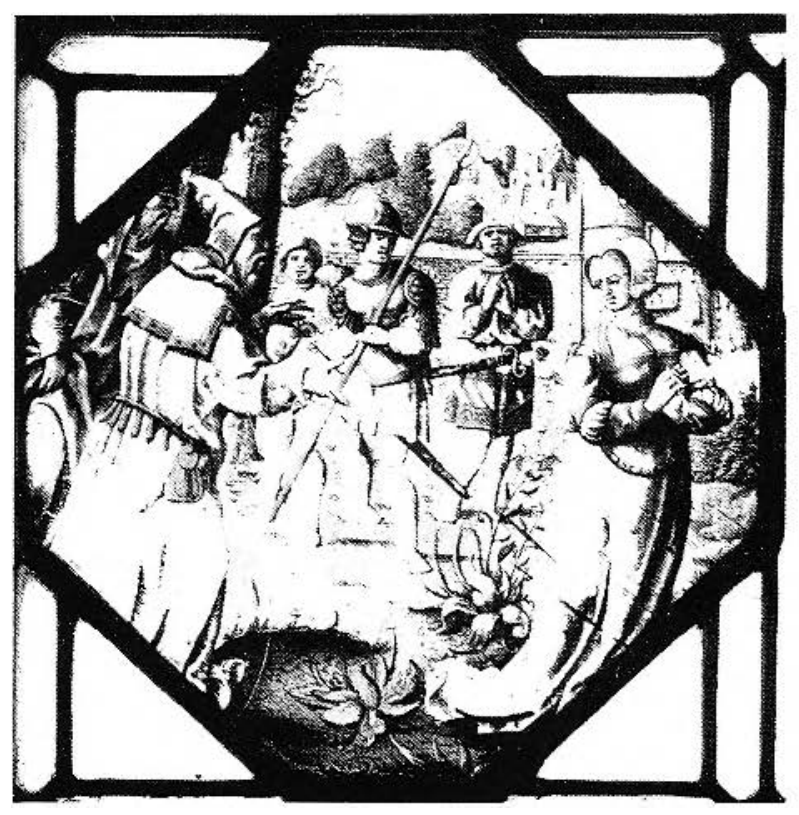

Figure. 54. Suzanne délivrée par l'intervention de Inaniel, vers 1530. Montréal, Lniversité McGill, Collection Hosmes, n" d'inventaire 85.008.2 (Photo: Philippe Isler, Montréal).

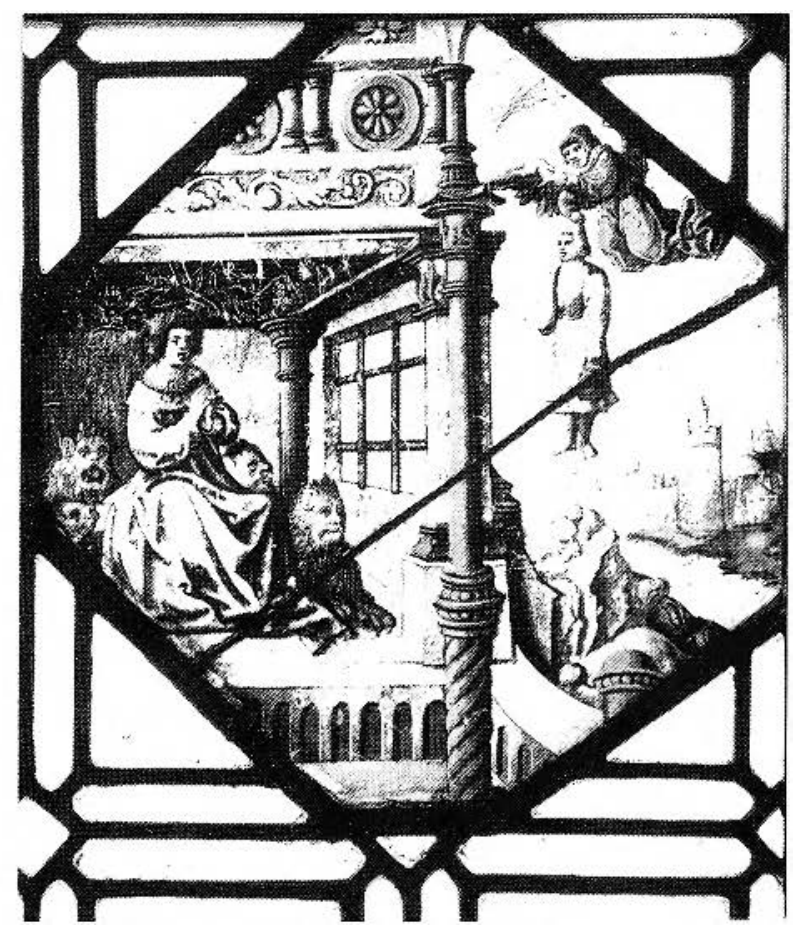

Figenre 53. Damial dams la fosse aux lions. vers 1530 Montréal, Univorsité McGill, Collection Hosmer, n" d'inventaire 85.008.1 (Photo): Philippe Isler, Montréal).

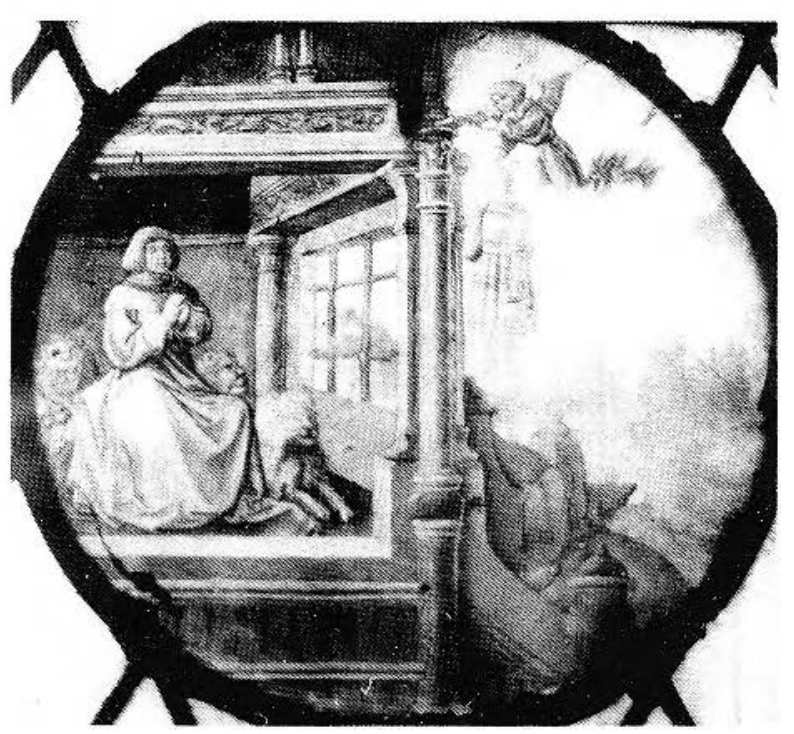

Ficiure 5). Daniel dans la fosse aux lions, Shrewsbury Shropshire, G. B., St Mary's Church (Photo: Yvette Vanden Bemden). 


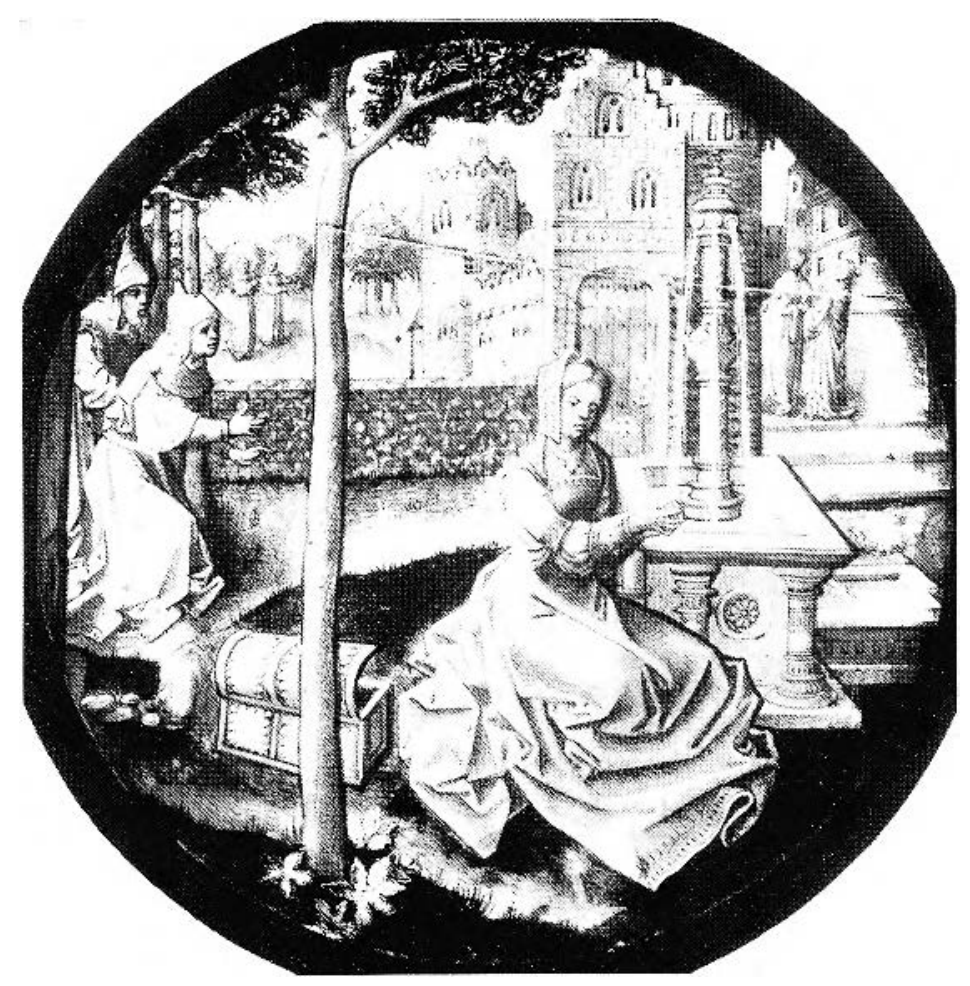

Facelre 56. Suzanne el les vireillards, vers 1530). Londres, Victoria and Albert Muscum, $10^{\prime \prime}$ d'inentaire 5(336-1859 (Photo: Victoria and Albert Muscum).

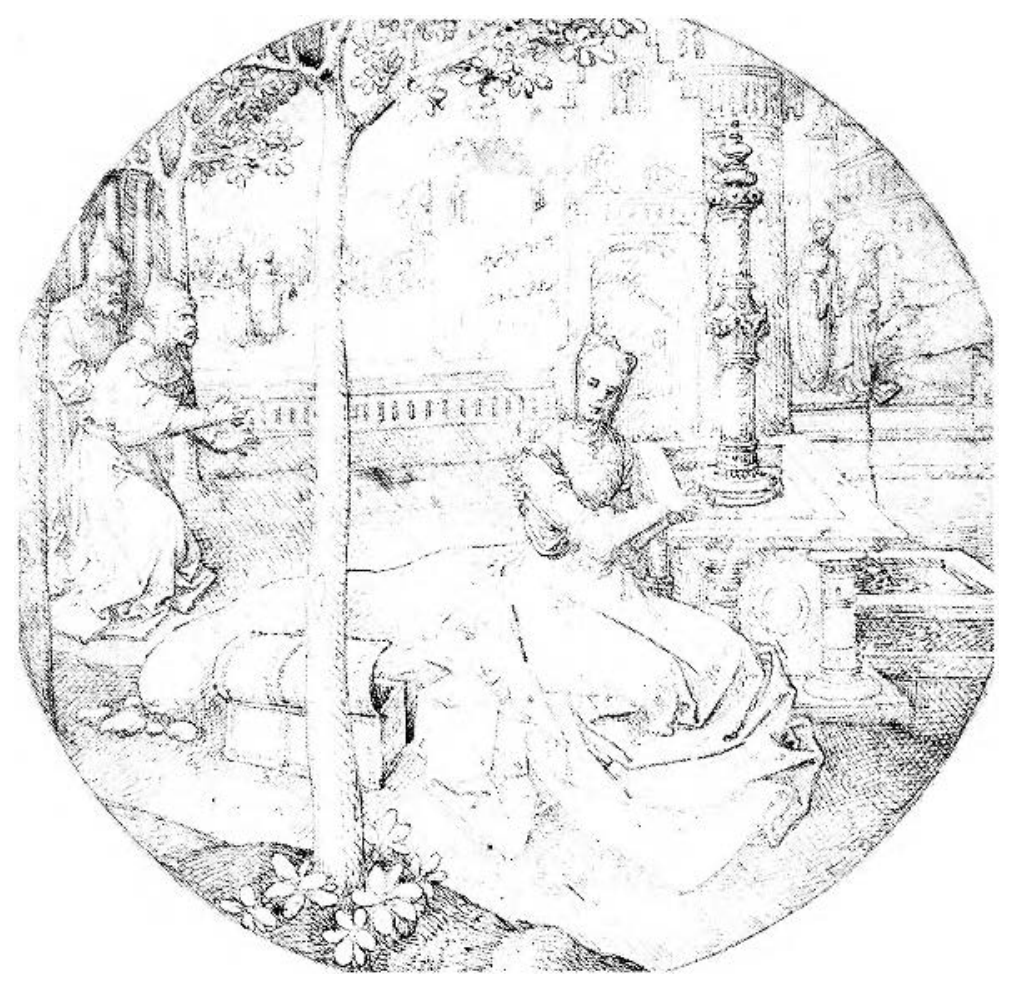

Figure 57. Attribué à Adrian van den Houte, Suzanne el les vieillards, arant 1521. Paris, Institut nécrlandais, Collection F. L.ugt, n" d'inventaire 16612 (Photo: Fondation Custodia, Institut nécrlandais, Paris, (c) (oll. F. Lugt). 


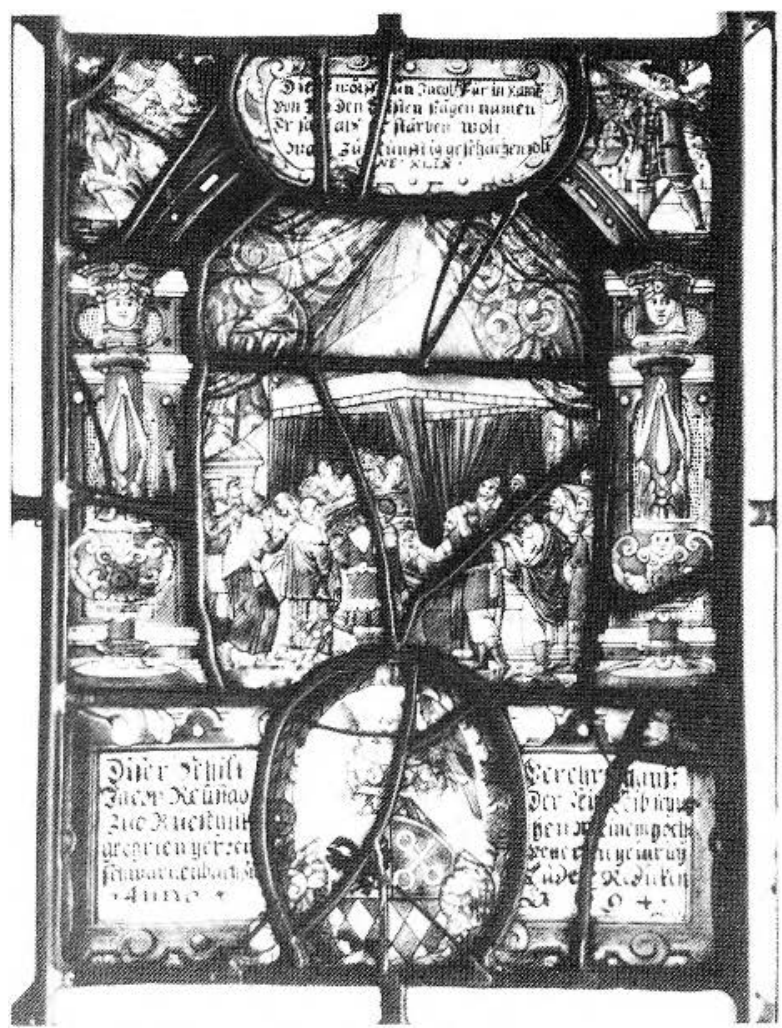

Ficitre 58. Fran\%-Joseph Müller. Lesprophéties de Jacob) sur sonl lit de mont, 1694. Montróal, Université McGill. Collection Hosmer. n" dimentaire 85.008.3 (Photo): Philippe Isler, Montréal).

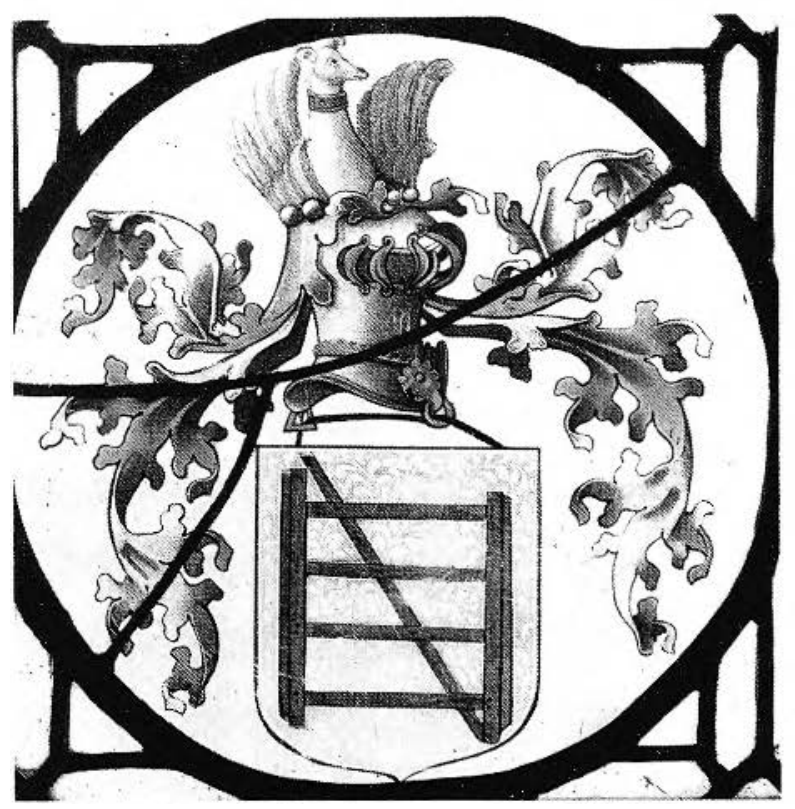

Ficure 60). Vitrail héraldique, xvires.? Montréal, Université McGill, Collection Hosmer, $\mathrm{n}^{\prime \prime}$ d'inventairc 8j.008.j (I'hoto: Philippe Isler, Montréal).

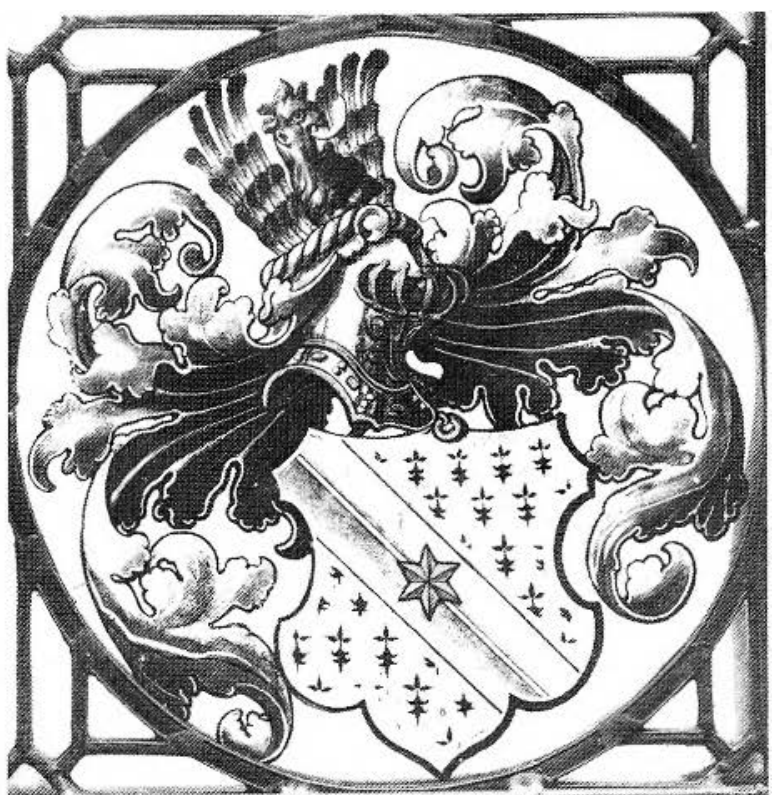

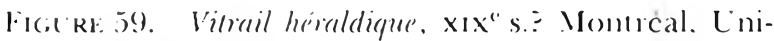
versite Mc(ill, (ollection Hosmer, n" d"incentaire 85.008.4 (Photo prise en 1977: photo: Dan Corsillo, ficole d’architecure. Lniversité Mc(iill. Montréal).

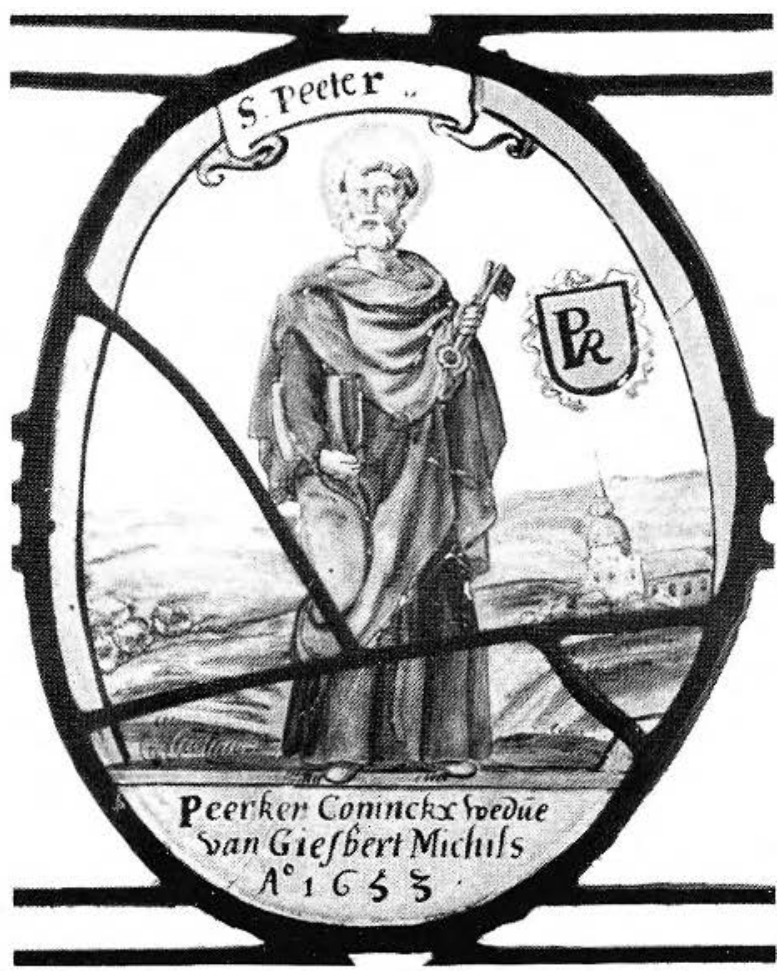

Ficine 61. Saint Pierre, 1653 (recomposci all xix"s.). Montréal, Universitć Macill. Collection Hosmer. n" d'inventaire 85.009. I (Photo : Philippe Isler, Montréal). 


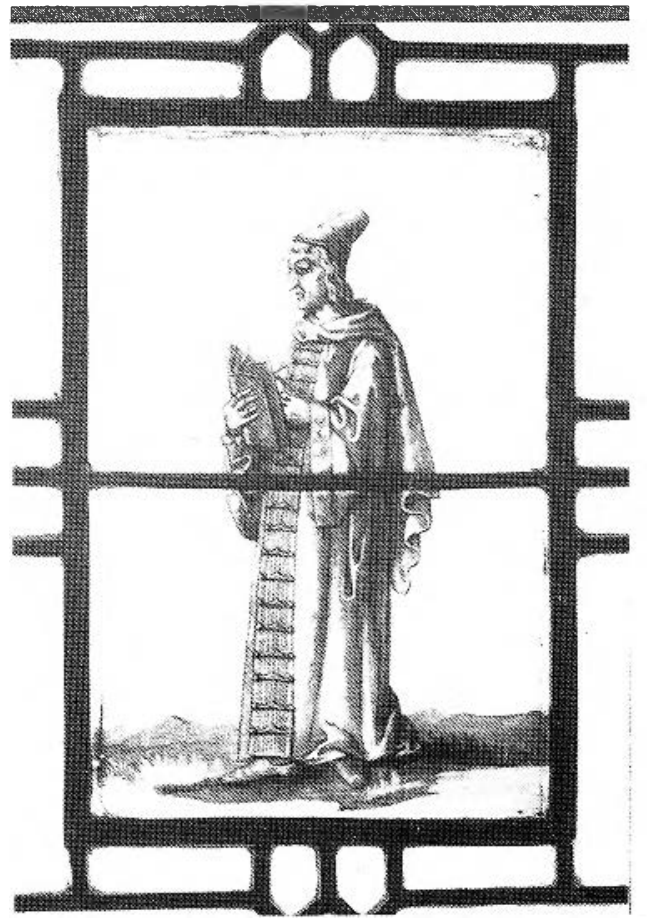

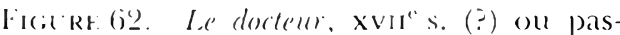
liche du xix"s. Montréal, Unicersite McGill, collection Hosmer, n" l'invemtance 85.009.? (Photo: Philippe Isler, Monncial).

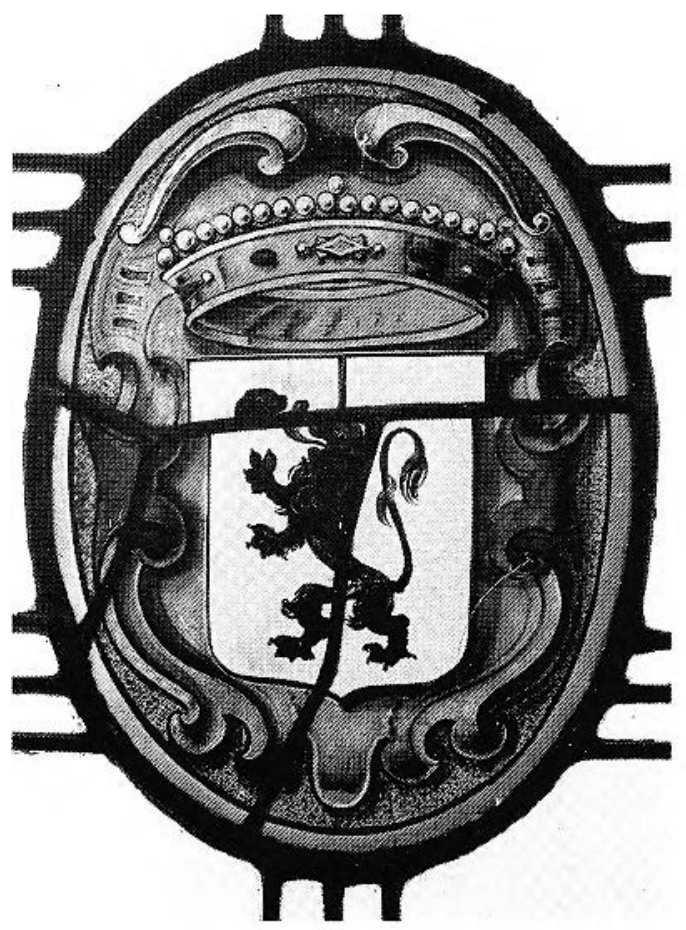

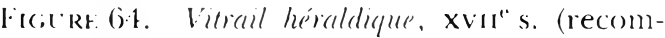
posc all xix"s.). Montréal. Lniversité McGill. (ollection Hosmer, n" d"inventalire 85.0lo) (Photo: Philippe Isler, Montróal).

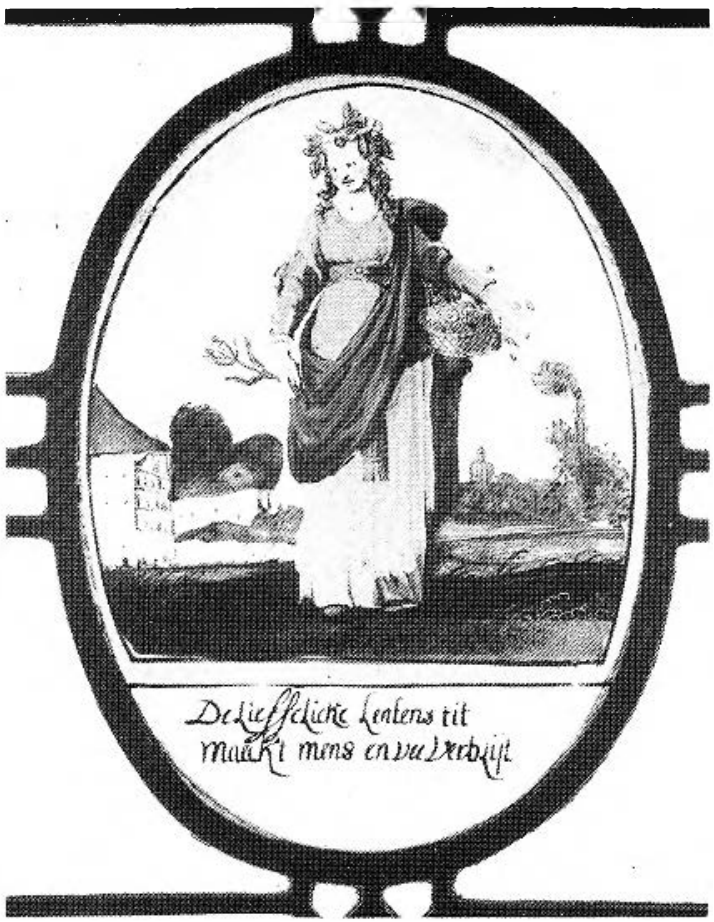

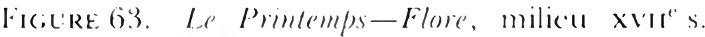
Montréal, Lnircrsite Mc(Bill, Collection Ilosmer, $\|^{\prime}$ d'inventaire 85.009.3 (Photo): Philippe Isler, Mon(reial).

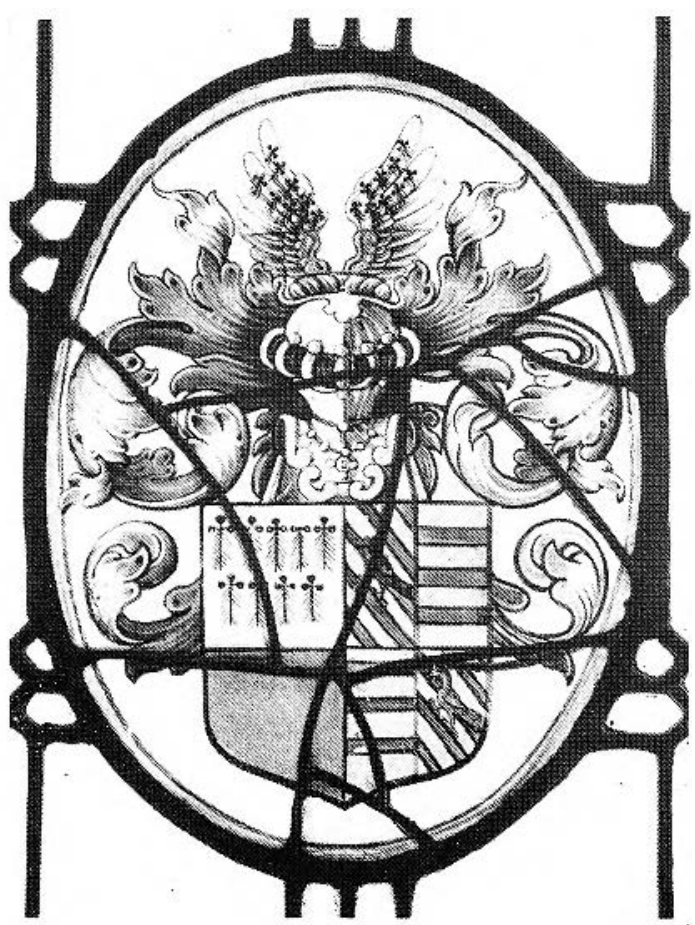

Ficilre 65. Vitrail héraldique, Xvin"s. Montréal, Liniversité Mc(jill, collection Hosmer, n" cl'imrontaire 85.011.1 (Photo: Philippe Isler, Montrćal). 


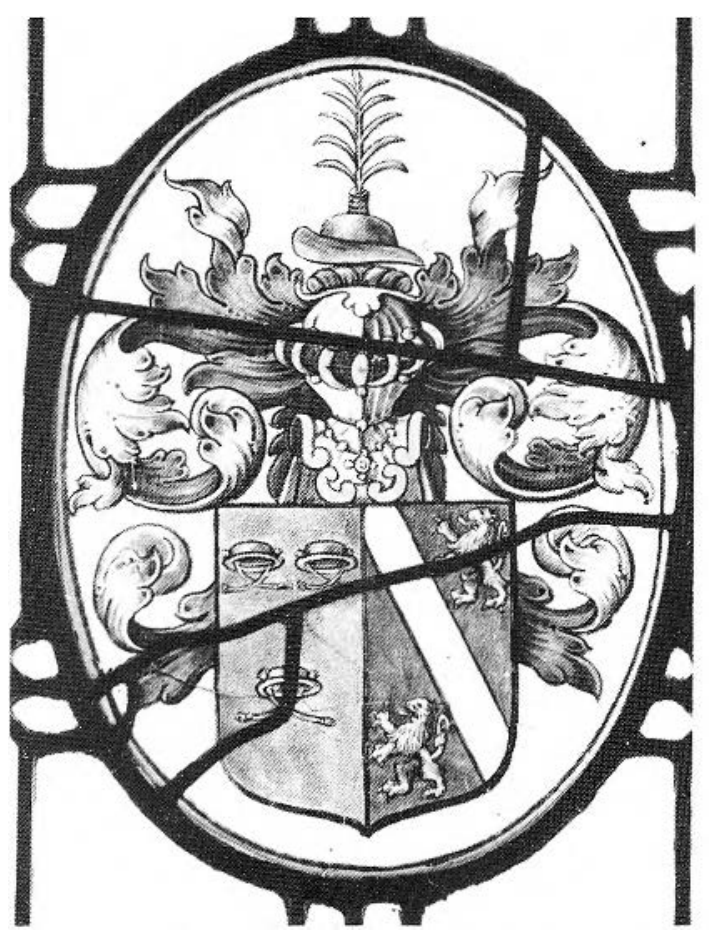

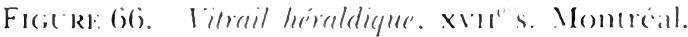

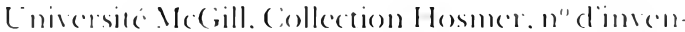
taire 85.0)11.2 (Photo: Philippe Isler, Montleal)

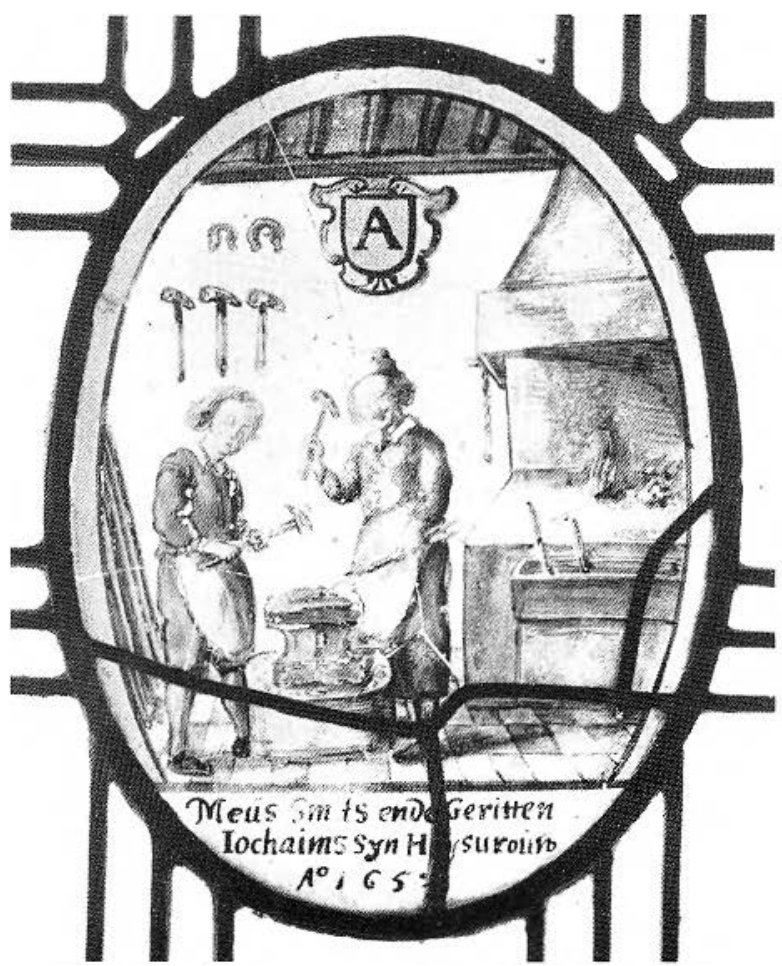

Figurf 68. Le forgeron, 1653. Montréal, Lniversité McGill, collection Hosmer, n" d'inventaire 8.5.(013.1 (Photo: Philippe Isler. Montréal).

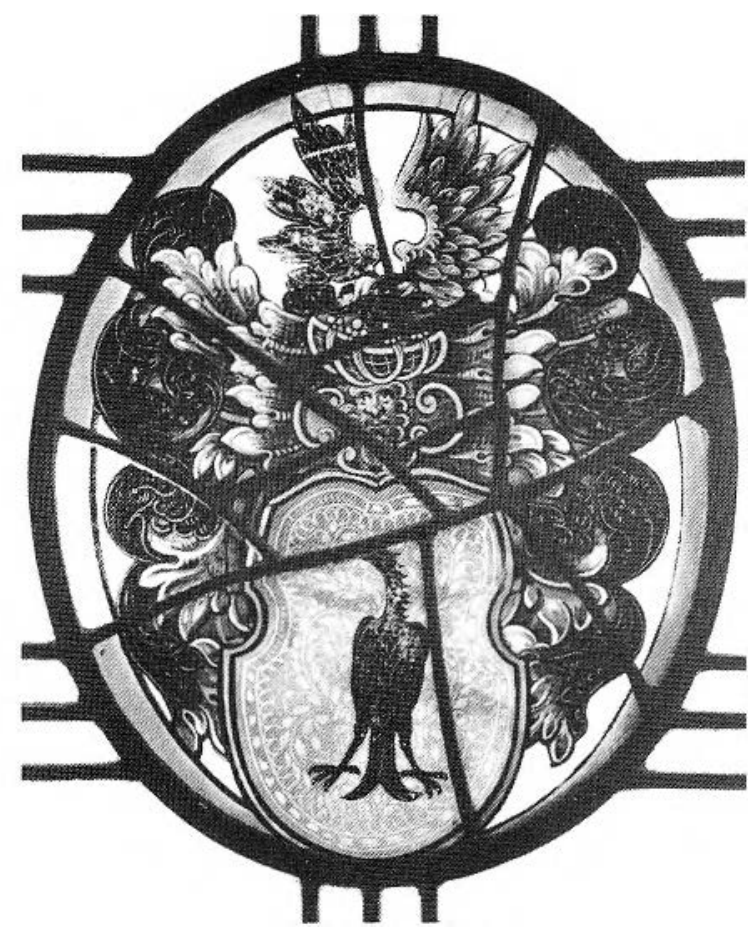

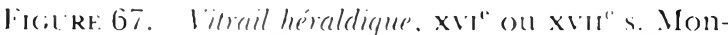
meal. Lniversite Me(jill, (a)llection Ilosmert. n" dimentaite 85.01!2 (Photo: Philippe lsker. Mon$\mid 1(\cdot a l)$.

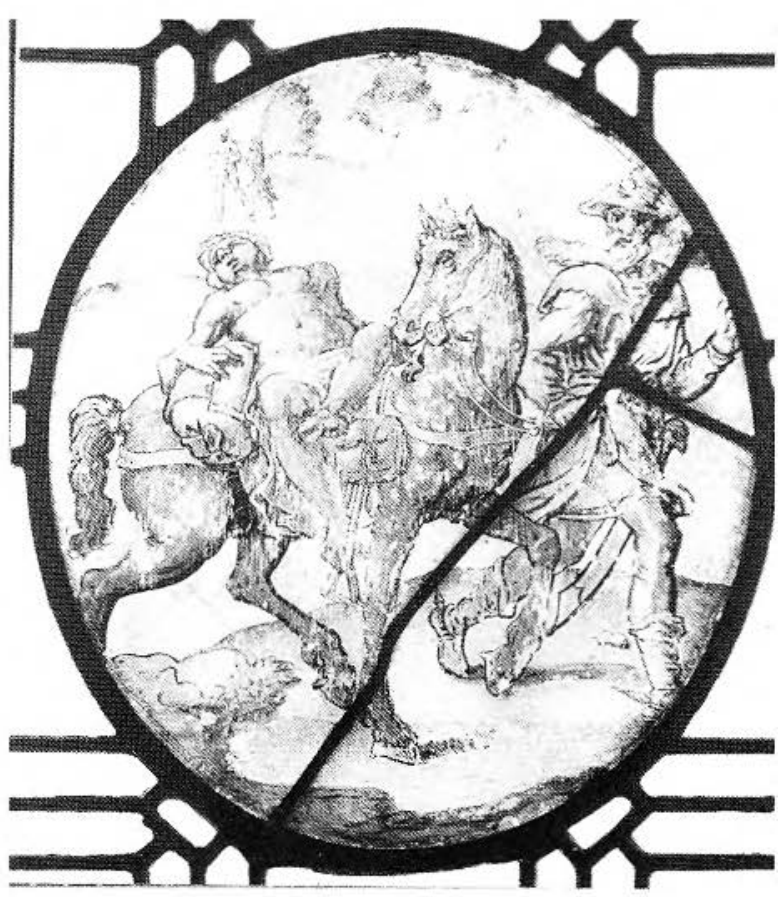

Ficick 69. D'après une grarure de Martin Heemskcrck, Le Bon Samaritain, fin xvi"s. Montrcal, Université McGill. Collection Hosmer, n" d'inventaire 85.013.2 (Photo: Philippe Isler, Montréal). 


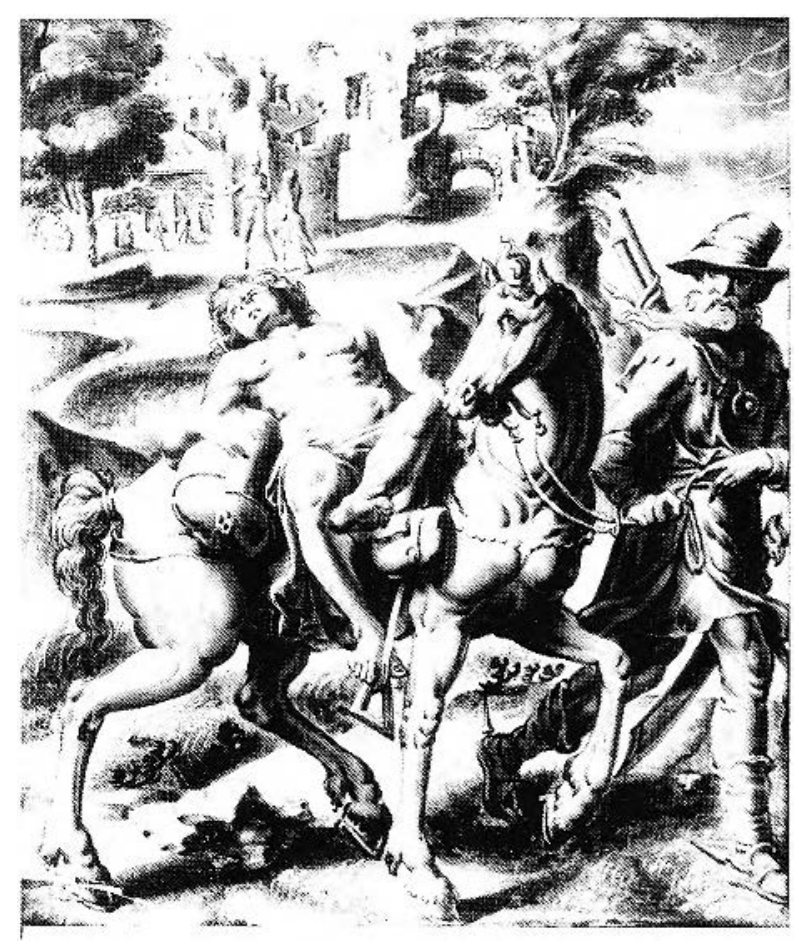

FigLRE 71. D) alpres Martin IIcemskerck, Le Bon Samaritain. Londres, Victoria and Albert Musemm, n" d'inventaire 1256-1855 (Photo: Victoria and Albert M(uscumil).

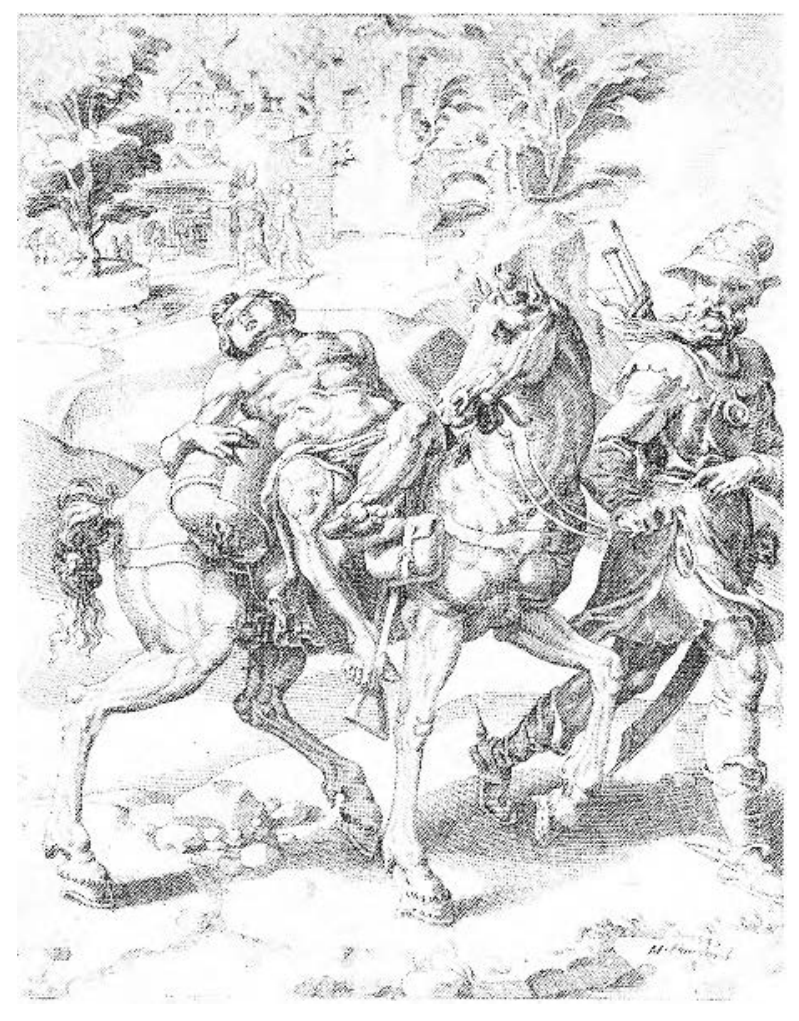

Figurt 7(). Mantin Hecmskerck, le Bon Samaritain, 1549. Londres. British Museum. $1^{\prime \prime}$ d'inventaire 1872-10-12-442 (Photo: repreduced b) courtess of the Trustees of the British Muscum).

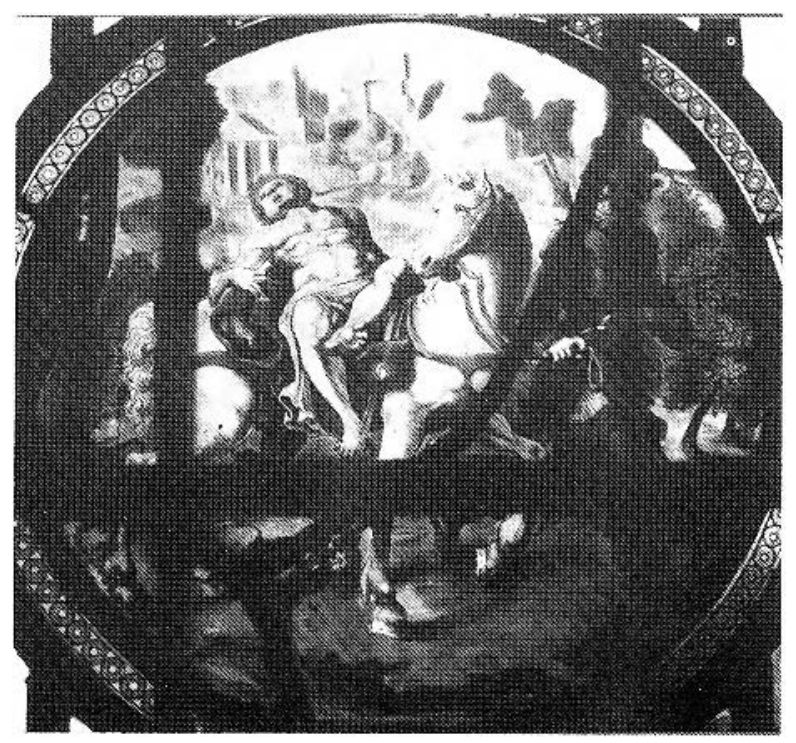

Figurl. 72. D’après Martin Heemskcrck, Le Bon Samaritain. Wisbech St Mary, G. B. (Photo : d'après une diapositive amablement fournic par le Dr. W. Colc). 


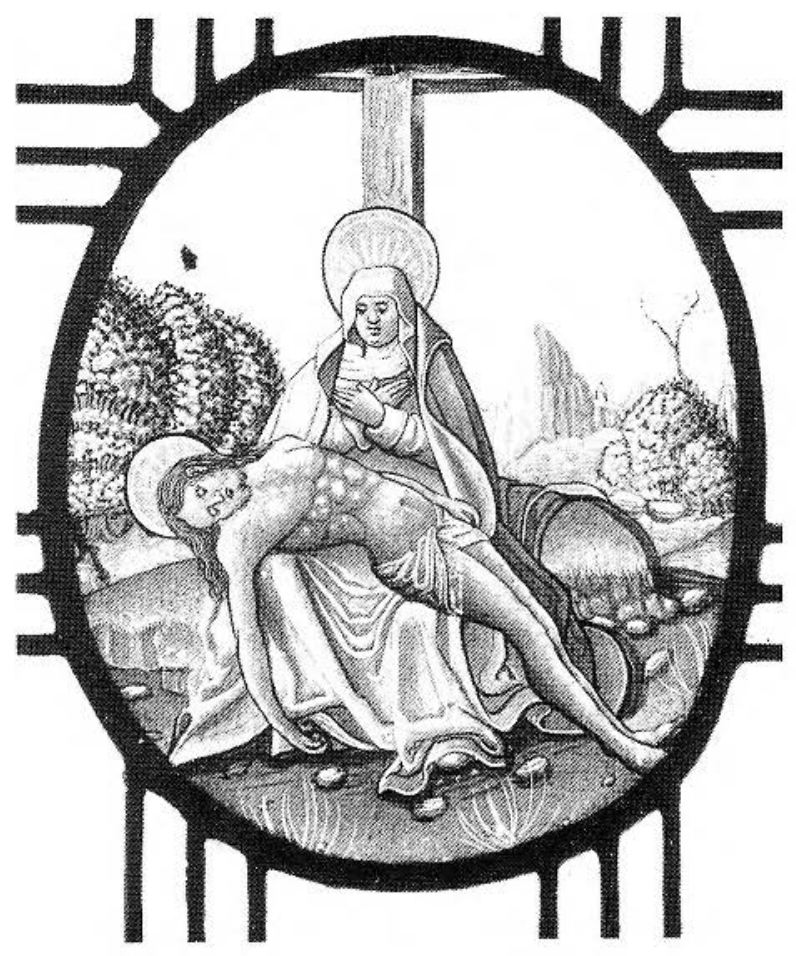

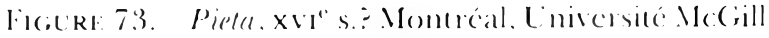

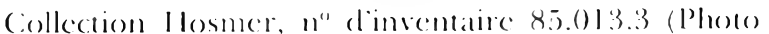
Philippe Isler, Montreal).

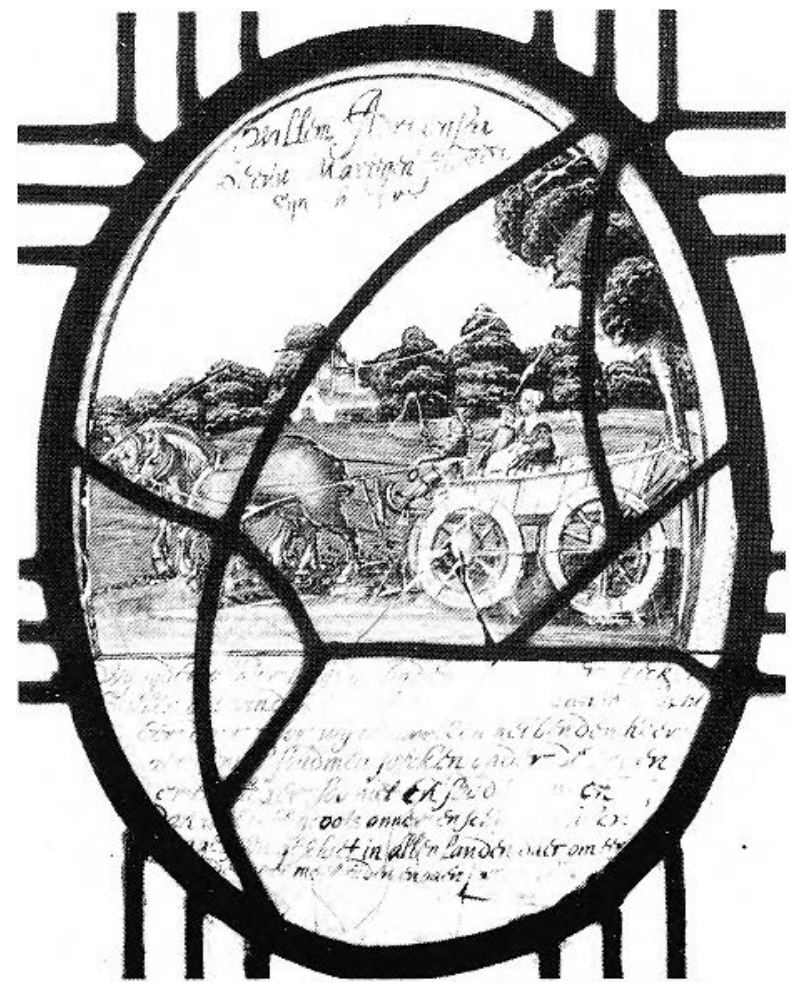

Ficere: 7j. Promenade sous lestillenls, xval"s. Montréat, Enirersité Mc(;ill, Collection Ilosmer, n" d'inventatre 8.0.014.1 (Photo: Philippe Isler, Montréal).

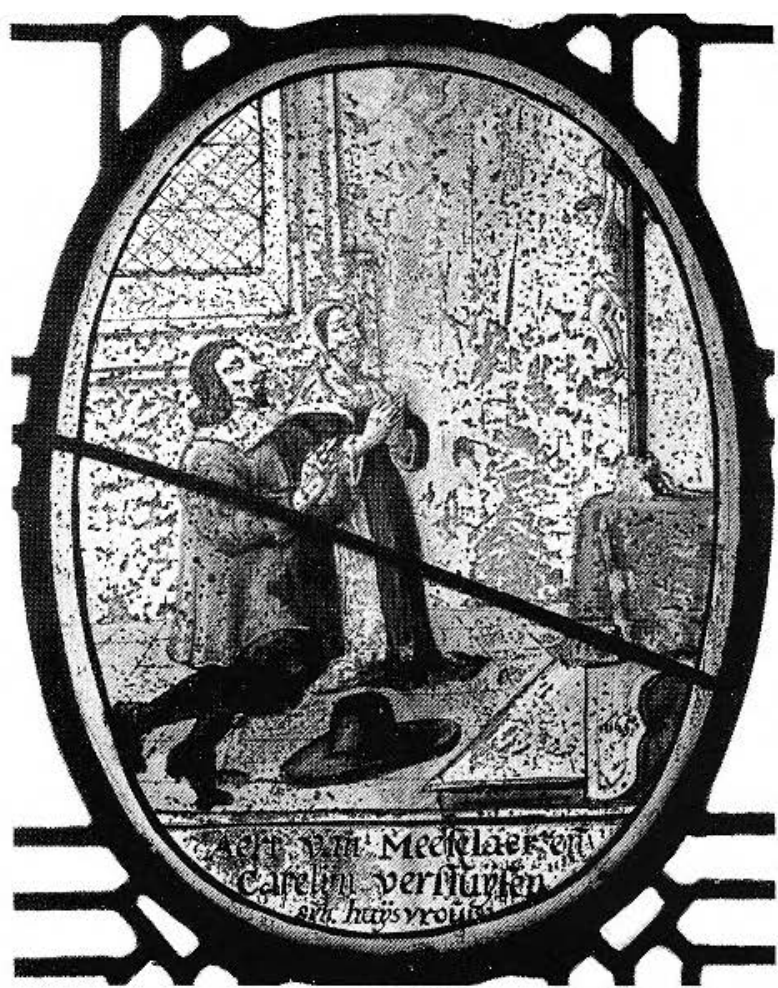

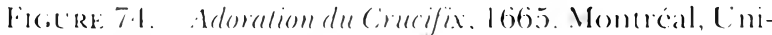
versite Macill, Collection Hosmer, n" d'insentate 8.5.)1.3.1 (Phoro: Philippe Isler, Momméal).

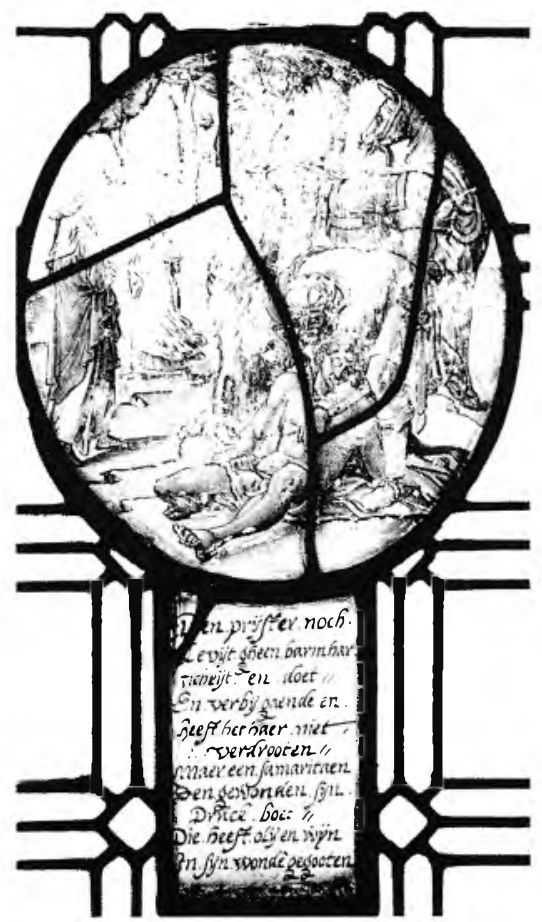

Figere: 76 . Le Ball Samarituill, fin xul"s. Momtral, Lniversite Mc(;ill. Collection Hosmer, n" d'imentaire 8.5.()1.1.2 (Photo): Philippe Ister, .Mon(réal). 


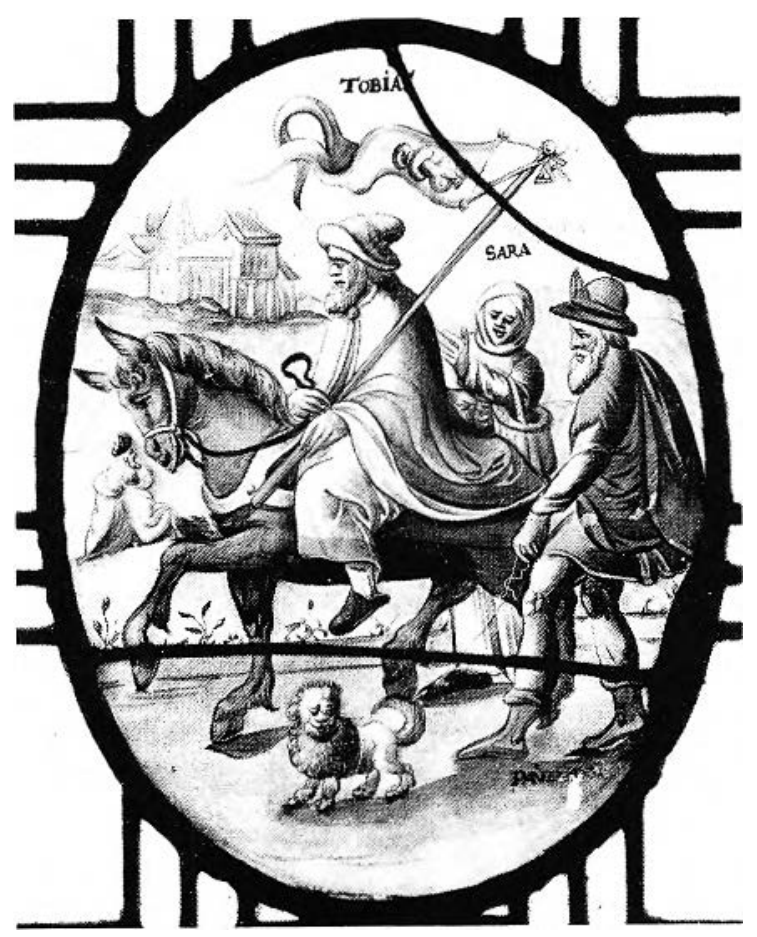

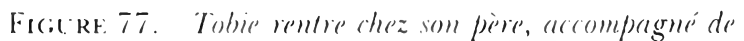
Sarah alde larchange (jabriel, xvir"s. Montréal, Uni-

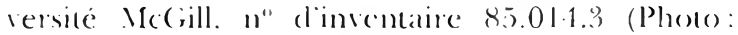
Philippe Isler. Montreal).

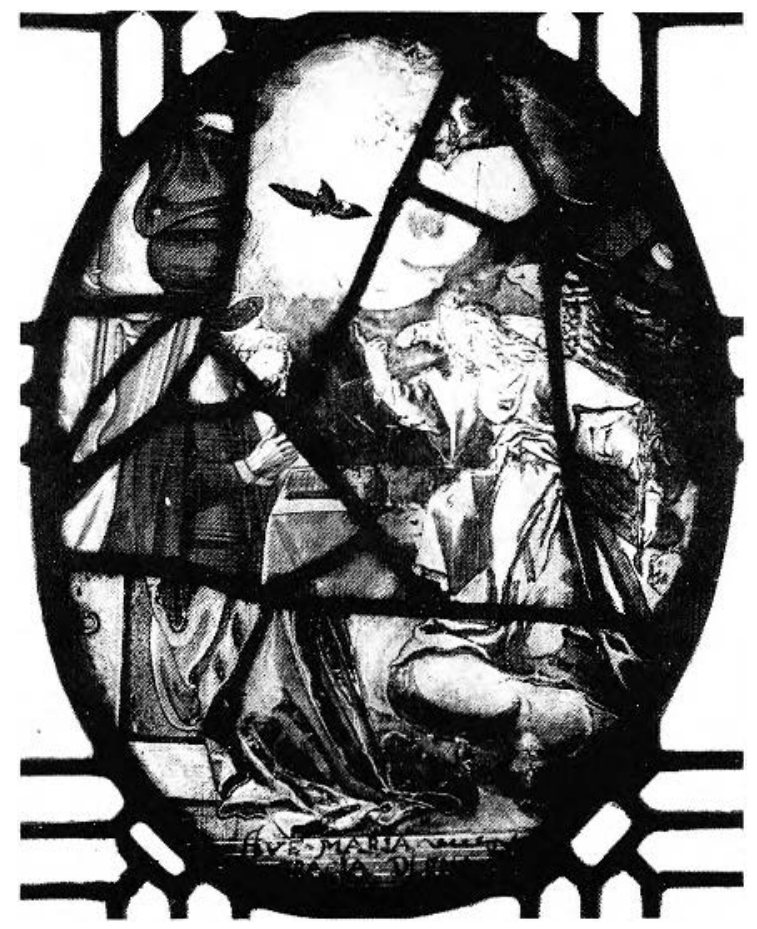

Fisenre 78. Annonciation, débul xvir"s. Montrial, Lnirersité McGill. Collection Hosmer, n" d'invenlaire 85.014.4 (Photo: Philippe Isler, Montréal). 


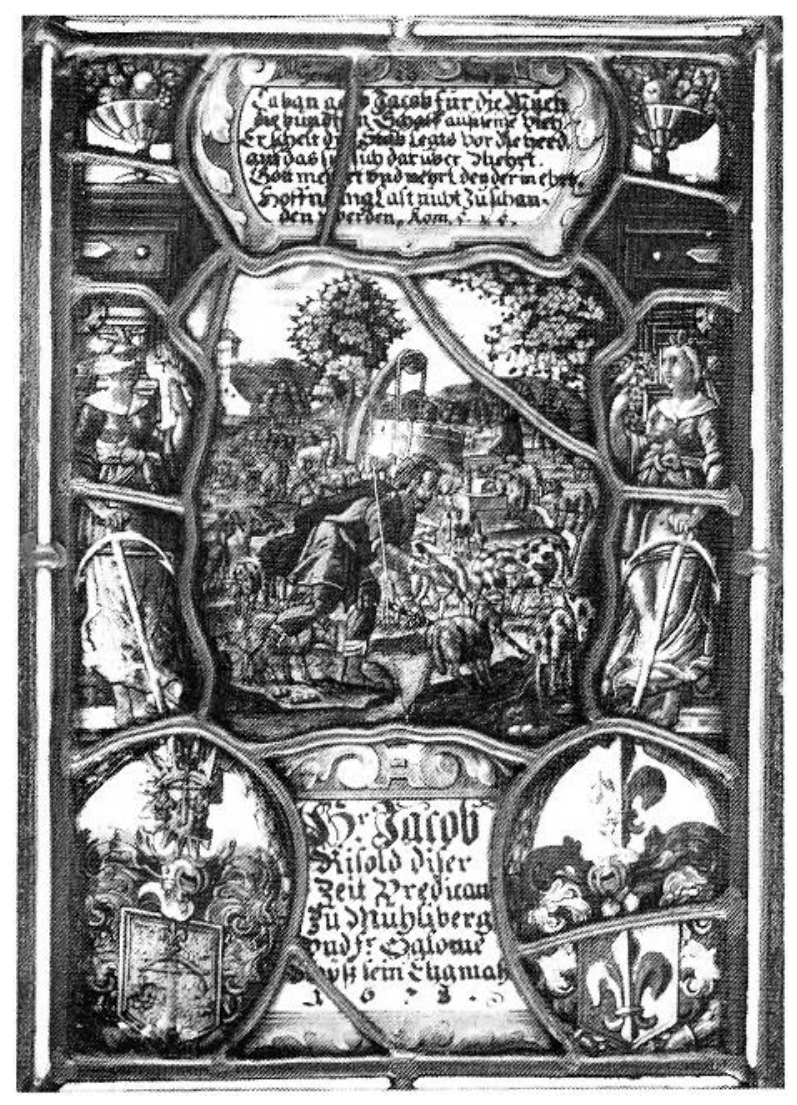

Ficiure: 79. Jacob et les troupeaux de Laban, 1678. Montrćal, Lniversić HcGill, Collection Hosmer, n" d'inventaire 85.015 (Photo: Dan Corsillo, Ecole d'architecture, Universitć Mc(;ill, Montréal).

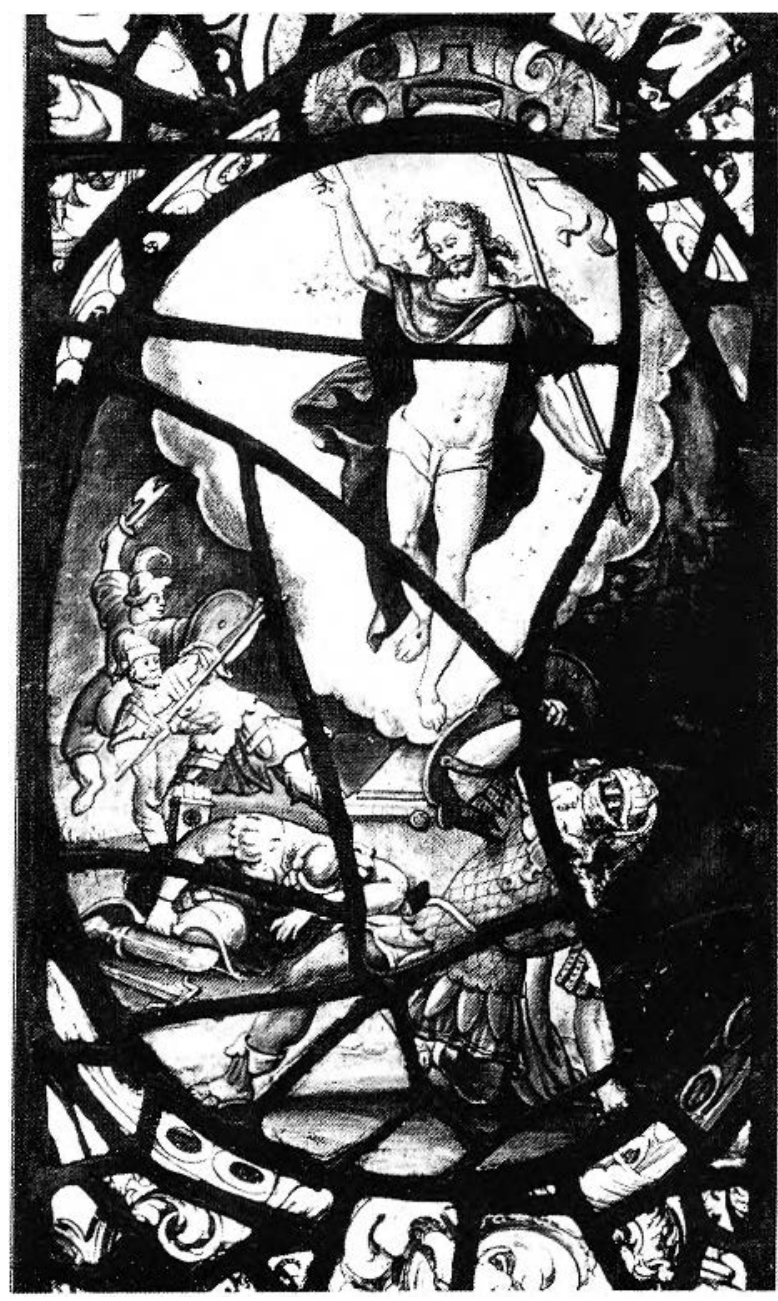

Figitre 80. La Résurrection, vers 1600. Montréal. Université McGill, Collection Hosmer, $n^{\prime \prime}$ d'inventaire 85.016 (Photo: Philippe Isler, Montréal). 


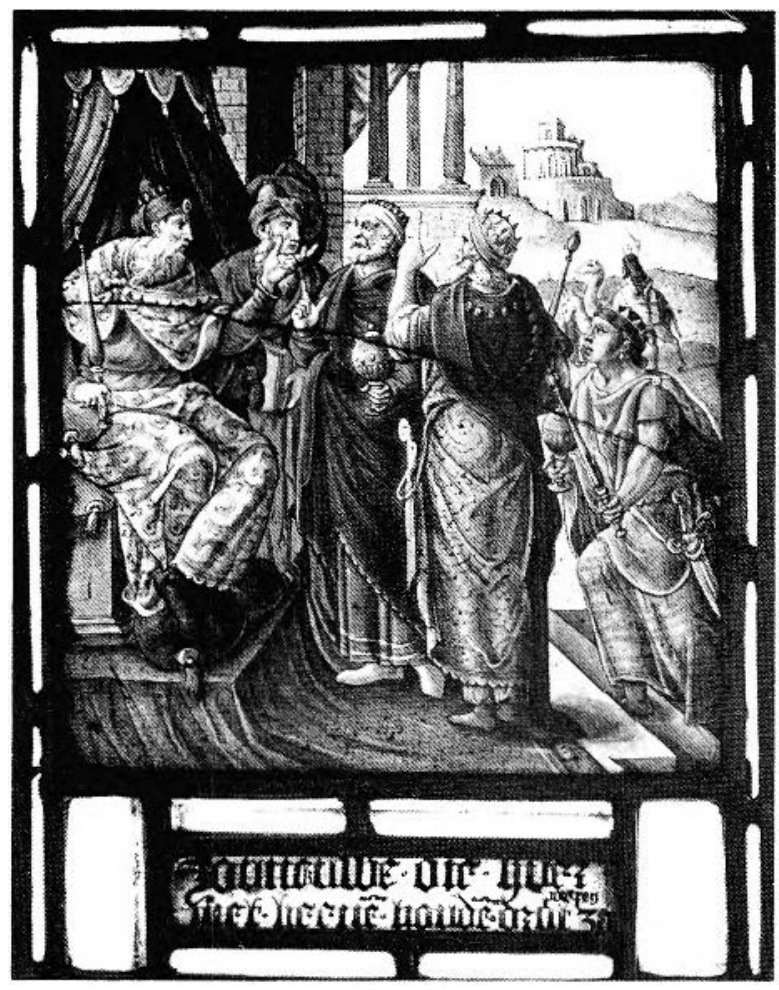

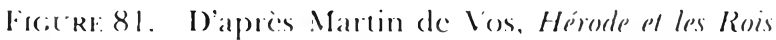
Mages. déhul xwil"s. Montréal. Ciniversite Mc(ill, (iollection Hosmer. n" dimentaire 85.017 (Photo : Philippe Isler, Montrial).

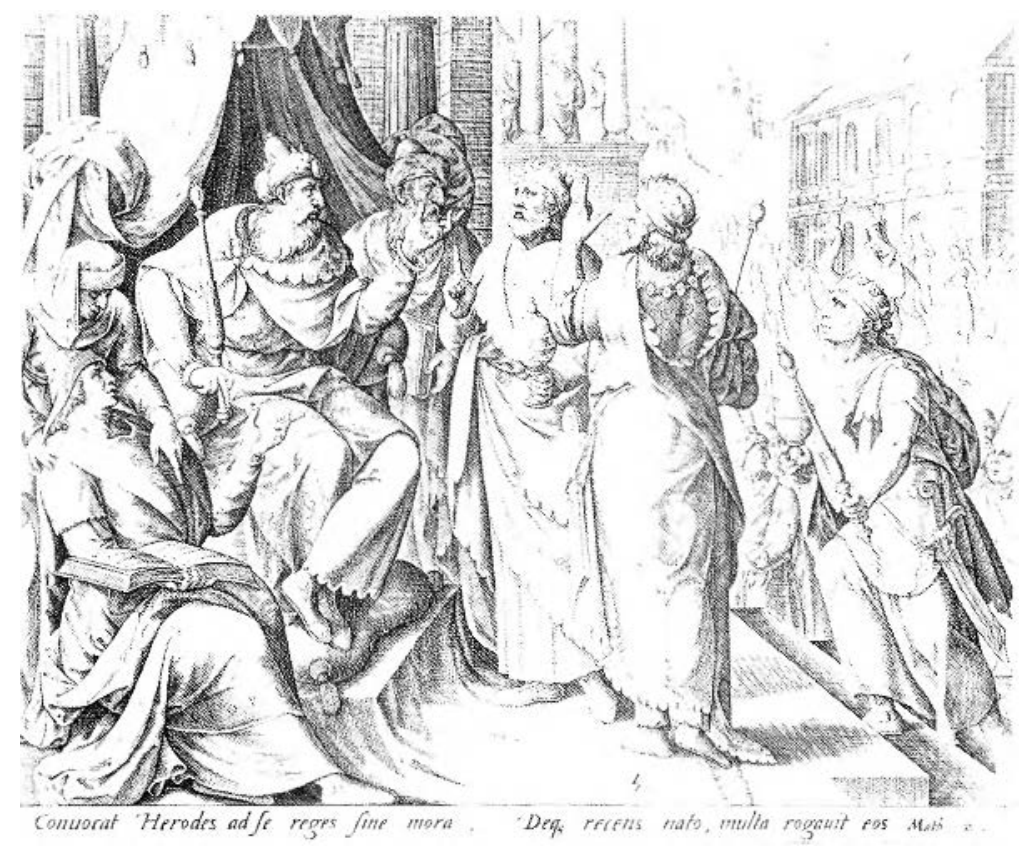

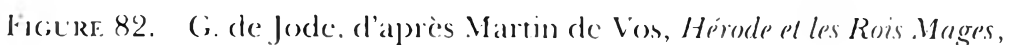
fin Xvi"s. I.ondres, British Museum. 1" dintentaire 1937-9-15-334 (Photo: reproduced by courtesy of the Trustecs of the British Musemu). 


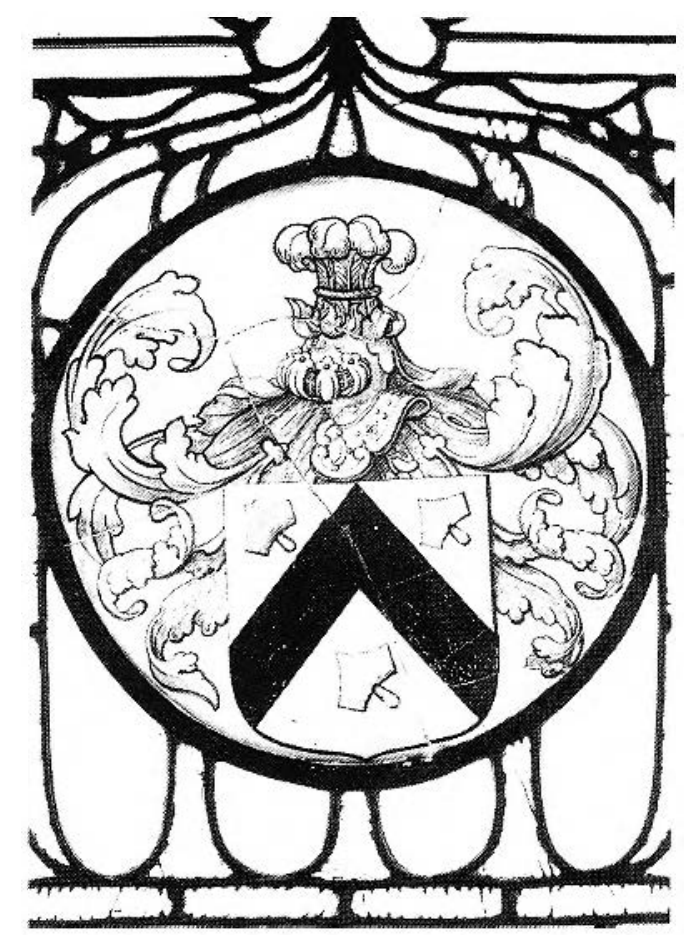

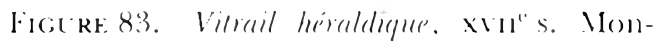
uéal. Lniversité .Ha (ill, Collection Hosmer, n" dionentaire 85.018 (Photo: Philippe Ister. Montréal).

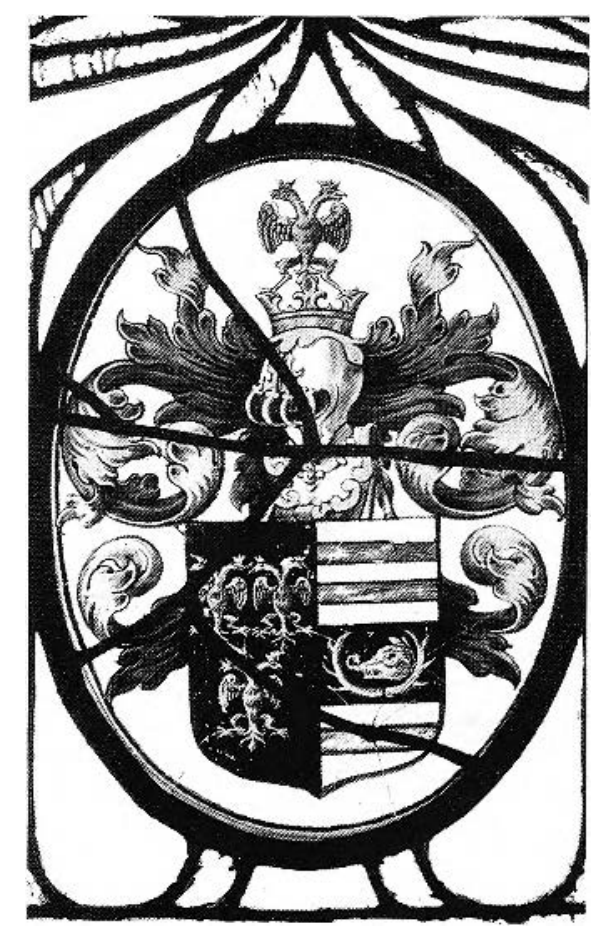

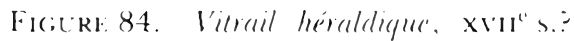

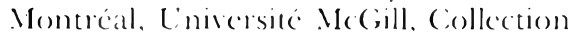

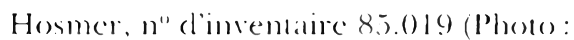
Philippe: Isler, Montréal).

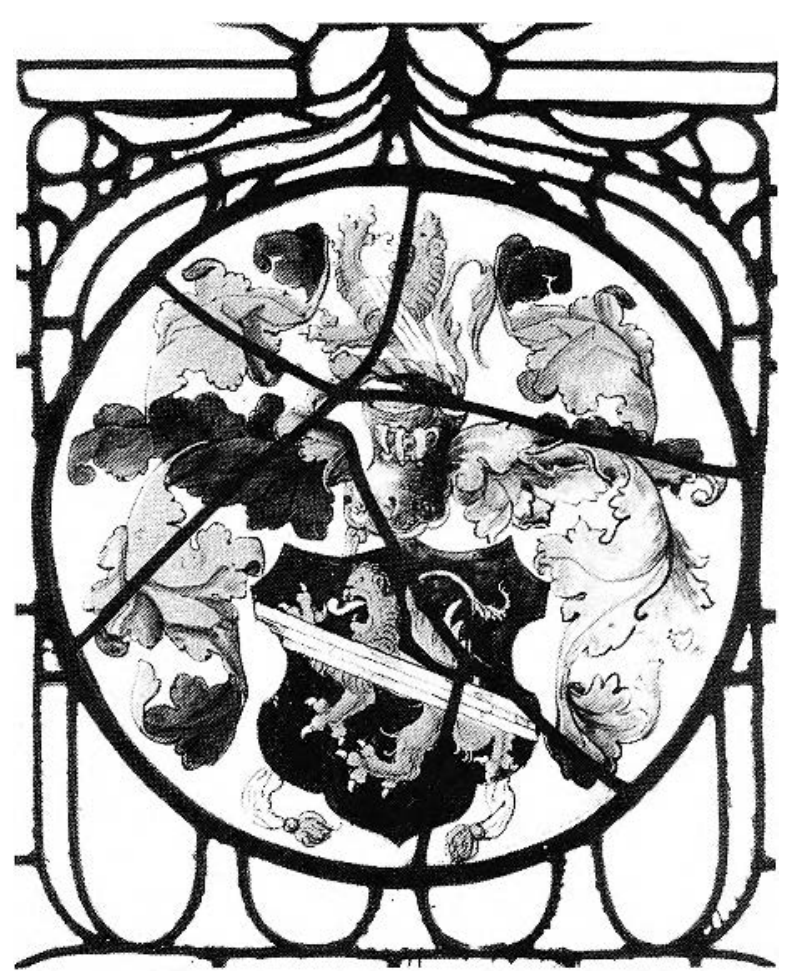

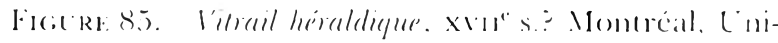

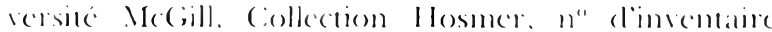
8.5.020) (Phoso): Philippe Isler. Montrial). 